NBER WORKING PAPER SERIES

\title{
MANAGEMENT, SUPERVISION, AND HEALTH CARE: \\ A FIELD EXPERIMENT
}

\author{
Felipe A. Dunsch \\ David K. Evans \\ Ezinne Eze-Ajoku \\ Mario Macis \\ Working Paper 23749 \\ http://www.nber.org/papers/w23749 \\ NATIONAL BUREAU OF ECONOMIC RESEARCH \\ 1050 Massachusetts Avenue \\ Cambridge, MA 02138 \\ August 2017, Revised April 2021
}

The intervention evaluated in this study is the result of a collaboration between the Nigerian Federal Ministry of Health, Nigerian National Primary Healthcare Development Agency (formerly known as the Saving One Million Lives initiative), and the World Bank. We gratefully acknowledge the invaluable support of Marcus Holmlund, Arianna Legovini, Marie Francoise Marie-Nelly, Kelechi Ohiri, Ado J.G Muhammad, Muhammad Ali Pate, and Hong Wang. We are also grateful to Oyebanji Filani, Giacomo de Giorgi, Benjamin Loevinsohn, Oluwole Odutolu, Chinny Ogunro, and participants in various conferences and seminars for helpful comments. We thank Md. Abul Kalam Azad and Ayodele Fashogbon for field coordination and Qiao Wang, Victoria Sung, and Amina Mendez Acosta for research assistance. The research protocol was reviewed and approved by Nigeria's National Health Research Ethics Committee and the Homewood Institutional Review Board of Johns Hopkins University. This study was made possible through generous funding from the Bill and Melinda Gates Foundation. The views expressed herein are those of the authors and do not necessarily reflect the views of the National Bureau of Economic Research.

NBER working papers are circulated for discussion and comment purposes. They have not been peer-reviewed or been subject to the review by the NBER Board of Directors that accompanies official NBER publications.

(C) 2017 by Felipe A. Dunsch, David K. Evans, Ezinne Eze-Ajoku, and Mario Macis. All rights reserved. Short sections of text, not to exceed two paragraphs, may be quoted without explicit permission provided that full credit, including $\odot$ notice, is given to the source. 
Management, Supervision, and Health Care: A Field Experiment

Felipe A. Dunsch, David K. Evans, Ezinne Eze-Ajoku, and Mario Macis

NBER Working Paper No. 23749

August 2017, Revised April 2021

JEL No. I15,M10,O15

\begin{abstract}
$\underline{\text { ABSTRACT }}$
We used a randomized management consulting intervention with 80 public-sector healthcare facilities in Nigeria to study the role of information, training, and supervision on the adoption of improved organizational practices. Facilities that received detailed improvement plans and nine months of implementation support-including regular visits to monitor progress and set intermediate goals related to the plans-showed large, significant short-term effects on the adoption of practices that were under the responsibility of facility staff. Facilities that received general improvement advice but no implementation support showed no change in practices. Implementation support appears crucial for improvements, especially in contexts without market incentives for the adoption of effective managerial practices.

Felipe A. Dunsch

World Bank

1818 H St NW

Washington, DC 20433

fdunsch@worldbank.org

David K. Evans

World Bank

1818 H St NW

Washington, DC 20433

devans2@worldbank.org

Ezinne Eze-Ajoku

Johns Hopkins University

eezeajo1@jhmi.edu

Mario Macis

Johns Hopkins University

Carey Business School

100 International Drive, Office 1333

Baltimore, MD 21202

and IZA

and also NBER

mmacis@jhu.edu
\end{abstract}




\section{Introduction}

Can organizations improve their managerial and organizational practices without increasing the recurrent resources employed? If so, how? We examine these questions with a randomized controlled trial of a management consulting intervention conducted in primary, public-sector healthcare centers in Nigeria.

In recent years, improving the quality of healthcare provision-beyond merely making it available - has become a higher priority for the World Health Organization (WHO) and other health agencies (WHO 2006; Institute of Medicine, 2001; Das et al. 2008). In wealthy economies, a wide dispersion in health outcomes remains after controlling for access, spending, and other structural aspects of quality (Chandra et al. 2016; Skinner 2011). At the same time, a recent and growing literature suggests that managerial and organizational practices matter greatly for organizational productivity and outcomes (Bloom, Sadun \& Van Reenen 2012; Bloom et al. 2013), including in the healthcare sector (Bloom et al. 2020), and that differences in management practices across organizations and countries account for a large share of the dispersion in productivity not explained by the quantity and quality of the inputs used. In fact, Bruhn, Karlan, and Schoar (2018) suggest that the lack of managerial and organizational capital may be a key constraint to productivity growth in low- and middle-income countries. If so, then simply increasing the quantity of inputs may not translate into improved quality of healthcare: Das and Hammer (2014) find "no correlation between structural inputs and practice quality” across a number of studies, and Das et al. (2012) find that differences in levels of medical training of caregivers account for small or no differences in the quality of provided care. Improving the management of health facilities holds the promise of improving the quality of care and increasing the returns to other inputs.

The empirical literature on the role of "managerial” or "organizational” capital on the quality of healthcare delivery in low- and middle-income countries is still scarce and, to our knowledge, limited to hospitals (Bloom et al. 2020). However, the typical first point of access to care in low- and middleincome countries is primary health centers (PHCs). The expansion of PHCs has been a crucial component of many countries' strategies to expand access to care to their populations, especially in rural areas. However, despite the expansion of PHCs, the quality of healthcare delivery remains low (Das \& Hammer 2014; Di Giorgio et al. 2020; Strasser, Kam \& Regalado 2016). The idea that improvements in healthcare quality can be achieved by changing organizational practices without 
increasing recurrent resources can be particularly appealing in resource-constrained environments. This will be especially true in contexts where the lack of competitive forces implies that the profit motive-which otherwise drives the adoption of superior organizational practices - is absent.

In this paper, we present results from a randomized field experiment conducted in partnership with the Nigerian Federal Ministry of Health (FMOH) to evaluate the effects of a healthcare management consulting program for public PHCs in six Nigerian states. The FMOH contracted SafeCare, an international agency that specializes in healthcare quality standards and patient safety in low- and middle-income countries, to (i) provide a general training session to representatives from the PHCs, (ii) conduct baseline assessments at each PHC accompanied by a brief report, (iii) assist the PHCs' staff in formulating improvement plans, and (iv) provide periodic feedback and support toward implementation of the plans for the duration of nine months. The assessment and plans focused on a set of organizational and managerial practices that comprise basic internationally accredited standards for running primary healthcare facilities, ranging from the management of human resources, information, and risk, to the organization of the pharmacy and management of the drug inventory. ${ }^{1}$

An independent evaluation of the SafeCare intervention is policy-relevant in its own right, as many countries across Africa - including Ghana, Kenya, Namibia, Tanzania and Uganda - are working or have worked with this agency to improve standards of care at primary and secondary healthcare facilities (Johnson et al. 2016; SafeCare 2017). However, our experimental design allows us to go beyond a simple program evaluation: we are able to distinguish between different mechanisms through which a management consulting intervention may affect practices and outcomes.

Of the 80 facilities included in the study, 24 were randomly assigned to receive the full intervention described above; 24 to receive a light, information-only treatment consisting of (i) a general training session to PHC representatives and (ii) a baseline quality assessment and a brief report highlighting basic improvement areas and actions, but without a detailed improvement plan and without any additional feedback and support; and 32 facilities to a control group. Comparing the full and the light interventions allows us to identify whether the main barriers to improving practices and quality of care are information constraints or implementation constraints. In the first case, the staff

\footnotetext{
${ }^{1}$ SafeCare is an agency created as part of a collaboration between the Joint Commission International based in the US, PharmAccess Foundation of the Netherlands, and the Council for Health Service Accreditation of Southern Africa established to "address issues of poor and limited healthcare delivered in developing countries." The SafeCare standards were accredited by the International Society for Quality in Healthcare in March of 2013 (SafeCare 2013).
} 
lacks knowledge of the appropriate or recommended organizational and operational practices, and providing that information (the light treatment) should improve practices. On the other hand, if the principal barrier to improvement is an implementation constraint - i.e., the staff lack the capacity to implement the changes, whether because of a lack of management ability or a lack of attention due to competing tasks - then information plus continued coaching and monitoring have the potential to improve practices. We went on to gather data one year after the end of the intervention to examine the persistence of these effects.

The focus of the intervention was to improve practices. Thus, our main outcomes of interest relate to the adoption by the PHCs of the recommended organizational standards. Although the ultimate objective of better organizational practices is to improve health outcomes, the scale of this program was insufficient to allow us to detect meaningful changes in outcomes such as infant or maternal mortality or infections. However, we measured a set of intermediate outcomes that should be affected by the improved practices and that are demonstrated to impact health outcomes in other contexts. For instance, a frequently recommended organizational standard was to organize drugs and vaccines in the drug storeroom by type, using labels and ordering them by expiration date. An organized pharmacy should reduce the likelihood of stock-outs, improving the PHCs' ability to provide patients with essential drugs and vaccines, thereby improving the recovery chances of sick patients and immunization rates. In our study, we observe how the pharmacy is organized (practice adoption) and whether stock-outs of essential drugs and vaccines are reduced (intermediate outcomes), which are both necessary conditions for improvements in actual health outcomes. Another intermediate outcome is the observed cleanliness of various areas of the PHC.

The full intervention had large and significant effects on the adoption of several organizational practices that were the responsibility of the facilities' staff. These included practices that required a minimal, one-time effort such as displaying posters with hand-washing guidelines or having clearly marked waste bins for different types of waste, but also practices that required moderate and sustained effort such as making hand-washing supplies consistently available in the consulting room and in other key areas of the facility. We also detected economically and statistically significant effects on some intermediate outcomes, including cleanliness of toilets and waiting rooms. In contrast, the light intervention had no systematic effects; in most cases, the estimated coefficients were both economically and statistically insignificant, indicating no meaningful differences with the control 
group. When we measured practices and intermediate outcomes one year after the end of the intervention, however, we found that almost all of these effects had disappeared, although this may be attributed to extremely high staff turnover between the end of the intervention and the one-year followup. Because we consider many outcomes, we correct for Multiple Hypothesis Testing (Anderson 2008) by combining outcomes into broad indices (z-scores), thereby reducing the number of tests being performed. The results are robust to these corrections.

Taken together, the two treatments suggest that, first, information alone on what practices should be adopted is not sufficient; results are obtained only when information on what changes need to occur is combined with sustained implementation support and monitoring. Second, if one is to infer anything from our one year post-intervention lack of impacts, it is that monitoring and support during implementation played a crucial role. The intervention may have failed to produce sustainable changes (in part due to staff turnover), but it did result in measurable changes in practices during the “implementation support” phase.

Finally, we found small and statistically insignificant effects on practices that were primarily the responsibility of the federal government (e.g., consistent access to power). This is not surprising, but it underlines the fact that improved management and organizational processes are insufficient to solve the major infrastructural constraints faced in many PHCs around the world. While our evaluation does not test this, lack of incentives may also contribute to explain the absence of effects for organizational practices requiring considerable additional and continued effort.

Our study makes several contributions. Our main contribution is to the literature on the adoption of organizational and managerial practices with novel evidence from primary healthcare facilities in a middle-income country context. Although in recent years, evidence has accumulated indicating that management practices have important effects on productivity, the mechanisms through which superior practices are adopted and the barriers to their adoption are still poorly understood. The profit motive can explain why managers in market contexts adopt better practices upon learning about them (Bloom et al. 2013). However, in many contexts the profit motive is absent. In the healthcare sector in particular, public providers play a central role in many countries, often with limited competition from private providers. Our experiment contributes to understanding whether and how better managerial and organizational practices can be adopted by staff in public healthcare facilities. Specifically, our design distinguishes between the effects of information and implementation support with supervision 
on the adoption of practices. Moreover, we advance the empirical literature on healthcare quality in low- and middle-income countries, by providing evidence on the effects of a policy-relevant intervention that several governments, particularly in African countries, are adopting to achieve improvements. Previous literature on improving healthcare quality examines non-managerial policies-including legal mandates, accreditation and administrative regulations, professional oversight, national and local guidelines, information sharing, and incentive provision-with mixed results (Peabody et al., 2006). Even when existing studies report positive results of interventions aimed at improving organizational and individual performance in adopting standards, they often have significant design limitations, in many cases focusing on longitudinal change without a credible control group. ${ }^{2}$ This can make interpretation of the results problematic. Moreover, the interventions typically have multiple components without a design that allows for the effects of the various components to be assessed separately. In contrast, the randomized-controlled nature of our study allows clearer causal inferences, and our experimental design allows us to distinguish the effects of different components of the intervention.

The remainder of the paper is structured as follows. In Section 2 we describe the context and provide details on the SafeCare program. In Section 3 we describe our experimental design and research questions, and in Section 4 we discuss the data and estimation strategy. We present the results in Section 5. In Section 6 we offer our conclusions and discuss policy implications.

\section{The Nigerian Context and the Program}

\subsection{The context}

Even though life expectancy in Nigeria has increased in the past decade (from 49 in 2007 to 54 in 2017), it is still 14 years shorter than the average among countries in the same income group (World Bank 2020). ${ }^{3}$ It is estimated that many deaths could be prevented by simple, essential interventions reaching patients (particularly women and children) on time, for example with antenatal care,

\footnotetext{
${ }^{2}$ For instance, Berwick (2004) reports on a successful intervention in Peru aimed at improving tuberculosis care by adopting standard practices such as treatment planning, systematic drug supply management, and maintenance of registries. Chakraborti et al. (2000) studied the effect of information, feedback and monitoring on private practitioners' casemanagement skills for treating sick children in rural India, finding large positive effects on a number of standard procedures. ${ }^{3}$ Nigeria is classified as a "lower middle income" country by the World Bank. Life expectancy at birth for all lower middle income countries is 68.3 years in 2017, the most recent year for which data are available (World Bank 2020).
} 
vaccination, and timely diagnosis of treatable infectious diseases such as malaria, pneumonia, diarrhea, and measles. ${ }^{4}$ Improved quality of healthcare delivery at primary healthcare facilities is one important vehicle to achieve better health outcomes (WHO 2006). Nigeria’s large population means that it accounts for a large share of total deaths in the African continent and worldwide. For example, in 2013 Nigeria alone accounted for about 14 percent of the total number of maternal deaths, 13 percent of under-five deaths and 10 percent of neonatal deaths worldwide (UNICEF 2014). Thus, even small reductions in mortality rates through improvements in the quality of health services could result in large reductions in the absolute number of lives saved. A one percent reduction in the under-five mortality rate would save the lives of about 8,000 children under the age of five every year in Nigeria.

Although healthcare in Nigeria is a joint responsibility for all tiers of government (Federal, State, and Local), each tier has oversight over different jurisdictions. The federal tier represented by the Federal Ministry of Health has oversight for tertiary facilities. The state government is responsible for providing care at secondary facilities. Within each state, a local government is responsible for the provision of primary care (Makinde et al. 2018). Funding for the public health sector is from state and local governments, direct allocations from the federal government, non-governmental organizations, international donors, and private organizations (Gustaffon-Wright \& Schellekens 2013). Out-ofpocket spending constitutes about 96 percent of the total private expenditures on health (USAID, 2016). In terms of access to care, healthcare facilities are concentrated in urban areas, with geographic imbalances in availability of secondary and tertiary care and primary care being the only immediate option in many rural areas (Nwakeze \& Kandala, 2011).

Across Nigeria, most (72 percent) primary health facilities are public. The opposite is true for secondary health facilities, where a minority (24 percent) are publicly administered. Across the six states included in this study, the ratio of public to private facilities (including both primary and secondary care) ranges dramatically, from just 0.39 in Anambra state in the southeast to 18.62 in Kebbi state in the northwest (Makinde et al. 2018). Thus, the level of competition between public and private

\footnotetext{
${ }^{4}$ The main causes of death in Nigeria are lower respiratory infections (14\%), HIV/AIDS (10.4\%), malaria (8.7\%), diarrheal diseases (6.3\%), pre-term birth complications (4.7\%) and birth asphyxia and birth trauma (4.3\%) (WHO 2015). In 2013, the under-five mortality rate was about 120 per 1000 live births (WHO 2015). About a quarter of all under-five deaths are accounted for by deaths of newborn babies. The leading cause of under-5 death is malaria (21\%), followed by acute respiratory infections (15\%), prematurity (12\%), birth asphyxia (10\%), diarrhea (10\%), and neonatal sepsis (5\%). In the same year, maternal mortality was 560 deaths per 100,000 live births.
} 
facilities will vary significantly across states. For health workers, insufficient pay is a common complaint, and a small sample study in two states suggests that it is not uncommon for health workers to refer patients from a public facility to a private one where they work (Akwataghibe et al. 2013). Retention of health workers, especially in rural areas, is a challenge (Holmlund et al. 2021), but improved social support, in addition to pay, leads to improved working conditions and potentially increased retention of workers (Abimbola et al. 2015). Both effort and knowledge among health workers are documented challenges (Okeke 2019; Di Giorgio et al. 2020). ${ }^{5}$

The intervention we evaluate in this paper was part of a broader set of actions implemented by the Nigerian government between 2011 and 2015 with the overarching goal of improving healthcare access and quality. The Health Strategy and Delivery Foundation, a not-for-profit organization, partnered with the FMOH to develop a National Framework for Quality Improvement. ${ }^{6}$ The FMOH partnered with the World Bank in the assessment of quality of service across primary, secondary and tertiary facilities nationwide. In addition, the FMOH set an agenda to improve the delivery of primary healthcare services around the country through its Subsidy Reinvestment and Empowerment Program - Maternal and Child Health component (SURE-P MCH), by improving staffing, upgrading primary healthcare facilities, and increasing use of MCH services through a conditional cash transfer incentive scheme. Quality improvement of PHCs was part of the national quality strategy across primary, secondary, and tertiary care facilities. Thus, in 2013, the FMOH implemented a management intervention to strengthen capacity at local facilities and improve quality of care through the organization SafeCare, in partnership with Health Strategy and Delivery Foundation. After several years of implementation, however, a new presidential administration entered in 2015 and ended government funding to the SURE-P program (Ebenso et al. 2019).

\footnotetext{
${ }^{5}$ One common recommendation to boost health worker performance involves pay for performance schemes. A recent evaluation of pay-for-performance for health workers in Nigeria suggests that pay-for-performance did increase performance, but it did not increase performance more than simple budget increases to facilities (Khanna et al. 2020).

${ }^{6}$ The Foundation was formerly known as the Saving One Million Lives Initiative.
} 


\subsection{The SafeCare Program}

Formed in 2001, SafeCare is an agency specializing in producing and assessing quality standards specific to resource-constrained public and private healthcare facilities of all kinds. These include tertiary (teaching) hospitals, referral hospitals, district hospitals, primary health centers (as in our case), basic health centers, and health shops or nurse-driven clinics. SafeCare also offers technical assistance, or consulting, with a focus on building knowledge to guide and facilitate the adoption of quality standards.

The SafeCare standards are grouped in 13 "service elements" in four broad areas: healthcare organization management, care of patients, specialized services, and ancillary services (Table 1). The service elements encompass the entire range of clinical services, including management of human resources, information and risk, logistics and management of medication, and laboratory and facility services, among others. For each service element, SafeCare has developed a set of indicators for specific standards or managerial/organizational practices or actions. The SafeCare standards were accredited by the International Society for Quality in Healthcare in March of 2013 (SafeCare 2013). The full set of standards can be found in SafeCare (2021).

The SafeCare program is independent of the World Management Survey, which informs much economic work on management, but understanding where they overlap and where they diverge will facilitate interpretation of our results. In a comparison of the World Management Survey for health (Bloom et al. 2020) and the SafeCare program, we observe overlap in almost all of the 13 service elements. For example, in the category of human resource management, SafeCare asks that there be "at least one documented appraisal of each personnel member each year" whereas the World Management Survey asks "how do you evaluate and rate your clinicians?" and "how often do you do this evaluation?”. However, many individual elements of the SafeCare program do not have a parallel within the World Management Survey, including management of the patients' right to privacy, of patients' medical records, of medication storage, and of risk (e.g., of fire or of infection) within the facility. In other words, the SafeCare quality standards all involve managing different aspects of the facility, but they define that more broadly than the World Management Survey.

The SafeCare program consists of the following five components: 
(1) General training session: SafeCare conducts an initial two-day general training session attended by one point person from each PHC. The attendees are trained in standard best practices according to the SafeCare model.

(2) Baseline assessment and gap analysis: SafeCare personnel visit each PHC and make a detailed assessment. Specifically, for each of 823 standards in healthcare organization management, care of patients, specialized services, and ancillary services, SafeCare gives a score to the facility ranging from 5 points (“not compliant, very serious”) to 100 points (“compliant”).

(3) Initial feedback: Based on the outcome of the assessment, SafeCare provides a written summary of the main gaps that were identified in the facility, highlighting areas where the facility needs to improve. The feedback is communicated to the PHC point person and the PHC's "officer in charge" (OIC or the "in charge" for short).

(4) Improvement Plan: In consultation with the facility’s staff and personnel from the Federal Ministry of Health, the SafeCare consultants formulate a detailed "quality improvement plan" (QIP) for each PHC. Appendix Table 1 lists extensive examples of the standards and actions that were recommended by SafeCare.

(5) Implementation Support and Feedback: SafeCare personnel provide both remote and in-person assistance and feedback to the PHC staff towards the implementation of the plan. The in-person visits by SafeCare personnel occur every other week for nine months from the introduction of the plan. A staff member of the FMOH accompanies the SafeCare personnel in their every-other-week visits and also visits each facility on the in-between weeks to monitor progress and assist the PHC's staff in the implementation of the improvement plan. These visits include a meeting with the officer in charge, nurse-midwives, and community health extension workers, which would include instruction on the areas covered by the QIPs (Ugo et al. 2016), a check-in on QIP actions the facility has improved on, and goal setting around QIP actions the facility can seek to improve on in the coming weeks. 


\section{Experimental Design}

\subsection{Experimental design}

To evaluate the program's effects, the assignment of PHCs to the treatment was randomized, and independent data collection took place. The randomized controlled trial involved a total of 80 PHCs, located in 20 hospital catchment areas in 6 states. These facilities were randomly assigned to one of the following experimental conditions:

- Full Intervention: The full SafeCare program as described in Section 2, including the general two-day training session, the initial assessment and feedback, the quality improvement plan, and the implementation support and monitoring for nine months.

- Light Intervention: A light version of the SafeCare program, including the general two-day training session, the baseline assessment and initial feedback, but without the specific improvement plan or implementation support.

- Control: Facilities in the control group did not receive any treatment.

Poor quality of health service delivery could be due to the PHC staff's lack of management training, which would imply that the staff is unaware of the recommended practices (standards) to organize a healthcare facility. Another possibility is that the staff is aware of how the facilities should be managed and organized, but they lack the capacity (either skill or attention) to implement the practices or to put in place the processes necessary for the practices to be adopted. The full intervention provided both information about what should be done and support for the implementation of the practices, whereas the light intervention only provided facilities with information, but not with implementation support. Therefore, comparison of the full and the light interventions allows us to identify whether the main barriers to improving practices and quality of care are information constraints or implementation constraints. ${ }^{7}$ The implementation assistance includes periodic visits to the PHCs by both SafeCare personnel and by FMOH staff. Thus, this component of the program contains both implementation support and monitoring. Both elements could potentially lead to better outcomes, but through different mechanisms: the implementation support is a form of training, whereas the monitoring could induce the staff at the PHC to exert additional effort to implement the plan, either because regular monitoring visits keep attention on quality improvements, or out of a

\footnotetext{
${ }^{7}$ Ugo et al. (2016) performed a before-after comparison using only the SafeCare assessments (i.e., no independent data collection) and comparing only the full and the light interventions (i.e., without a control group).
} 
concern that failure to do so might be penalized by the FMOH financially or with dismissal. ${ }^{8}$ In an effort to distinguish between these two channels, in addition to collecting data during and immediately after the intervention, we collected data one year after the end of the intervention. If any process and outcome improvements associated with the full intervention are simply due to the periodical monitoring, then they are more likely to depreciate once the monitoring ceases; if, however, the improvements are mainly due to the support component, then we expect them to be more likely to persist over time.

\subsection{Selection of states and PHCs}

The FMOH selected six states for the intervention in order to achieve representation from each of Nigeria’s six geopolitical zones: Niger (North Central zone), Bauchi (North East), Kebbi (North West), Anambra (South East), Cross River (South South), and Ekiti (South West). The PHCs selected to participate in the evaluation, 80 facilities in total, were all facilities included in the SURE-P subsidy program in these states (described in section 2.1).

\subsection{Baseline PHCs characteristics in participating and non-participating facilities}

Although the random assignment of facilities to experimental conditions, coupled with the fact that facilities could not opt out of the intervention, ensures the internal validity of our comparisons, how representative are facilities that participated in the trial of primary healthcare facilities in Nigeria? Facility characteristics are not available for the universe of PHCs in Nigeria; however, our baseline data provide us with rich data on a number of characteristics of all 474 PHCs that were included in the nationwide subsidies program (SURE-P) described in section 2.1, 80 of which were located in the six states that constitute our study's sample. The comparisons presented in Table 2 reveal that on most dimensions, the participating PHCs are similar to the remaining 394 non-participating PHCs. For example, the average number of staff members qualified as midwives or nurses is 2.5 in participating facilities and 2.7 in non-participating facilities; 73 percent of the participating PHCs and 74 percent of the non-participating ones have at least one midwife per shift; participating facilities have on average

\footnotetext{
${ }^{8}$ Although there were no formally stated consequences for failure to implement the quality improvements, attention from superiors can still induce a concern for consequences. Qualitative evidence from Zambia shows that with regular and thorough supervision visits to health centers, health workers "feel pressured to improve performance and also take pride in their recognized accomplishments” (Evans 2017).
} 
2.8 beds while non-participating facilities have 3.2 beds; the average total number of health workers is 12.3 in participating facilities and 12.4 in non-participating facilities; 50 percent of the participating PHCs and 58 percent of the non-participating PHCs had developed a "facility workplan" for the current year (prior to the intervention); and both groups of facilities are located on average around 20 $\mathrm{km}$ from the nearest referral hospital. The only statistically significant difference between PHCs participating in the trial as either treatment or comparison is that participating PHCs were more likely to have a staff reward system in place (30 percent versus 21 percent).

\subsection{Assignment of PHCs to treatment and control conditions}

Twenty-four of the 80 PHCs were randomly assigned to the full intervention, and 24 were assigned to the light intervention. The number of facilities assigned to the two interventions was constrained by FMOH budget limitations. The remaining 32 facilities were assigned to the control condition. For the random assignment, we stratified by state and SURE-P intervention. ${ }^{9}$ Table 3 shows the distribution of facilities across experimental conditions by state, and Figure 1 shows a map indicating the 6 states and the location of the study's PHCs by experimental condition.

\section{Data, Baseline comparisons and Estimation methods}

\subsection{Data sources}

We use data from existing PHC-level surveys as well as data that we collected specifically for the purposes of this study. There is no facility-level attrition, since all 48 PHCs assigned to the two treatment groups participated in the program and were surveyed.

Pre-intervention data: Pre-intervention (i.e., baseline) data stems from two sources, the Service Delivery Indicators (SDI) from August 2013, and a World Bank data collection exercise that covered

\footnotetext{
${ }^{9}$ The randomization of PHCs into the two treatment groups and the control group followed these steps: (1) We assigned a random number to each of the 80 PHCs in our population; (2) These numbers were ranked in ascending order; (3) We ranked these numbers within each hospital cluster (i.e., all PHCs that referred to a given hospital for secondary care); (4) The PHC with the highest random number in each hospital cluster was assigned to the full intervention, the second highest number was assigned to the light intervention, and the third highest number was assigned to the control group. This created groups of 20 for each treatment arm; (5) lastly, the 20 PHCs with the fourth highest numbers were ranked again. Then, the 4 highest numbers were allocated to the full intervention, numbers 5-8 went to the light intervention, and the rest were assigned to the control group. Each hospital cluster was within a single state and SURE-P intervention group. The SURE$\mathrm{P}$ intervention groups included monetary incentives for midwives, non-monetary incentives for midwives, a combination, and a control group (Holmlund et al. 2021).
} 
all of Nigeria’s 500 SURE-P PHCs in September/October 2013. The SDI include data from a facility questionnaire with general facility information, infrastructure, as well as availability of equipment, materials, drugs, and supplies. ${ }^{10}$ From the SURE-P baseline data collection, we use information on facility characteristics and staffing details (e.g., number of doctors, nurses, and community-health workers). The SDI and SURE-P data are used to make baseline comparisons and randomization checks; we also include them as controls in a set of robustness analyses.

Follow-up data: We implemented six rounds of monthly data collection, the first about two months after the start of the SafeCare program (in June 2014), and the last one about one year after its conclusion. This repeated data collection over the course of the intervention improves the statistical power of our tests for actions and outcomes that are not strongly autocorrelated (McKenzie 2012).

Details of data collection instrument and implementation: Our data collection instrument included three parts. First, we administered a questionnaire to each “officer-in-charge” of the PHCusually the senior clinical staff member-to collect detailed information on facility practices, staff, inputs, challenges and so on. Second, we employed a facility observation module to check for available infrastructure and equipment, and stockouts of drugs and vaccines. More details on these data will be provided below. Third, we conducted monthly patient exit interviews with about three patients per PHC right after their consultation to inquire about demographics (e.g., wealth, education, and family size), satisfaction with the services rendered, and perceptions about the quality of care. The data collection was carried out by a professional survey firm independent of SafeCare or the Nigerian government. ${ }^{11}$ The enumerator visits occurred on dates that were not communicated to the PHCs in advance, and the data were collected electronically using tablets. ${ }^{12}$ Questions were read directly from the devices and responses were recorded.

\footnotetext{
${ }^{10}$ The five modules of the SDI are: (1) Facility questionnaire: general facility information, infrastructure, availability of equipment, materials, drugs, and supplies. (2) Staff roster: Part A: List of all health workers by cadre type; Part B: Administered to 10 randomly selected health workers to measure absenteeism. (3) Clinical knowledge assessment: Clinical knowledge using five medical vignettes + two vignettes for maternal \& newborn complications. (4) Public expenditure module: Collects receipts and spending (monetary and in-kind) by health facilities. (5) Exit module: User satisfaction, socio-demographic characteristics \& payments. The SDI data collection included 79 of the 80 clinics in this evaluation. One clinic in Anambra was omitted in the data collection.

${ }^{11}$ While the data collection firm was not employed by the government, the survey carried the imprimatur of both the World Bank and the government, with the following introductory language: "We are collecting data for a World Bank research study on quality of healthcare in Nigeria. The goal of this research is to help Nigerian policymakers understand the situation better in order to make decisions that improve the quality of healthcare for all.”

${ }^{12}$ The data collection employed Asus Google Nexus 7 tablets with the software SurveyCTO.
} 


\subsection{Randomization checks}

In Appendix Table 2 we present the results of balance tests on several PHC-level characteristics. Consistent with our random assignment of PHCs to experimental conditions, comparisons between the treatment groups show reasonably satisfactory balance at baseline. Differences across experimental conditions along a number of facility-level variables tend to be small, and t-tests indicate that they are not statistically significant. ${ }^{13}$ Taking into account the relatively small sample size of our treatment groups, ( $\mathrm{N} F u l l=24, \mathrm{~N}_{\mathrm{Light}}=24, \mathrm{C}=32$ ), we performed permutation tests in addition to the standard t-tests (Butar and Park 2008). Specifically, we computed Fisher's exact tests and Wilcoxon rank-sum tests with 1,000 permutations. The results again show that the differences across experimental conditions are in most cases not statistically significant. Although overall our randomization was reasonably successful in creating comparable treatment and control groups, in some cases we do detect differences across treatment and control facilities in observed characteristics that are non-negligible. To account for these differences, we perform our analyses without and with baseline control variables: they do not affect the pattern of results. (These results are included in the appendix results tables.)

\subsection{Estimation methods}

We estimate pooled-OLS models with dummies for each wave of data collection:

$$
Y_{i, t}=\beta_{0}+\beta_{1} T_{F u l l}+\beta_{2} T_{\text {Light }}+X_{i}+\delta_{t}+\varepsilon_{i, t}
$$

in which $Y_{i, t}$ are the outcome variables (described in the next section), and $T_{F u l l}$ and $T_{\text {Light }}$ indicate whether clinic $i$ is in the full intervention group or the light intervention group. The term $\delta_{t}$ designates survey round fixed effects, and $X_{i}$ designates the stratification dummies including state dummies and SURE-P intervention status.

We further estimate all the main results with an additional set of baseline controls as an alternate specification (Appendix Table 3). ${ }^{14}$ This is not our main specification because additional controls are

${ }^{13}$ The $\mathrm{p}$-value for the F-tests that the covariates included in Appendix Table 2 jointly predict assignment to treatment are $\mathrm{p}$ $=0.79$ for full treatment vs. control, $\mathrm{p}=0.27$ for light treatment vs. control, $\mathrm{p}=0.95$ for full treatment vs. light treatment, and $\mathrm{p}=0.39$ for any treatment vs. control.

${ }^{14}$ The additional controls were baseline values for the number of observation beds, the number of staff qualified as midwives or nurses, the number of antenatal care cases in the previous month, the number of days without any electricity in the previous week, the number of staff meetings in the past twelve months, and the absenteeism rate. 
not available for every facility, thus reducing the sample size. However, the results are very similar across the two specifications.

Because we consider a large number of indicators that are potentially affected by the treatments, we are concerned about the possibility of Type I errors (i.e., false positives). It is well known that the probability of finding a statistically significant effect when the true effect is zero increases sharply with the number of hypotheses being tested (Savin 1984). In our study, the concern is attenuated because if our findings were purely due to Type I errors we would expect a roughly similar proportion of positive and significant coefficients for the full intervention and the light intervention, whereas, as we show below, almost all of the statistically significant effects are associated with the full intervention. Nonetheless, to correct for potential false positives as a result of multiple hypothesis testing (MHT), we aggregated the outcomes into indices of the indicators (Anderson 2008; Kling et al. 2007). While our primary results are from the indices, we show the impacts on the underlying indicators as well. The index approach is useful because it allows us to answer the question, "Did the intervention lead to statistically significant changes overall?”15

For our index regressions, we use only one observation per facility and so do not need to cluster the standard errors. However, for the underlying regressions of individual outcomes, we cluster at the level of the facility.

\section{Outcome Variables and Results}

\subsection{Outcome variables}

The goal of the SafeCare program was to assist the PHCs in adopting a set of organizational practices. The full set of SafeCare standards includes more than 800 indicators. Taken together, these indicators define the "standard" according to which primary healthcare facilities in resource-restricted settings should be managed. In coordination with the FMOH, we have selected a subset of 74 indicators. We did so prior to the intervention, with the agreement that the research team would collect data on these outcomes independently of the consultants. Our aim was to select a broad range of outcomes in critical managerial and organizational areas and with varying degrees of ease of

\footnotetext{
${ }^{15}$ Anderson (2008) proposes that "summary index tests make sense when testing for an intervention's overall effect and when there is an a priori reason to believe that a group of outcomes will be affected in a consistent direction.”
} 
implementation. In fact, the "standards" (both the full set and the subset on which we focus) vary in whether they are either the responsibility of PHC staff or are even feasible for PHC staff to change.

To organize the analysis, we group the outcomes into four sets of indices. For the first, at the outset of the intervention, representatives of the Federal Ministry of Health categorized each Quality Improvement Plan item based on who was responsible - either staff at the facility, the Ministry of Health, local government, or some mix. For example, whether or not the facility has an organization structure chart and a written list of all clinical staff are under the full control of the PHC, whether there are water or waste bins available are under shared control (i.e., the PHC has responsibility to keep them functional but the FMOH provides them or resources to purchase them), and whether the facility is connected to the national power grid is entirely outside of the responsibility of the PHC. We report outcomes separately for items that were under full control of the PHC, under shared control between the PHC and other government bodies, or under no control of the PHC (i.e., entirely under local or federal government). The specific items in each category are listed in Appendix Table 4 Panel A (titled "Responsible - Government designation).

We supplement that categorization, which was carried out before the intervention, with a secondary categorization based on our own judgments as to how feasible it was for health facilities to implement the actions. The classifications were assigned prior to knowing the distribution of impacts. It is correlated with the government responsibility categorization, but it is not identical because it combines who is responsible for the action (e.g., the facility staff versus the Ministry of Health) with how much effort the action requires (e.g., putting up a poster will require less effort than consistently ensuring water and soap are present). The specific items in each category are listed in Appendix Table 4 Panel B (titled “Feasibility - Researcher designation”).

At the time when we selected and classified the outcome variables, we did not yet have access to the Quality Improvement Plans (QIPs) that the 24 full intervention facilities had received. When we received access to the detailed QIPs, we matched the actions in the QIPs to the variables that we used in our data collection. The actions in the QIPs are fairly broad in their formulation (see the examples in Figure 2 and the complete list in Appendix Table 1), and therefore we were able to match each of our 74 indicators from our survey with an individual QIP action. However, for other QIP actions, there were no variables in our surveys that matched. The FMOH and representatives from the PHCs involved in the full intervention determined which entity was responsible for implementing the 
suggested improvements. As shown in Appendix Table 4 - Panel A, of our 74 indicators, 30 were matched with QIP actions that were the responsibility of the PHC, 19 were the responsibility of the local government or the federal government (SURE-P program managers), and 25 were the shared responsibility of the PHCs and the local and/or federal government. Turning to our secondsry classification, Appendix Table 4 - Panel B shows that 17 indicators were classified as "High feasibility”, 39 as “Medium feasibility”, and 18 as "Low feasibility”. A detailed list of QIP actions, their corresponding variables in our surveys, and the government-designated and researcherdesignated classifications can be found in Appendix Table 5.

For the third grouping, we group items according to an adaptation of the SafeCare categories (management and leadership, patient rights, facility management, etc.). ${ }^{16}$ Fourth and finally, we classified indicators according to where they reach the clinical process. Some changes ("process” indicators) focus principally on process but only indirectly affect patient health, such as putting up a poster with clinical information. Other changes (“intermediate outcome” indicators) may have a more direct effect on patient health, such as the cleanliness of the facilities and the availability of hand washing materials. Across our 74 measured indicators, we identified 64 that focus on process and 10 that capture intermediate outcomes. ${ }^{17}$ The ultimate goal of any intervention targeting health-care organizations, of course, is to improve final health outcomes. However, as explained above, given the sample size of the evaluation, implausibly large changes in health outcomes would be required in order to emerge as statistically significant; as such, our study was designed to focus on the adoption of practices and on a set of intermediate outcomes.

To limit the number of hypothesis tests, we report outcomes in four sets of indices: responsibility (as assigned by the government), feasibility (as assigned by us), SafeCare categories, and process versus outcomes (also assigned by us). After allocating each outcome variable to one index, we adjusted the signs so that a positive sign would be always associated with an improved outcome for all variables. Next, we demeaned all variables and divided them by the overall standard deviation,

\footnotetext{
16 The SafeCare categories are listed in Table 1. We adapted these slightly based on measures included in our survey (which inclusion was in consultation with the government) - e.g., diagnostic imaging services is absent from our survey and risk management is split into three categories that included many survey items - risk related to waste management, risk related to handwashing, and other risk. Our categories are listed in Table 4.

${ }^{17}$ Intermediate outcomes include the following indicators: cleanliness of the waiting area, cleanliness of toilets, cleanliness of stored bed linens, neat arrangement of the drug storage area, availability of essential drugs and vaccines, presence of unexpired essential drugs and vaccines, reorder levels for essential drugs and vaccines. All other indicators are classified as process indicators.
} 
which converted them into normalized effect sizes. ${ }^{18}$ Lastly, we regressed the index variable on the treatment status to estimate the treatment effects. All regressions include survey round fixed effects and stratification dummies, as discussed in section 4.4 above.

\subsection{Results}

\subsubsection{Main Results}

The impact of the full intervention and the light intervention on each class of actions, by responsibility (government designated) and by feasibility (researcher designated) are in Figure 3 and Table 4. For the full intervention, across all variables we find a strongly statistically significant impact of 0.29 standard deviations (SDs). By responsibility, we find strong, significant, positive impacts for actions that are under either full control of the PHC (0.33 SDs) or shared control (0.35 SDs). We see a much smaller, statistically insignificant point estimate for items not under control of the PHC. The impact of the light intervention is much smaller and statistically insignificant in all three categories.

By feasibility, we see a related pattern. For the full intervention, we see the largest impacts for actions that are highly feasible (i.e., both under control of PHC staff and relatively low effort) -0.52 SDs. For medium feasibility items we see a small but still significant impact of 0.29 SDs. We see no impact for low feasibility actions. Again, we observe no impact of the light intervention by this grouping. Across the adapted SafeCare categories (Table 4), we observe significant positive impacts in five out of 12 categories for the full intervention, with no impacts for the light intervention.

We observe positive, statistically significant results for both process indicator and intermediate outcomes indicators (Figure 4 and Table 4). Here, we do observe a marginally significant impact of the light intervention on intermediate outcomes, about half the size of the point estimate of the full intervention. On the whole, the full intervention translated into many changes in organizational processes for those actions that were under the control of the PHCs, feasible for the PHCs to implement. In the next section, we examine the results for each category.

18 Several indicators showed no or little variation in the control group; for this reason we opted to perform the standardization against the full-sample means and standard deviations. 


\subsubsection{Disaggregated Results}

\section{Governance and management (Appendix Figure 1.1; Appendix Table 3.1)}

The SafeCare program emphasized aspects of facility management, including the need for regular communications between the health center staff. Across all aspects of Management and Leadership, the full intervention increased actions by 0.65 standard deviations, significant with 99 percent confidence (Table 4). This increase is driven by the fact that full intervention clinics were more likely to have staff meetings and to have a posted organizational chart. Full intervention clinics were 16 percentage points more likely to hold staff meetings in the previous month (95 percent significance), and they reported holding about 0.17 additional meetings in the previous month (marginally significant). By comparison, 67 percent of facilities in the control group reported holding a staff meeting in the last month, and the average number of meetings held in the control facilities was slightly above 1 . PHCs in the full intervention are also 15 percentage points more likely (statistically insignificant) to report that they are "working towards quality improvement targets.” However, staff did not appear to be more likely to make suggestions for improvement to the officer-in-charge.

Full intervention clinics displayed a 64 percentage point higher likelihood than control facilities of posting an organizational chart on the wall (versus a rate of zero in the control group), an action classified as within the control of the PHC and high feasibility. No meaningful effects - statistically or economically - were found for the light intervention.

\section{Human Resources Management (Appendix Figure 1.2; Appendix Table 3.2)}

We do not observe changes in either the index related to the management of human resources (Table 4) nor in the underlying indicators. There are no differences between the numbers of clinic staff or human resource practices such as performance measurement systems or reward programs. However, some indicators that were classified as highly feasible, namely whether the facility had a written list of all clinical staff and whether they had submitted a request for additional staff, were also unaffected by the treatment. ${ }^{19}$

\footnotetext{
19 The intervention had no impact on absenteeism. It also had no impact on patient satisfaction. This does not appear in the main analysis as it was not one of the objectives of the program and was not included in the Quality Improvement Plans of PHCs. Furthermore, our analysis of patient satisfaction items not only showed extremely high rates of satisfaction but also evidence of "acquiescence bias," that patients tend to agree with interviewer statements and so satisfaction may be an artifact of positively framed statements common in patient satisfaction surveys (Dunsch et al. 2018).
} 


\section{Patient Rights and Access to Care (Appendix Figure 1.3; Appendix Table 3.3)}

The full intervention had a statistically significant impact on actions related to patient rights (Table 4). That includes a 63 percentage point increase in PHCs visibly posting a patient rights charter in the waiting area (versus a rate of zero in the control group). No effect was found for posters with clinical information, although those started from a much higher baseline of 57 percent. Both of these processes were classified as highly feasible. The number of ward screens in the facility - an action classified as having low feasibility - increased for both treatment groups; however, the estimated effect of the full intervention is twice as large as that of the light intervention, and it is statistically significant, whereas the estimated coefficient is insignificant for the light intervention.

\section{Management of Information (Appendix Figure 1.4; Appendix Table 3.4)}

For management of information, including whether the facility keeps individual case records, whether those records are available, whether case files are complete, and whether files are kept for all patients, we observe no impact for either interventions.

\section{Risk Management- Waste Management (Appendix Figure 1.5; Appendix Table 3.5)}

Risk management and sterilization processes are core elements of quality of care and patient safety. The index for this class of actions again shows significant improvements in this category (Table 4). SafeCare also emphasized the separation of medical waste from ordinary waste, as medical waste that is not properly handled and disposed of represents a high risk of infection or injury to healthcare personnel, as well as a lesser risk to the general public through the spread of micro-organisms from healthcare facilities into the environment (Windfield and Brooks 2015). The full intervention led to a 32 percentage point increase in the adoption of clearly marked bins for different types of waste (versus a baseline of 32 percent in the control PHCs), and to a (marginally significant) 17 percentage point increase in the availability of a poster showing waste separation. Also, full intervention facilities were 20 percentage points more likely to have guidelines on waste management, compared to a baseline of zero (significant at the 10 percent level). However, we do not detect effects on medical and other waste actually being disposed of differently, which is a harder to change intermediate outcome indicator (classified as moderate feasibility) than the relatively low effort processes of putting up posters or marking waste bins. 
Risk Management - General Risk (Appendix Figure 1.6; Appendix Table 3.6)

General risk management is another area in which the general intervention had significant positive impacts (Table 4). The full intervention led to a 34 percentage point increase (from a baseline of 16 percent) in the likelihood that facilities designate an individual responsible for infection control. SafeCare also emphasized the importance of using different cleaning devices, such as mops, for the different areas of the clinic, for example to reduce the likelihood of spreading germs from the toilets to the waiting area. Despite this emphasis, we do not observe that the treatments increased usage of different mops, which could have been implemented with some effort (medium feasibility). However, for the clinics that did use different mops, both treatments increased the likelihood that a color-coded system was employed to differentiate the respective mops. Neither treatment increased the availability of medical gloves.

\section{Risk Management - Handwashing (Appendix Figure 1.7; Appendix Table 3.7)}

Critical goals of the quality improvement program were procedures that would improve hygiene and cleanliness. Evidence from other studies demonstrates that handwashing improves health (EjemotNwadiaro et al. 2015; WHO 2009) and that the provision of handwashing materials can increase handwashing (Kotch et al. 2007; Maury et al. 2000). We find that the full intervention increased the availability of hand washing guidelines and equipment on the whole by a significant amount (Table 4). Specifically, hand washing facilities for patients rose by 18 percentage points (from a baseline of 42 percent), and both the full intervention and the light intervention increased the availability of hand washing facilities for medical personnel, although the baseline in control PHCs in this case was 84 percent. The full intervention also increased the availability of water in the consulting room and the waiting room by 28 percent and 13 percent, respectively (from a baseline of about 30 percent in both cases). We detected no effects on water availability in the bathrooms and the delivery room. All these indicators were classified as "medium feasibility." The full intervention also had a large impact on the availability of a poster describing hand-washing behavior (which was a "highly feasible” action). 


\section{Care of Patients (Appendix Figure 1.8; Appendix Table 3.8)}

The full intervention program showed no impacts on whether or not a partograph was available, ${ }^{20}$ nor on records of antenatal care visits, nor on whether the respondent used written records to respond to questions about antenatal care, one indicator of organization of pregnancy services. However, the full intervention facilities are significantly more likely to report Apgar scores for newborns ("Within PHC control/Moderate effort"), an important tool. ${ }^{21}$ The treatments also did not affect whether the clinics would keep individual case records nor on diagnosis of malaria.

\section{Clinical Support - Operating theater and anesthetic services (Appendix Figure 1.9;} Appendix Table 3.9)

We observe no impact from either intervention on whether materials for sterilization of equipment for present or for whether there were a functional autoclave. Both of these were rated "low feasibility” because the PHCs are dependent on actions by government authorities to provide these tools.

Clinical Support - Medication Management (Appendix Figure 1.10; Appendix Table 3.10)

On average, we do not observe significant impacts on medication stock management and storage for either group (Table 4). Among the underlying actions, we see that PHCs receiving the full intervention were 20 percentage points more likely to have drugs and vaccines labeled and organized by expiry date (with 95 percent significance), and marginally significant impacts on having more unexpired essential drugs and more essential drugs in stock. We see no impacts of the light intervention.

\section{Facility Management Services (Appendix Figure 1.11; Appendix Table 3.11)}

We do not observe systematic changes in facility management services (Table 4). This reflects a lack of improvement in basic facility infrastructure (e.g., whether the facility has electricity

\footnotetext{
${ }^{20}$ The partograph is a graphical record of the course of labor. Its use can reduce the rate of maternal mortality since abnormal markers in the progress of labor can be identified early on (Asibong et al. 2014).

${ }^{21}$ Apgar is a quick test performed on a baby at 1 and 5 minutes after birth. The 1-minute score determines how well the baby tolerated the birthing process. The 5-minute score tells the doctor how well the baby is doing outside the mother's womb. The Apgar test is done by a doctor, midwife, or nurse. The healthcare provider examines the baby's breathing effort, heart rate, muscle tone, reflexes, and skin color.
} 
interruptions or clean water available all year), which are "low feasibility” actions for the PHC. Access to power and water were not affected by the full intervention or the light intervention. However, if the facility possessed a generator (which is classified as a "low feasibility" process indicator), the full intervention led to a 26 percentage point increase in the availability of fuel for the generator (a “medium feasibility” action with a baseline of 58 percent in control PHCs). Note that PHCs did not receive an additional discretionary budget, so additional availability of fuel may imply some community mobilization.

\section{Support Services (Appendix Figure 1.12; Appendix Table 3.12)}

We do not observe systematic changes in support services on average (Table 4). However, among the underlying indicators, we observe significant positive impacts on the cleanliness of the patient toilets and the waiting room for the full intervention, albeit not for the light intervention.

\subsubsection{Intermediate Outcomes}

In Figure 4, we show the results of our regressions for the process indicators index and for the intermediate outcomes indicators index. We classify the following items as intermediate outcomes: cleanliness of the waiting area, cleanliness of the toilets, cleanliness of the stored bed linens, whether drug and vaccines are stored neatly, labeled and ordered by expiration date, whether essential drugs are available, whether essential vaccines are available, and whether there are reorder levels for essential drugs and vaccines. ${ }^{22}$ All other indicators are classified as process indicators. Overall, the full intervention had positive and statistically significant effects on both process indicators (0.30 SDs) and intermediate outcomes (0.27 SDs) (Table 4). Appendix Table 3.13 shows the regressions results for each element included in the intermediate outcomes index. The full intervention significantly increased the cleanliness of some areas in the facilities. With the full intervention, the likelihood that the toilets are perceived as “clean” or “very clean” increased by 22.7 percentage points (95 percent confidence). The full intervention also increased the likelihood that waiting rooms were reported to be “clean” or “very clean” by 10.1 percentage points (90 percent confidence). As reported above, we did

${ }^{22}$ Enumerators took pictures and evaluated the degree of cleanliness of the waiting areas, the toilets, and the bed linens stored at the facility. Cleanliness was rated on a five-point Likert scale. Enumerators also visited the drug storage area in each facility, took pictures, and checked the organization of the pharmacy and whether unexpired essential drugs and vaccines were available. 
not observe significant effects on storage and availability of drugs and vaccines, although there is statistically significant movement in some of the underlying actions. Full intervention PHCs were 19.7 percentage points more likely to have organized drugs and vaccines by the expiration date (95 percent significant), had 0.64 more unexpired essential drugs (out of 9 possible) (90 percentage significance) and 0.59 more available or in stock essential drugs (90 percent significance). We find no effect on the availability of vaccines, nor on the likelihood of having a well-defined level at which a PHC would re-order drugs or vaccines. We do not detect any significant impacts for the light intervention on any of the intermediate outcomes.

\subsection{Longer Term Effects}

One year after the intervention ended, we gathered a final round of data in order to examine whether the impacts were likely driven by improved management capacity (which would be signaled by persistent effects) or by supervision (non-persistent effects). However, staff turnover was extremely high: only 9 percent of staff were retained between the beginning of the intervention and the followup, almost two years later (Table 5). While high staff turnover in health facilities is reportedly a recurring challenge in Nigeria, this rate seems exceptional (Abimbola et al. 2015; Holmlund et al. 2021). ${ }^{23}$ It may be because the government changed and with that, the overarching program to invest in health centers (SURE-P) was discontinued. With such a high rate of turnover, it is possible that most of the skills gained from training and supervision were lost as staff left the clinic, so our longer term results should be seen as suggestive only.

With that caveat in mind, our summary indices suggest a persistent effect of the full intervention on actions that are under shared control (Figure 5.1) and among those that are highly feasible (Figure 5.2). Previously significant effects on other areas have dissipated. The light intervention continues to have no measured impacts. ${ }^{24}$ With our high turnover rates, interpretation of the longer term results is difficult. If anything, one interpretation of these reduced findings is that the driver of our effects in the

\footnotetext{
${ }^{23}$ Despite repeated qualitative references to high staff turnover as a challenge, we were not able to identify concrete numbers on staff turnover over time.

${ }^{24}$ Only 3 of our 22 rejected null-hypotheses for the full intervention are still significant in our long-run follow up data (round 7): The visible display of a patients' rights charter $(\beta=0.571 * * * ; \mathrm{SE}=0.098)$, clearly marked waste bins of different types of waste $\left(\beta=0.308^{* *}\right.$; $\left.\mathrm{SE}=0.111\right)$, and the availability of an organizational structure chart in the facility $\left(\beta=0.557^{* * *} ; \mathrm{SE}=0.119\right)$. The visible presence of hand washing supplies $(\beta=0.202 * ; \mathrm{SE}=0.079)$ and clean bed linens $(\beta=0.254 * ; \mathrm{SE}=0.106)$ were marginally significant in the long-run follow-up, but were not significant during rounds 1 6 , although other indicators related to hand washing were significant in the earlier rounds.
} 
full intervention, which was a composite of providing information and support/monitoring, was likely the regular monitoring component.

\section{Conclusions}

We conducted a randomized field experiment evaluating the effects of a healthcare management consulting program for public-sector, primary healthcare centers in Nigeria. The objective of our study was to evaluate the effects of management consulting on the adoption of accredited, organizational standards in primary healthcare facilities in a middle-income country context. Moreover, our experimental design allows us to distinguish between information effects, on the one hand, and implementation support and supervision effects, on the other. We find that providing a detailed quality improvement plan paired with continuous monitoring and feedback increased the adoption of several standards and processes in the short term. This more intensive treatment also led to improvements in some intermediate outcomes, namely those that were within direct control of the PHC staff, such as cleanliness of toilets and waiting rooms and availability of hand-washing equipment. These effects disappeared one year after the end of the intervention, although we cannot rule out that this is due to high staff turnover at the facilities with a reduction in financing. Alternatively, merely presenting baseline quality assessments and summary feedback were insufficient to change healthcare practices, even in the short term.

All of the short-term effects were found for practices that were under the direct responsibilityeither total or shared—of the PHC staff, and that were feasible for them to implement. The lack of adequate infrastructure and support structures for PHC staff which our data reveal is a contributing factor to persistent poor quality of healthcare provision. For example, many clinics do not have access to the national power grid, and stock-outs of essential drugs are not always promptly replenished. Moreover, the PHC staff may lack incentives to implement process improvements that require extra effort.

These findings indicate that information alone on what practices should be adopted is not sufficient. We find no evidence of minimal, low-cost interventions that immediately lead to the sustained adoption of modern organizational practices. We find that improvements occur when specific information on practices to be adopted is combined with implementation support. In particular, periodical monitoring of the PHC's progress appears to be important for achieving 
sustained improvements in contexts where the absence of external competition or managerial pay-forperformance fail to create incentives for the adoption of organizational standards. In a context where many healthcare facilities share the same challenges, a lower-cost alternative to the intervention evaluated here may involve a less intensive baseline evaluation but more sustained monitoring. Further research is needed. Ultimately, the results of our study suggest that improving organizational practices requires sustained support, not a one-time, short-term intervention. 


\section{Data Availability Statement}

The data that support the findings of this study are currently available from the corresponding author upon reasonable request; by the time of publication, we plan to have the anonymized data posted publicly.

\section{References}

Abimbola, S., Olanipekun, T., Igbokwe, U., Negin, J., Jan, S., Martiniuk, A., Ihebuzor, N., \& Aina, M. (2015). How decentralisation influences the retention of primary health care workers in rural Nigeria. Glob Health Action 8, 26616. https://doi.org/10.3402/gha.v8.26616

Anderson, M.L. (2008). Multiple inference and gender differences in the effects of early intervention: A reevaluation of the Abecedarian, Perry Preschool, and Early Training Projects. Journal of the American Statistical Association 103(484), 1481 - 1495

Akwataghibe, N., Samaranayake, D., Lemiere, C., \&, Dieleman, M., (2013). Assessing health workers' revenues and coping strategies in Nigeria - a mixed-methods study. BMC Health Serv Res 13, 387. https://doi.org/10.1186/1472-6963-13-387

Asibong, U., Okokon, I. B., Agan, T. U., Oku, A., Opiah, M., Essien, E. J., \& Monjok, E. (2014). The use of the partograph in labor monitoring: a cross-sectional study among obstetric caregivers in general Hospital, Calabar, Cross River state, Nigeria. International Journal of Women's Health, 6, 873.

Berwick, D. (2004). Lessons from developing nations on improving healthcare. British Medical Journal 328 (7448): 1124-29.

Bloom, N., Eifert, B., Mahajan, A., McKenzie, D. \& Roberts, J. (2013). Does management matter: evidence from India. Quarterly Journal of Economics 128(1), 1-51.

Bloom, N., Sadun, R., \& Van Reenen, J. (2012). The organization of firms across countries. Quarterly Journal of Economics 127(4):1663-1705.

Bloom, N., Lemos, R., Sadun, R., \& Van Reenen, J. (2020). Healthy business? Managerial education and management in health care. The Review of Economics and Statistics 102, 506-517. https://doi.org/10.1162/rest_a_00847

Bruhn M., Karlan D., \& Schoar A. (2018). The impact of consulting services on small and medium enterprises: Evidence from a randomized trial in Mexico. Journal of Political Economy, 126(2), 635-687.

Butar, F. B., \& Park, J. W. (2008). Permutation tests for comparing two populations. Journal of Mathematical Science \& Mathematics Education V3, (2), 19-30.

Chakraborty, S., D'Souza, S. A., \& Northrup, R. S. (2000). Improving private practitioner care of sick children: testing new approaches in rural Bihar. Health Policy and Planning, 15(4), 400-407. 
Chandra, A., Finkelstein, A., Sacarny, A., \& Syverson, C. (2016). Healthcare exceptionalism? Performance and allocation in the US healthcare sector. American Economic Review, 106(8): 2110-2144.

Das, Jishnu and Jeffrey Hammer. (2014). Quality of primary care in low-income countries. Annual Review of Economics. DOI 10.1146/annurev-economics-080213_041350.

Das, J., Holla, A., Das, V., Mohanan, M., Tabak, D., \& Chan, B. (2012). In urban and rural India, a standardized patient study showed low levels of provider training and huge quality gaps. Health Affairs, 31(12), 2774-2784.

Das, J., Hammer, J., \& Leonard, K. (2008). The quality of medical advice in low-income countries. The Journal of Economic Perspectives, 22(2), 93-114.

Di Giorgio, L., Evans, D.K., Lindelow, M., Nguyen, S.N., Svensson, J., Wane, W., Tärneberg, A.W., (2020). Analysis of clinical knowledge, absenteeism and availability of resources for maternal and child health: a crosssectional quality of care study in 10 African countries. BMJ Global Health 5, e003377. https://doi.org/10.1136/bmjgh-2020-003377

Dunsch, F.A., Evans, D.K., Macis, M., \& Wang, Q. (2018). Bias in patient satisfaction surveys: a threat to measuring healthcare quality. BMJ Global Health, 3(2), e000694.

Ebenso, B., Manzano, A., Uzochukwu, B., Etiaba, E., Huss, R., Ensor, T., Newell, J., Onwujekwe, O., Ezumah, N., Hicks, J., Mirzoev, T. (2019). Dealing with context in logic model development: Reflections from a realist evaluation of a community health worker programme in Nigeria. Evaluation and Program Planning 73, 97110. https://doi.org/10.1016/j.evalprogplan.2018.12.002

Ejemot-Nwadiaro, R. I., Ehiri, J. E., Arikpo, D., Meremikwu, M. M., \& Critchley, J. A. (2015). Hand washing promotion for preventing diarrhoea. The Cochrane Database of Systematic Reviews, (9), 1-95. http://doi.org/10.1002/14651858.CD004265.pub3

Evans, A. (2017). Amplifying accountability by benchmarking results at district and national levels. Development Policy Review. doi: 10.1111/dpr.12213.

Gustaffon-Wright, E, \& Schellekens, O. (2013). Achieving Universal Health Coverage in Nigeria: A PublicPrivate Partnership Community-Based Health Insurance Model. Brookings Institution working paper. Retrieved from https://www.brookings.edu/wp-content/uploads/2016/06/Achieving-Universal-HealthCoverage-in-Nigeria.pdf

Holmlund, M., Jervis, P., Maniquet, P., Dias, P.R., \& Vera-Hernandez, M. (2021). Monetary incentives and image motivation: Evidence from a large-scale experiment with Nigerian midwives. Unpublished Manuscript.

Institute of Medicine. (2001). Crossing the quality chasm: A new health system for the 21st century. Washington D.C.: National Academy Press.

Johnson M.C., Schellekens O., Stewart J., van Ostenberg P., de Wit T. R., \& Spieker N. (2016). SafeCare: An innovative approach for improving quality through standards, benchmarking, and improvement in low- and middle-income countries. Joint Commission Journal on Quality and Patient Safety, 42(8), 350-360.

Khanna, M., Loevinsohn, B., Pradhan, E., Fadeyibi, O., McGee, K., Odutolu, O., Fritsche, G.B., Meribole, E., Vermeersch, C., \& Kandpal, E. (2020). Decentralized facility financing as a cost-effective alternative to 
performance-based payments in primary health care: a large-scale experimental trial in Nigeria. Unpublished Manuscript.

Kling, J. R., Liebman, J. B., \& Katz, L. F. (2007). Experimental analysis of neighborhood effects. Econometrica, 75(1), 83-119.

Kotch, J.B., Isabell, P., Weber, D.J., Nguyen, V., Savage, E., Gunn, E., Skinner, M., Fowlkes, S., Virk, J., \& Allen, J. (2007). Hand-washing and diapering equipment reduces disease among children in out-of-home child care centers. Pediatrics 120(1).

Makinde, O.A., Sule, A., Ayankogbe, O., \& Boone, D. (2018). Distribution of health facilities in Nigeria: Implications and options for Universal Health Coverage. The International Journal of Health Planning and Management 33, e1179-e1192. https://doi.org/10.1002/hpm.2603

Maury, E., Alzieu, M., Baudel, J.L., Haram, N., Barbut, F., Guidet, B., \& Offenstadt, G. (2000). Availability of an alcohol solution can improve hand disinfection compliance in an intensive care unit. American Journal of Respiratory and Critical Care Medicine, 162:324-327.

McKenzie, D. (2012). Beyond baseline and follow-up: The case for more $\mathrm{T}$ in experiments. Journal of Development Economics, 99(2), 210-221.

Nwakeze, N. M., \& Kandala, N. (2011). The spatial distribution of health establishments in Nigeria. African Population Studies, 25(2).

Okeke, E., (2019). Working Hard or Hardly Working: Health Worker Effort and Health Outcomes. Economic Development and Cultural Change. https://doi.org/10.1086/706823

Peabody J.W., Taguiwalo M.M., Robalino D.A., \& Frenk, J. (2006). Improving the quality of care in developing countries. In: Jamison DT, Breman JG, Measham AR, et al., editors. Disease Control Priorities in Developing Countries. 2nd edition. Washington (DC): World Bank. Chapter 70. Available from: http://www.ncbi.nlm.nih.gov/books/NBK11790/

SafeCare. (2013). "SafeCare Standards receive International ISQua Accreditation.” http://www.safecare.org/index.php?mact=News,cntnt01,detail,0\&cntnt01articleid=17\&cntnt01returnid=45. Accessed October 30, 2015.

SafeCare. (2014). "Standards: SafeCare Advanced Assessment." http://www.safecare.org/uploads/Standards\%202014\%20ADVANCED.pdf. Accessed October 30, 2015.

SafeCare. (2021). "SafeCare Healthcare Standards.” https://www.safe-care.org/who-we-are/safecarestandards/. Accessed March 29, 2021.

SafeCare. "Government partners.” http://www.safe-care.org/index.php?page=government-partners (accessed July 31, 2017).

Savin, N. E. (1984). "Multiple hypothesis testing." Handbook of econometrics 2 (1984): 827-879.

Skinner J. (2011). “Causes and consequences of regional variations in health care.” M. V. Pauly, T.G. Mcguire, \& P. P . Barros, eds., Handbook of Health Economics Volume 2. 45-93. 
Strasser, R., Kam, S.M. \& Regalado, S.M. (2016). Rural healthcare access and policy in developing countries. Annual review of public health, 37, pp.395-412.

Ugo, O., Eze-Ajoku, E., Modupe, O., Nicole, S., Winifred, E. \& Kelechi, O., (2016). Improving quality of care in primary health-care facilities in rural Nigeria: Successes and Challenges. Health Services Research and Managerial Epidemiology, 3, p.2333392816662581.

UNICEF (2014), "Levels \& trends in child mortality - Report 2013”. Available at http://www.childinfo.org/files/Child_Mortality_Report_2013.pdf (downloaded on 7/18/2015).

USAID. (2016). Health financing profile: Nigeria. Retrieved April 11, 2018, from http://www.africanstrategies4health.org/uploads/1/3/5/3/13538666/country_profile_-_nigeria__us_letter_final.pdf

Windfeld, E. S., \& Brooks, M. S. L. (2015). Medical waste management-A review. Journal of environmental management, 163, 98-108.

World Bank. (2020). World development indicators. Available at http://databank.worldbank.org/data/reports.aspx?source=world-development-indicators (accessed on February 25, 2020).

World Health Organization. (2006). Quality of care: a process for making strategic choices in health systems.

World Health Organization. (2009). WHO guidelines on hand hygiene in healthcare: A summary. http://www.who.int/gpsc/5may/tools/who_guidelines-handhygiene_summary.pdf (accessed on August 1, 2017).

World Health Organization. (2015). “Nigeria: WHO statistical profile,” World Health Organization, Geneva. http://www.who.int/gho/countries/nga.pdf?ua=1 (accessed on August 1, 2017). 


\section{Figure 1: Map with Study Sites}



Notes: The map shows the 6 states where the intervention took place. Full Intervention facilities are marked with a green dot, Light Intervention facilities are marked purple, and facilities in the control group are orange. A higher resolution map can be found here: http://tinyurl.com/map-nigeria. 


\section{Figure 2: Examples of action items from the Quality Improvement Plans and our outcome variables.}

QIP Example 1: Design an organizational chart or document which describes the lines of authority and accountability from governance and within the service.

Our survey question:

Is an organizational structure chart available in the facility?

QIP Example 2: Introduce a quality management system in the facility (appoint quality manager, train staff, organize bi-weekly quality team meetings, keep minutes of these meetings).

Our survey questions:

Are you currently working towards any targets to improve the quality of care at this clinic?

$>$ Last month, were any staff meetings held at this facility?How many?

$>$ Do you have a written summary for the most recent meeting last month? Can we see it?

QIP Example 3: Obtain policy on waste management. Train personnel on waste segregation \& containers for collection. Keep adequate records. Monitor implementation. Display posters on waste segregation at different areas of the facility. Establish a policyguided waste management system at the facility. Provide relevant tools/resources (sharps boxes, PPEs, pedaled bins, etc). Train personnel, provide reminders and monitor the adherence to protocols.

Our survey questions:

$>$ Does this facility have any guidelines on health care waste management?

$>$ Are there posters showing waste separation in the facility?

$>$ Is medical waste disposed together with regular waste or separately?

$>$ Have you or any provider(s) received training in health care waste management? 


\section{Figure 3: Summary Indexes}

\subsection{By entity responsible - Government designation}

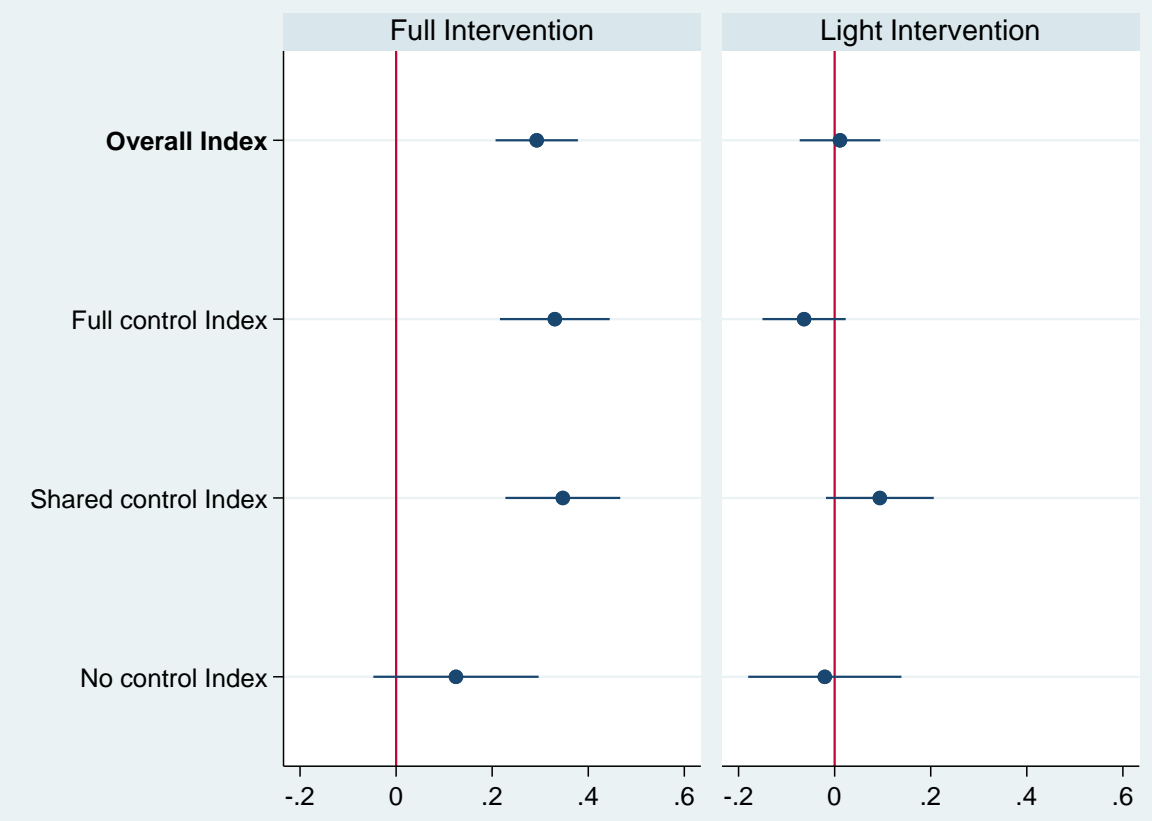

\subsection{By feasibility - Researchers designation}

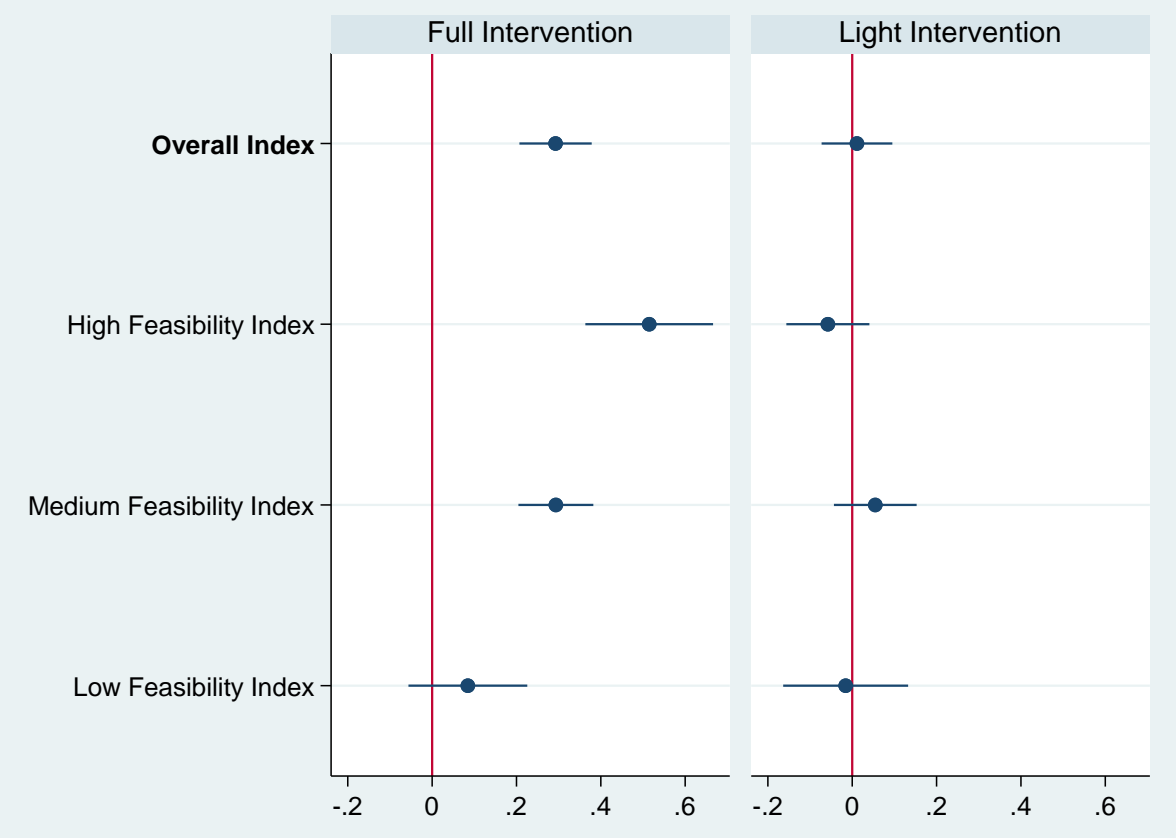


Notes: The figures show estimated coefficients on Full Intervention and Light Intervention indicators of indices of the outcome variables for rounds 1 through 6. Z-scores were obtained for each variable by subtracting the overall mean and dividing by the overall standard deviation. Next, indicators were calculated as equally-weighted averages of the Z-scores of its components. 3.1: "Full Control Index" refers to indicators that were designated (by the Government) as being within the control of the facility, "Shared Control Index" refers to indicators for which responsibility was shared between the facility and the local and/or the federal government, and "No Control Index" includes indicators that were designated as being the responsibility of the local and/or federal government (i.e., not of the facility). 3.2: "High Feasibility Index" refers to indicators that we classified as being within the control of the facility and that require minimal or moderate effort, "Medium Feasibility Index" to indicators that are within the control of the facility and that required more sustained effort to be implemented, and "Low Feasibility Index" refers to indicators that are either outside the facilities' control or that required high levels of resources and effort to be implemented. 


\section{Figure 4: Process and Intermediate Outcomes Indicators}

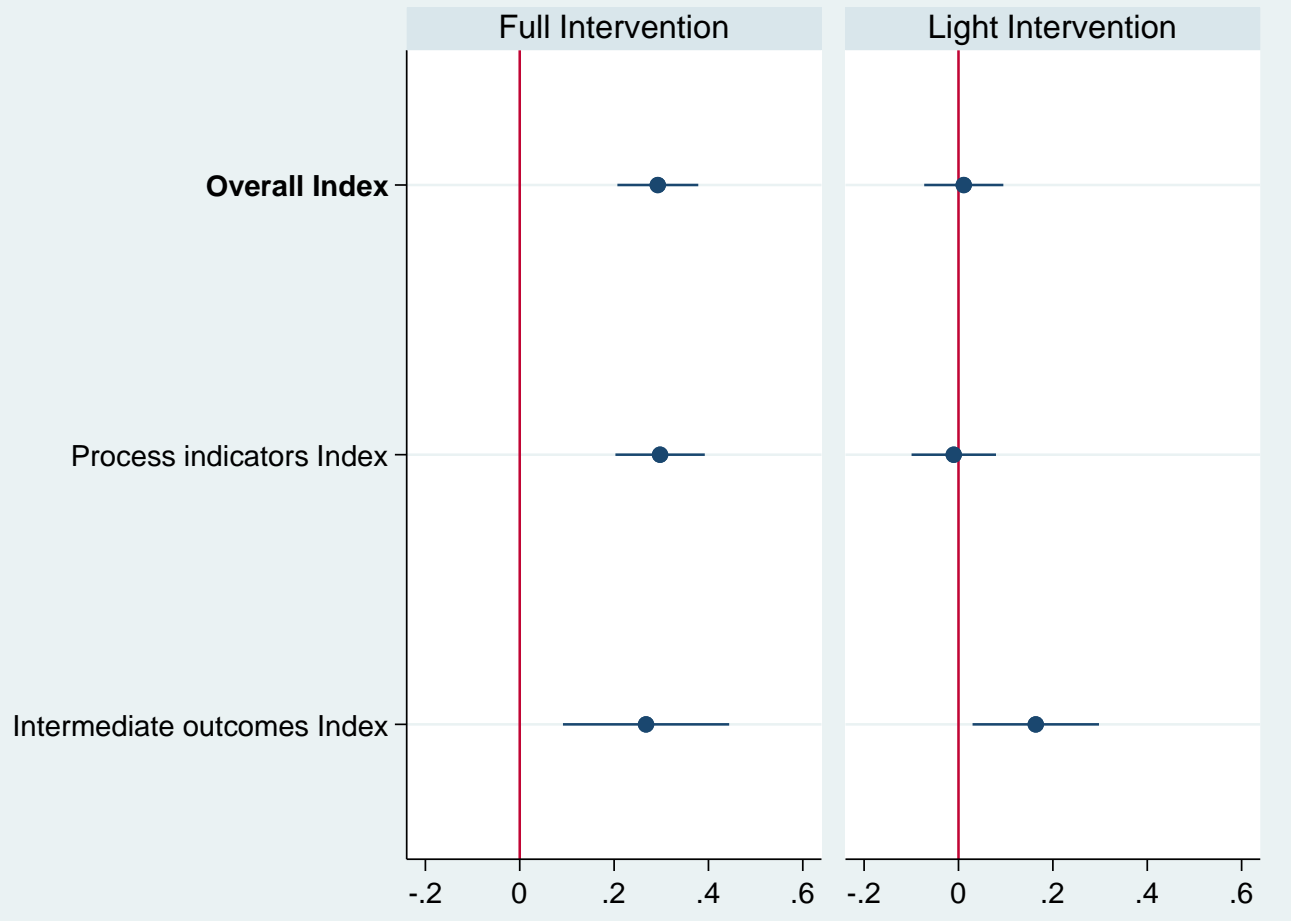

Notes: Intermediate outcomes include the following indicators: cleanliness of the waiting area, cleanliness of toilets, cleanliness of stored bed linens, neat arrangement of the drug storage area, availability of essential drugs and vaccines, reorder levels for essential drugs and vaccines. All other indicators are classified as Process indicators. 


\section{Figure 5: Long-term results}

\subsection{By entity responsible - Government designation}

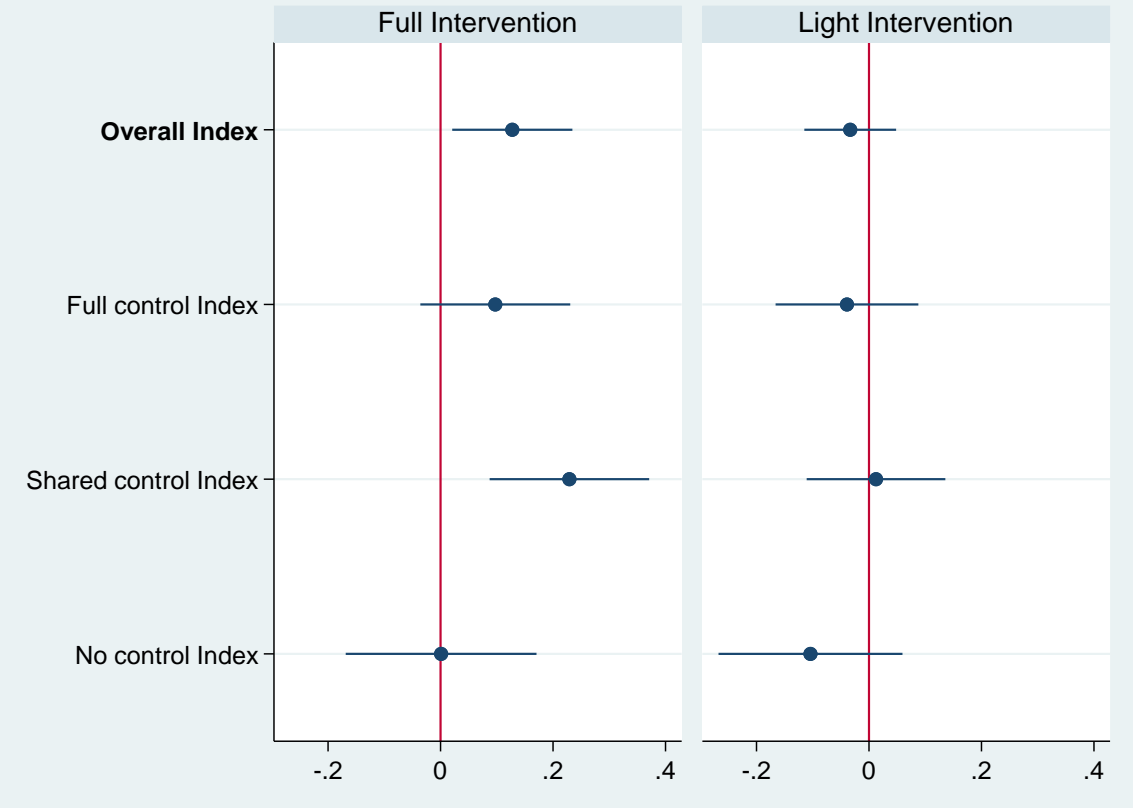

\subsection{By feasibility - Researchers designation}

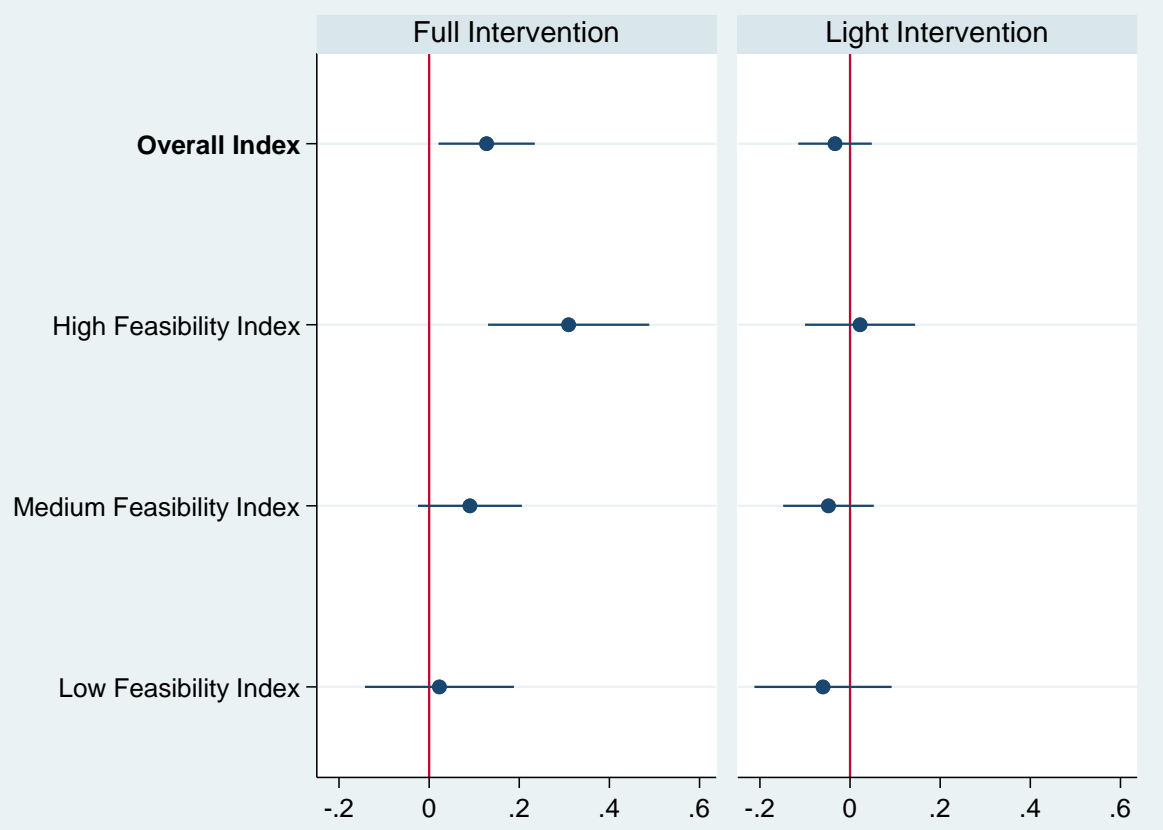

Notes: The figures show estimated coefficients on Full Intervention and Light Intervention indicators of indices of the outcome variables for round 7 (one year after the end of the intervention). Z-scores were obtained for each variable by subtracting the overall mean and dividing by the overall standard 
deviation. Next, indicators were calculated as equally-weighted averages of the Z-scores of its components. 5.1: "Full Control Index" refers to indicators that were designated (by the Government) as being within the control of the facility, "Shared Control Index" refers to indicators for which responsibility was shared between the facility and the local and/or the federal government, and "No Control Index" includes indicators that were designated as being the responsibility of the local and/or federal government. 5.2: "High Feasibility Index" refers to indicators that we classified as being within the control of the facility and that require minimal or moderate effort, "Medium Feasibility Index" to indicators that are within the control of the facility and that required more sustained effort to be implemented, and "Low Feasibility Index" refers to indicators that are either outside the facilities' control or that required high levels of resources and effort to be implemented. 
Table 1: SafeCare standards categories

\begin{tabular}{ll}
\hline \hline \multirow{2}{*}{ Management } & $\begin{array}{l}\text { 1. Governance and management } \\
\text { 2. Human resources management }\end{array}$ \\
& $\begin{array}{l}\text { 3. Patient rights and access to care } \\
\text { 4. Management of information } \\
\text { Care of patients }\end{array}$ \\
\hline \multirow{2}{*}{ Clinical support } & $\begin{array}{l}\text { 6. Primary health care (outpatient) services } \\
\text { 7. Inpatient care }\end{array}$ \\
\hline \multirow{2}{*}{ Ancillary services } & $\begin{array}{l}\text { 8. Operating theatre and anesthetic services } \\
\text { 9. Laboratory services } \\
\text { 10. Diagnostic imaging services } \\
\text { 11. Medication management }\end{array}$ \\
\hline \hline
\end{tabular}

Note: The full list of SafeCare standards can be found at SafeCare (2021). 
Table 2: Comparison of participating and non-participating facilities

\begin{tabular}{|c|c|c|c|}
\hline N. of facilities & $\begin{array}{l}\text { (1) } \\
\text { Participating PHCs } \\
79\end{array}$ & $\begin{array}{l}\text { (2) } \\
\text { Non-Participating } \\
\text { PHCs } \\
394\end{array}$ & $\begin{array}{l}\text { (3) } \\
\text { p-values } \\
\text { (Participating vs. } \\
\text { Non-participating) }\end{array}$ \\
\hline \multicolumn{4}{|l|}{ Facility Characteristics } \\
\hline $\begin{array}{l}\text { \% having } 24 \text { hours shift rotation } \\
\% \text { having at least one midwife per shift } \\
\% \text { having a reception/registration room } \\
\text { number of observation beds } \\
\text { number of days with no electricity/light at all during the last week } \\
\text { distance to the referral facility/hospital }(\mathrm{km}) \\
\% \text { having transportation for patients }\end{array}$ & $\begin{array}{c}0.86 \\
0.73 \\
0.66 \\
2.77 \\
4.83 \\
19.18 \\
0.10 \\
\end{array}$ & $\begin{array}{c}0.88 \\
0.74 \\
0.72 \\
3.23 \\
4.74 \\
20.76 \\
0.15 \\
\end{array}$ & $\begin{array}{l}0.67 \\
0.97 \\
0.31 \\
0.16 \\
0.78 \\
0.58 \\
0.22 \\
\end{array}$ \\
\hline \multicolumn{4}{|l|}{ Working Conditions } \\
\hline $\begin{array}{l}\text { number of staff meeting in the past } 12 \text { months } \\
\text { \% having developed a facility workplan for this year } \\
\% \text { having a WDC supervisor } \\
\% \text { having a patients feedback mechanism } \\
\% \text { having a staff reward system }\end{array}$ & $\begin{array}{l}8.17 \\
0.50 \\
0.95 \\
0.63 \\
0.30\end{array}$ & $\begin{array}{l}9.41 \\
0.58 \\
0.93 \\
0.68 \\
0.21\end{array}$ & $\begin{array}{l}0.23 \\
0.21 \\
0.51 \\
0.47 \\
0.08\end{array}$ \\
\hline \multicolumn{4}{|l|}{ Human Resources } \\
\hline $\begin{array}{l}\text { number of staff qualified as midwife and nurse } \\
\text { number of staff qualified as midwife only } \\
\text { number of staff qualified as nurse only } \\
\text { number of health workers }\end{array}$ & $\begin{array}{r}2.54 \\
0.63 \\
0.33 \\
12.25 \\
\end{array}$ & $\begin{array}{c}2.67 \\
0.73 \\
0.31 \\
12.35 \\
\end{array}$ & $\begin{array}{l}0.69 \\
0.55 \\
0.88 \\
0.93\end{array}$ \\
\hline \multicolumn{4}{|l|}{ Patients } \\
\hline $\begin{array}{l}\text { number of women discharges last week after having given birth } \\
\text { number of registered cases of antenatal care last month } \\
\text { number of registered cases of deliveries last month }\end{array}$ & $\begin{array}{c}3.99 \\
40.05 \\
6.92\end{array}$ & $\begin{array}{c}3.59 \\
35.86 \\
6.54\end{array}$ & $\begin{array}{l}0.46 \\
0.40 \\
0.68\end{array}$ \\
\hline
\end{tabular}

Notes: Data are from the 2013 Nigeria SURE-P MCH facilities' survey. The universe consists of the 474 PHCs nationwide that participated in the SURE-P subsidies program (see Section 2.1 of the paper for information on the SURE-P program). 
Table 3: Distribution of PHCs across experimental conditions, by State

\begin{tabular}{lcccc}
\hline State & $\begin{array}{c}\text { Total \# of } \\
\text { PHCs }\end{array}$ & $\begin{array}{c}\text { Full } \\
\text { Intervention }\end{array}$ & $\begin{array}{c}\text { Light } \\
\text { Intervention }\end{array}$ & Control \\
\hline Anambra & 12 & 5 & 4 & 3 \\
Bauchi & 16 & 4 & 5 & 7 \\
Cross River & 12 & 3 & 3 & 6 \\
Ekiti & 12 & 4 & 4 & 4 \\
Kebbi & 16 & 4 & 4 & 8 \\
Niger & 12 & 4 & 4 & 4 \\
Total & 80 & 24 & 24 & 32 \\
\hline
\end{tabular}

Notes: This table shows the number of PHCs by State and experimental

conditions. A total of 80 facilities were involved in the study. 
Table 4 - Main Results: Summary Indexes

\begin{tabular}{|c|c|c|c|c|c|c|}
\hline \multirow[b]{2}{*}{ Overall Index } & \multicolumn{2}{|c|}{$\begin{array}{l}\text { Full } \\
\text { intervention }\end{array}$} & \multicolumn{2}{|c|}{$\begin{array}{l}\text { Light } \\
\text { intervention }\end{array}$} & \multirow[b]{2}{*}{$\begin{array}{l}\mathrm{R}^{2} \\
0.732\end{array}$} & \multirow[b]{2}{*}{$\begin{array}{l}\text { N. Obs. } \\
80\end{array}$} \\
\hline & $\begin{array}{l}\text { coeff. } \\
0.293 * * *\end{array}$ & $\begin{array}{l}\text { std. err. } \\
{[0.043]}\end{array}$ & $\begin{array}{l}\text { coeff. } \\
0.011\end{array}$ & $\begin{array}{l}\text { std. err. } \\
{[0.0421]}\end{array}$ & & \\
\hline \multicolumn{7}{|l|}{ By responsibility (government designation) } \\
\hline Full control & $0.330 * * *$ & {$[0.057]$} & -0.064 & {$[0.043]$} & 0.679 & 80 \\
\hline Shared control & $0.347 * * *$ & {$[0.060]$} & 0.094 & {$[0.056]$} & 0.713 & 80 \\
\hline No control & 0.125 & {$[0.086]$} & -0.020 & {$[0.080]$} & 0.249 & 80 \\
\hline \multicolumn{7}{|l|}{ By feasibility (researcher designation) } \\
\hline High & $0.515^{* * *}$ & {$[0.076]$} & -0.058 & [0.049] & 0.703 & 80 \\
\hline Medium & $0.293^{* * *}$ & {$[0.045]$} & 0.055 & [0.049] & 0.726 & 80 \\
\hline Low & 0.085 & {$[0.071]$} & -0.016 & {$[0.074]$} & 0.330 & 80 \\
\hline \multicolumn{7}{|l|}{ Indexes by category } \\
\hline Governance and management & $0.647 * * *$ & {$[0.116]$} & -0.052 & {$[0.113]$} & 0.607 & 80 \\
\hline Human resources management & 0.049 & [0.115] & -0.036 & {$[0.117]$} & 0.233 & 80 \\
\hline Patient rights and access to care & $0.922 * * *$ & {$[0.126]$} & 0.131 & {$[0.092]$} & 0.648 & 80 \\
\hline Management of information & 0.232 & [0.239] & 0.115 & {$[0.249]$} & 0.206 & 80 \\
\hline Risk management - waste & $0.421^{* * *}$ & {$[0.120]$} & 0.056 & {$[0.101]$} & 0.264 & 80 \\
\hline Risk management - general risk & $0.433 * * *$ & {$[0.108]$} & -0.119 & {$[0.112]$} & 0.370 & 80 \\
\hline Risk management - handwashing & $0.462 * * *$ & {$[0.097]$} & 0.216 & {$[0.110]$} & 0.625 & 80 \\
\hline Care of patients & 0.151 & {$[0.084]$} & 0.053 & {$[0.084]$} & 0.624 & 80 \\
\hline Clinical support - operating theater services & -0.238 & [0.223] & -0.180 & {$[0.240]$} & 0.219 & 80 \\
\hline Clinical support - medication management & 0.186 & {$[0.116]$} & 0.119 & {$[0.072]$} & 0.460 & 80 \\
\hline Facility management services & 0.079 & [0.123] & -0.103 & {$[0.107]$} & 0.208 & 80 \\
\hline Support services & 0.172 & [0.153] & 0.167 & {$[0.119]$} & 0.512 & 80 \\
\hline \multicolumn{7}{|l|}{ By process/intermediate outcomes } \\
\hline Process indicators & $0.298 * * *$ & {$[0.048]$} & -0.010 & {$[0.045]$} & 0.703 & 80 \\
\hline Intermediate outcomes & $0.268^{* *}$ & [0.089] & $0.164^{*}$ & {$[0.067]$} & 0.588 & 80 \\
\hline
\end{tabular}

Notes: The table shows estimated coefficients on Full Intervention and Light Intervention indicators of indices of the outcome variables for rounds 1 through 6 . Z-scores were obtained for each variable by subtracting the overall mean and dividing by the overall standard deviation. Next, indicators were calculated as equally-weighted averages of the Z-scores of its components. See Appendix Tables 2 and 3, and Appendix Figure 1 for the list of indicators comprised in each of the indexes. 
Table 5 - Staff Turnover (Doctors, Midwives, Nurses)

$\begin{array}{ccc}\text { Retention rate } & \text { Retention rate } \\ \text { through round 6 } & \text { (nine months } \\ \text { of staff in round 1 } & \begin{array}{c}\text { (through round 7 } \\ \text { after the start of } \\ \text { the intervention) }\end{array} & \begin{array}{c}\text { (one year after } \\ \text { the end of the } \\ \text { intervention) }\end{array}\end{array}$

Overall, by

experimental condition

Control

5.31

5.79

$75.8 \%$

$10.3 \%$

Full Intervention

5.67

$69.1 \%$

$8.9 \%$

Light Intervention

5.56

$66.7 \%$

$6.7 \%$

Total

$71.1 \%$

$8.8 \%$

Totals, by state:

Anambra

7.33

$64.7 \%$

$15.1 \%$

Bauchi

5.19

$56.4 \%$

$1.9 \%$

Cross River

5.92

$74.4 \%$

$6.7 \%$

Ekiti

6.58

$68.8 \%$

$6.3 \%$

Kebbi

4.00

$86.2 \%$

$13.5 \%$

Niger

5.00

$75.6 \%$

$10.2 \%$ 


\section{ONLINE APPENDIX}

for

Management, Supervision, and Health Care:

A Field Experiment

by Felipe A. Dunsch, David K. Evans, Ezinne Eze-Ajoku, and Mario Macis 


\section{Appendix Table 1: Recommended standards/practices at treated PHCs}

\begin{tabular}{lc}
\hline Standard & $\begin{array}{c}\% \text { of treated facilities } \\
\text { with standard } \\
\text { included in } \\
\text { improvement plan }\end{array}$ \\
\hline
\end{tabular}

Governance and management

Document the organizational structure from governance and within the facility. Roles and responsibilities should be documented and education provided to all staff on work dynamics (clinical and administrative).

$88 \%$

$83 \%$

$83 \%$

$4 \%$

Strengthen the community involvement process through establishing goals for the WDC and incorporating quality improvement indicators in the performance review for the unit.

\section{Human resources management}

Ensure the provision of the needed staff cadres according to the Minimum Standards for PHCs in Nigeria.

Develop an orientation program for new staff at the facility. Keep appropriate records of program content and those in attendance including their signatures.

$38 \%$

Create a mechanism that ensures that at the facility levels, job descriptions are known and facility-level performance measurement is done to inform designation and delegation of duties.

$4 \%$

Patient rights \& access to care

Obtain patients rights charter. Display strategically in the facility. Train all staff on the patient's right to privacy during examinations, counselling \& provision of information (OPD, wards, pharmacy, laboratory, etc).

Ensure the availability of ward screens in relevant areas of the facility (at least 1 ward screen to 2 beds). Ensure windows in patient interaction areas have drapes. Ensure doors are closed during examinations \& counselling.

Make provision for more ward screens in all relevant areas (ward, examination room etc.)

Management of information

Ensure all patient records are standardized, dated, up to date, signed and contain the designation of personnel carrying out the assessment.

Make available a secure cabinet/cupboard for the storage of patient files. Ensure files are neatly arranged according to colour, condition and unique identification number. Implement systems for easy retrieval of records.

Ensure all national and local registers are completely filled with correct information. Designate an individual to oversee this process.

Designate an individual to be responsible for the management of information. Establish policy-guided processes regarding data management and provide personnel education/training for the use of data at the facility level. 


\section{Appendix Table 1 (continued)}

\begin{tabular}{|c|c|}
\hline Standard & $\begin{array}{c}\% \text { of treated facilities } \\
\text { with standard } \\
\text { included in } \\
\text { improvement plan }\end{array}$ \\
\hline \multicolumn{2}{|l|}{ Risk management - Waste Management } \\
\hline $\begin{array}{l}\text { Obtain policy on waste management. Train personnel on waste segregation \& appropriate containers for } \\
\text { collection. Keep adequate records. Display posters on waste segregation at different areas of the facility. }\end{array}$ & $100 \%$ \\
\hline $\begin{array}{l}\text { Ensure the availability of safety boxes and covered dustbins in all areas of the facility for waste collection. } \\
\text { Dustbins should have colour coded bin liners or should be painted with the respective colour codes. }\end{array}$ & $92 \%$ \\
\hline $\begin{array}{l}\text { Make available a schedule for emptying waste from the facility to the pit as well as a schedule for burning } \\
\text { waste in the pit. Ensure implementation of these schedules. }\end{array}$ & $83 \%$ \\
\hline Construct waste disposal pit with a parapet and cover and train personnel in the use of this. & $79 \%$ \\
\hline Make provision for more waste bins in the facility. & $13 \%$ \\
\hline \multicolumn{2}{|l|}{ Risk management - Handwashing } \\
\hline $\begin{array}{l}\text { Ensure the provision of soap, water and paper towels/single use towels at hand washing facilities. Water } \\
\text { should be distributed to relevant areas of the facility with the use of buckets with tap heads (veronica buckets). }\end{array}$ & $83 \%$ \\
\hline Display posters addressing hand washing at different areas of the facility. & $83 \%$ \\
\hline $\begin{array}{l}\text { Ensure completion of the bore-hole-overhead tank-facility system(re-install motor) and provide the means of } \\
\text { supplying the water to the point of use. Provide Veronica buckets and other hand washing facilities. }\end{array}$ & $8 \%$ \\
\hline
\end{tabular}

Risk management - Safety and security

Develop \& document a mechanism for summoning the assistance of external sources of security in an emergency (eg. Police, community guards, etc.). Make it known to all personnel. Have available contact details displayed in relevant areas.

Develop a process that protects personnel \& patients from assault. Ensure staff are aware. Control access to the facility $\&$ restricted areas. Display posters on no-tolerance for violence. Ensure no dark areas are within $\&$ around the facility.

Provision should be made for at least 2 security personnel who can run daily shifts, covering the facility round the clock.

Guiding/supporting rails should be fitted for all staircases and along the high corridors.

Ensure access control measures are in place at the pharmacy, laboratory, labour room and other restricted areas. Ensure doors are lockable and have appropriate signage eg. "authorized entry only", "restricted area", etc. 


\section{Appendix Table 1 (continued)}

\% of treated facilities
with standard
included in
improvement plan

Risk management - General risk

Designate an individual to be responsible for infection control and ensure the provision of continuous inservice training to all personnel. Retrain staff on disinfection techniques. Keep records of training.

$96 \%$

$96 \%$

service training to all personnel. Retrain staff on disinfection techniques. Keep records of training.

Provision should be made for the secure storage of cleaning materials and equipment (mops, brooms, buckets, etc.). Chemicals for cleaning should be kept in a dedicated and secure cabinet clearly labelled for the purpose.

$92 \%$

$79 \%$

$67 \%$

$13 \%$ personnel.

Clinical support - Primary health care services

Obtain the national treatment guidelines and standing orders to guide all staff in their clinical practice.

identifying and fast-tracking these patients.

$63 \%$

referred, services to be referred, a list of referral centers, and details of contact persons in the referral centers.

$54 \%$

records of health education provided to each patient.

$50 \%$ the facility.

$4 \%$ well as follow-up instructions.

Clinical support - diagnosis and treatment of malaria

Obtain national guidelines for the treatment of Malaria. Ensure that the management of malaria accords with national guidelines. Keep appropriate records of cases receiving ACT following a laboratory confirmation. 


\section{Appendix Table 1 (continued)}

Standard

$\%$ of treated facilities

with standard

included in

improvement plan

Clinical support - Antenatal care and deliveries

Ensure the use of partograph to monitor all deliveries and keep records of apgar score for newborns. Ensure all tests, observations and examinations are recorded for all antenatal and postnatal cases.

Make provision for a delivery table with stirrups.

Supply the SURE-P ANC patients files to provide a template for proper records.

Make provision for an angle-poise lamp for adequate lighting in the delivery room.

Put in place a system to identify newborns (eg. use of wristbands). Display posters reminding mothers not to

leave their babies unattended to. Ensure only authorized access to the wards.

Clinical support - Operating Theatre \& Anaesthetics

Ensure the availability and use of autoclaves for sterilization of all instruments. Calico and sterility tapes should be available for the sterilization process.

Make available a secure and well ventilated storage area for sterilized instrument packs. These should be stored off the ground.

Ensure a clear flow and dermacation of activities in the sterilization area (decontamination, washing, drying, packing, sterilizing and storage).

Obtain a storage drum/ container for disinfected instruments.

$50 \%$

\section{Clinical support - Laboratory Services}

Designate an individual (with documented job descriptions) to manage the laboratory. Ensure there are policyguided processes that foster collaborative work between the other units and the laboratory.

Clinical support - Medication Management

Carry out checks on expiry date of all pharmaceutical and laboratory supplies in all areas of the facility. Ensure proper documentation of these checks. Ensure the 'first expired first out' principle is adhered to.

General storage facilities should be secure, adequate, ventilated and well organised putting different groups of items in sections.

Implement a stock management system with definitions of maximum \& reorder levels. Records of stock received, distribution to different units and usage should be kept to prevent stock-outs. Ensure continuous monitoring of stock.

Ensure all new supplies (medication, vaccines, kits, consumables, etc.) are checked for expiry, batch number, labels, signs of tampering, potency, completeness, colour, smell etc. Keep records of action taken if required.

Institute a system that tracks adverse drug reactions (immunization/medication) for patients. Records with details of preventive and remedial actions taken should be kept in registers and patient records as appropriate.

Develop and implement a system for the disposal of expired stock. Records of all expired stock should be kept as well as method of disposal. Expired stock should be separated from all other stock and appropriately labeled. 


\section{Appendix Table 1 (continued)}

\begin{tabular}{cc}
\hline Standard & $\begin{array}{c}\% \text { of treated facilities } \\
\text { with standard } \\
\text { included in } \\
\text { improvement plan }\end{array}$ \\
\hline
\end{tabular}

Ancillary services - Facility management services

Ensure the provision of a regular source of power supply. Ensure that a back-up system for power supply is available and functional.

$92 \%$

Make provision for a reliable and safe source of water supply to this facility. Ensure that there is a back-up source of water in case of contamination or failure.

Ensure all the identified structural defects in the facility (torn mosquito netting, damaged doors and windows, etc) are fixed. Establish a facility maintenance process.

$54 \%$

A list of all equipment, furniture and supplies at the facility should be available. This list should be dated, signed and updated periodically. A policy guiding this process should be available.

$50 \%$

Implement a system that ensures all equipment and supplies are available, properly stored and distributed to all relevant areas of the facility. A list of all equipment and supplies should be available.

$21 \%$

Ensure all sources of electricity are functional and provision is made for the regular supplies of needed fuel. For each shift, a designated individual should be available who oversees this function.

$13 \%$

Ensure all construction debri and broken furniture which are no longer useful are kept neatly in an area of the facility, cordoned off, and arrangements put in place to clear them out of the facility.

$13 \%$

$4 \%$

Rehabilitation of the staff quarters to solve the space constraints in the clinic area and renovation of all dilapidated structures in the facility.

Provide mosquito nets for all the windows and external doors in the facility.

$4 \%$

$4 \%$

Ancillary services - Support services

Ensure the availability of bed linen at this facility and secure storage facilities for these.

Make arrangements within the community for a patient transport system. Document this system and make it known to all personnel. Contact telephone numbers should be available and functional.

Provision should be made for at least 2 cleaners who will be responsible for the daily cleaning of the facility, and should be guided by written service-related policies and procedures.

Ensure the provision of a minimum of 2 functional sanitary facilities (patient and staff) in the facility. 
Appendix Table 2: Baseline balance tests - 2A: Full Intervention vs. Control

\begin{tabular}{|c|c|c|c|c|c|c|c|c|}
\hline \multirow[b]{3}{*}{ Respondent } & (1) & (2) & (3) & (4) & (5) & (6) & (7) & (8) \\
\hline & \multicolumn{2}{|c|}{ Mean } & \multicolumn{3}{|c|}{ non-Permutation Tests } & \multicolumn{3}{|c|}{ Permutation Tests } \\
\hline & Control & $\begin{array}{l}\text { Full } \\
\text { Intervention }\end{array}$ & T-test & Exact & Ranksum & T-test & Exact & Ranksum \\
\hline age & 43.32 & 45.08 & 0.35 & 0.22 & 0.47 & 0.39 & 0.79 & 0.47 \\
\hline gender & 0.48 & 0.63 & 0.31 & 0.41 & 0.30 & 0.32 & 0.69 & 0.32 \\
\hline \multicolumn{9}{|l|}{ Facility Characteristics } \\
\hline \% having 24 hours shift rotation & 0.77 & 0.92 & 0.16 & 0.27 & 0.16 & 0.16 & 0.83 & 0.17 \\
\hline$\%$ having at least one midwife per shift & 0.65 & 0.83 & 0.12 & 0.14 & 0.12 & 0.12 & 0.91 & 0.11 \\
\hline$\%$ having a reception/registration room & 0.61 & 0.75 & 0.29 & 0.39 & 0.29 & 0.26 & 0.76 & 0.26 \\
\hline number of observation beds & 3.13 & 2.30 & 0.15 & 0.57 & 0.22 & 0.14 & 0.45 & 0.22 \\
\hline $\begin{array}{l}\text { number of days with no electricity/light at all during the } \\
\text { last week }\end{array}$ & 5.00 & 5.04 & 0.96 & 0.53 & 0.98 & 0.96 & 0.48 & 0.98 \\
\hline distance to the referral facility/hospital (km) & 21.90 & 16.17 & 0.27 & 0.92 & 0.24 & 0.24 & 0.09 & 0.23 \\
\hline$\%$ having transportation for patients & 0.10 & 0.13 & 0.74 & 1.00 & 0.74 & 0.78 & 0.32 & 0.79 \\
\hline \multicolumn{9}{|l|}{ Working Condition } \\
\hline number of staff meeting in the past 12 months & 10.77 & 7.61 & 0.27 & 0.19 & 0.41 & 0.22 & 0.81 & 0.42 \\
\hline$\%$ having developed a facility workplan for this year & 0.55 & 0.43 & 0.41 & 0.58 & 0.41 & 0.42 & 0.57 & 0.42 \\
\hline \% having a WDC supervisor & 0.97 & 0.88 & 0.20 & 0.31 & 0.19 & 0.18 & 0.82 & 0.22 \\
\hline \% having a patients feedback mechanism & 0.68 & 0.63 & 0.69 & 0.78 & 0.69 & 0.72 & 0.40 & 0.72 \\
\hline \% having a staff reward system & 0.42 & 0.21 & 0.10 & 0.15 & 0.10 & 0.11 & 0.88 & 0.11 \\
\hline \multicolumn{9}{|l|}{ Human Resources } \\
\hline number of staff qualified as midwife and nurse & 1.97 & 3.08 & 0.07 & 0.25 & 0.07 & 0.10 & 0.75 & 0.07 \\
\hline number of staff qualified as midwife only & 0.84 & 0.50 & 0.42 & 0.98 & 0.80 & 0.37 & 0.04 & 0.79 \\
\hline number of staff qualified as nurse only & 0.45 & 0.38 & 0.74 & 0.31 & 0.95 & 0.69 & 0.71 & 0.93 \\
\hline number of health workers & 14.00 & 12.13 & 0.33 & 0.04 & 0.11 & 0.28 & 0.95 & 0.11 \\
\hline \multicolumn{9}{|l|}{ Patients } \\
\hline $\begin{array}{l}\text { number of women discharges last week after having } \\
\text { given birth }\end{array}$ & 3.94 & 3.30 & 0.46 & 0.06 & 0.87 & 0.56 & 0.95 & 0.87 \\
\hline number of registered cases of antenatal care last month & 40.38 & 40.95 & 0.95 & 0.18 & 0.92 & 0.95 & 0.84 & 0.91 \\
\hline number of registered cases of deliveries last month & 6.89 & 7.78 & 0.65 & 0.15 & 0.51 & 0.65 & 0.85 & 0.53 \\
\hline
\end{tabular}


Appendix Table 2 (Continued) - 2B: Light Intervention vs. Control

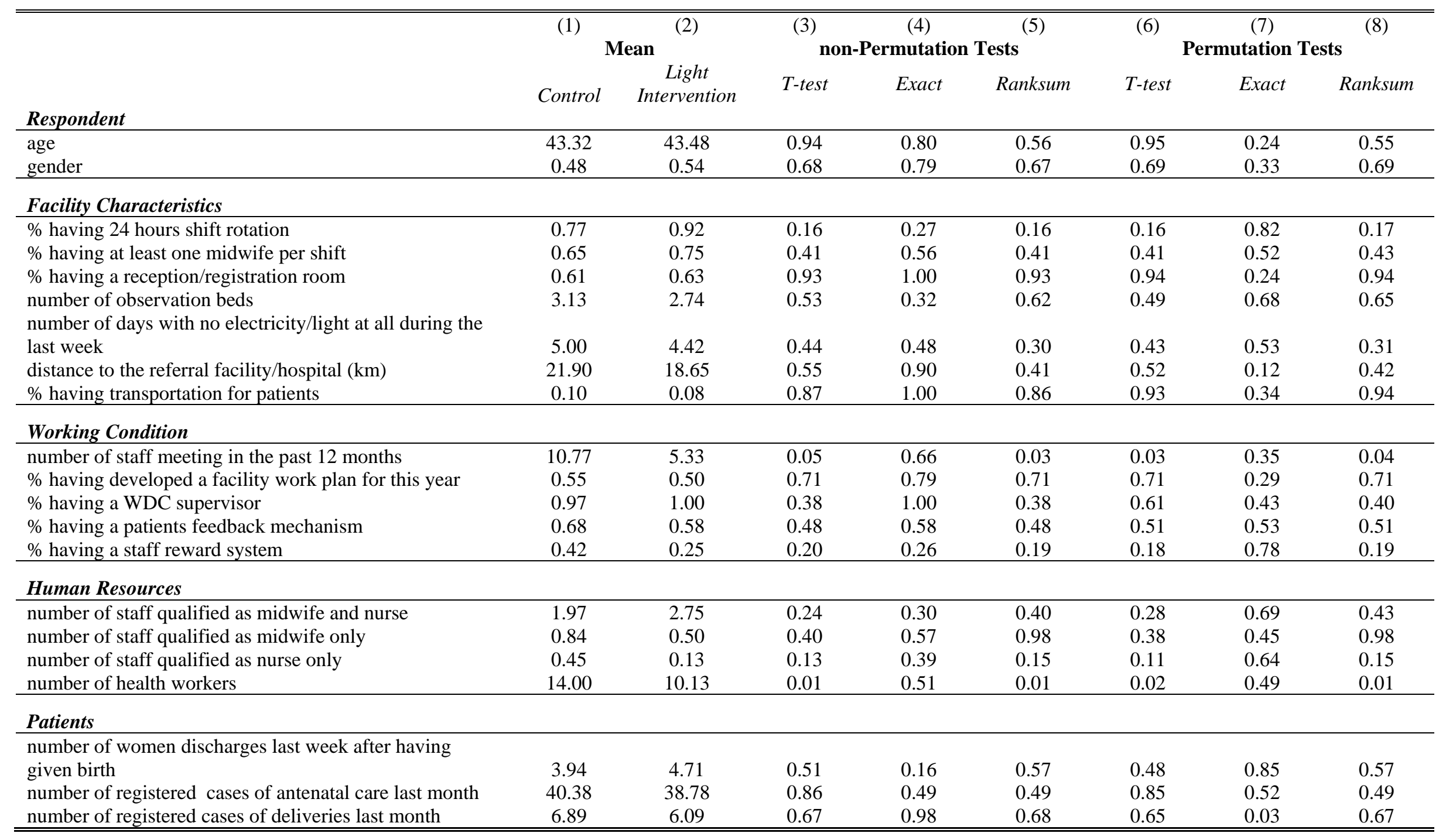


Appendix Table 2 (Continued) - 2C: Full Intervention vs. Light Intervention

\begin{tabular}{|c|c|c|c|c|c|c|c|c|}
\hline \multirow[b]{3}{*}{ Panel A: Respondent } & \multirow{2}{*}{\multicolumn{2}{|c|}{ Mean }} & \multirow{2}{*}{\multicolumn{3}{|c|}{ non-Permutation Tests }} & (6) & (7) & (8) \\
\hline & & & & & & \multicolumn{3}{|c|}{ Permutation Tests } \\
\hline & $\begin{array}{c}\text { Full } \\
\text { Intervention }\end{array}$ & $\begin{array}{c}\text { Light } \\
\text { Intervention }\end{array}$ & T-test & Exact & Ranksum & T-test & Exact & Ranksum \\
\hline age & 45.08 & 43.48 & 0.50 & 0.71 & 0.96 & 0.47 & 0.35 & 0.96 \\
\hline gender & 0.63 & 0.54 & 0.57 & 0.77 & 0.56 & 0.64 & 0.55 & 0.52 \\
\hline \multicolumn{9}{|l|}{ Panel B: Facility Characteristics } \\
\hline \% having 24 hours shift rotation & 0.92 & 0.92 & 1.00 & 1.00 & 1.00 & 1.00 & 0.46 & 1.00 \\
\hline$\%$ having at least one midwife per shift & 0.83 & 0.75 & 0.49 & 0.72 & 0.48 & 0.63 & 0.57 & 0.47 \\
\hline$\%$ having a reception/registration room & 0.75 & 0.63 & 0.36 & 0.53 & 0.36 & 0.44 & 0.69 & 0.36 \\
\hline number of observation beds & 2.30 & 2.74 & 0.39 & 0.93 & 0.39 & 0.47 & 0.07 & 0.39 \\
\hline number of days with no electricity/light at all during the & & & & & & & 063 & \\
\hline $\begin{array}{l}\text { last week } \\
\text { distance to the referral facility/hospital }(\mathrm{km})\end{array}$ & $\begin{array}{c}5.04 \\
16.17\end{array}$ & $\begin{array}{c}4.42 \\
18.65\end{array}$ & 0.40 & $\begin{array}{l}0.39 \\
0.48\end{array}$ & $\begin{array}{l}0.34 \\
0.82\end{array}$ & $\begin{array}{l}0.44 \\
0.66\end{array}$ & 0.63 & 0.36 \\
\hline \% having transportation for patients & $\begin{array}{c}16.1 / \\
0.13\end{array}$ & $\begin{array}{l}18.65 \\
0.08\end{array}$ & $\begin{array}{l}0.61 \\
0.65\end{array}$ & $\begin{array}{l}0.48 \\
1.00\end{array}$ & $\begin{array}{l}0.82 \\
0.64\end{array}$ & $\begin{array}{l}0.66 \\
0.81\end{array}$ & $\begin{array}{l}0.54 \\
0.51\end{array}$ & $\begin{array}{l}0.83 \\
0.76\end{array}$ \\
\hline \multicolumn{9}{|l|}{ Panel C: Working Condition } \\
\hline number of staff meeting in the past 12 months & 7.61 & 5.33 & 0.12 & 0.19 & 0.16 & 0.39 & 0.82 & 0.16 \\
\hline$\%$ having developed a facility workplan for this year & 0.43 & 0.50 & 0.66 & 0.77 & 0.66 & 0.67 & 0.35 & 0.66 \\
\hline$\%$ having a WDC supervisor & 0.88 & 1.00 & 0.08 & 0.23 & 0.08 & 0.10 & 0.98 & 0.10 \\
\hline$\%$ having a patients feedback mechanism & 0.63 & 0.58 & 0.77 & 1.00 & 0.77 & 0.89 & 0.32 & 0.86 \\
\hline$\%$ having a staff reward system & 0.21 & 0.25 & 0.74 & 1.00 & 0.73 & 0.87 & 0.35 & 0.67 \\
\hline \multicolumn{9}{|l|}{ Panel D: Human Resources } \\
\hline number of staff qualified as midwife and nurse & 3.08 & 2.75 & 0.67 & 0.17 & 0.43 & 0.66 & 0.83 & 0.44 \\
\hline number of staff qualified as midwife only & 0.50 & 0.50 & 1.00 & 0.84 & 0.78 & 1.00 & 0.21 & 0.78 \\
\hline number of staff qualified as nurse only & 0.38 & 0.13 & 0.15 & 0.32 & 0.13 & 0.31 & 0.72 & 0.14 \\
\hline number of health workers & 12.13 & 10.13 & 0.20 & 0.39 & 0.66 & 0.30 & 0.63 & 0.68 \\
\hline \multicolumn{9}{|l|}{ Panel E: Patients } \\
\hline number of women discharges last week after having given & & & & & & & & \\
\hline birth & 3.30 & 4.71 & 0.22 & 0.76 & 0.59 & 0.21 & 0.25 & 0.60 \\
\hline number of registered cases of antenatal care last month & 40.95 & 38.78 & 0.84 & 0.23 & 0.62 & 0.82 & 0.79 & 0.64 \\
\hline number of registered cases of deliveries last month & 7.78 & 6.09 & 0.40 & 0.21 & 0.30 & 0.38 & 0.80 & 0.28 \\
\hline
\end{tabular}


Notes: Nigeria SURE-P MCH Survey Data; Column (1) and (2) present the mean of the indicated group. Column (3) presents p-values from simple T-tests with null hypothesis Full Intervention (mean) = Control (mean). Column (4) and (5) present p-values from Fisher's exact tests (Exact) and Wilcoxon rank-sum tests. Column (6), (7) and (8) are p-values from permutated T-tests, Fisher's exact tests and Wilcoxon rank-sum tests with 1000 repetitions. Permutation p-value $=$ number of cases with absolute difference value $\geq \mid$ diff $\mid$ (real observed one) $/$ number of random permutations performed (reps(1000)). 


\section{Appendix Table 3: Detailed Regressions Results - By Category}

\subsection{Governance and management}

\begin{tabular}{|c|c|c|c|c|c|}
\hline & Rounds & Obs. & Ctrl Mean & $\begin{array}{c}\text { Full } \\
\text { Intervention }\end{array}$ & $\begin{array}{c}\text { Light } \\
\text { Intervention }\end{array}$ \\
\hline \multicolumn{6}{|l|}{ A. Standard specification } \\
\hline Organizational structure chart available in the facility & 6 & 80 & 0.03 & $\begin{array}{l}0.643^{* * *} \\
{[0.0977]}\end{array}$ & $\begin{array}{c}-0.0478 \\
{[0.0477]}\end{array}$ \\
\hline At least one staff meeting held last month & $1-6$ & 466 & 0.67 & $\begin{array}{c}0.161^{* *} \\
{[0.0539]}\end{array}$ & $\begin{array}{c}0.0260 \\
{[0.0558]}\end{array}$ \\
\hline N. meetings held last month & $1-6$ & 336 & 1.13 & $\begin{array}{c}0.169 * \\
{[0.0732]}\end{array}$ & $\begin{array}{c}-0.0125 \\
{[0.0687]}\end{array}$ \\
\hline Written summary for the most recent meeting last month & $1-6$ & 332 & 0.79 & $\begin{array}{c}0.0772 \\
{[0.0443]}\end{array}$ & $\begin{array}{c}-0.0202 \\
{[0.0569]}\end{array}$ \\
\hline The officer-in-charge was approached by staff with suggestions for improvement & 1 and 6 & 471 & 0.25 & $\begin{array}{c}0.0792 \\
{[0.0405]}\end{array}$ & $\begin{array}{l}-0.00776 \\
{[0.0491]}\end{array}$ \\
\hline Currently working towards improvement targets & 6 & 76 & 0.61 & $\begin{array}{c}0.152 \\
{[0.0997]}\end{array}$ & $\begin{array}{l}-0.0982 \\
{[0.116]} \\
\end{array}$ \\
\hline \multicolumn{6}{|l|}{ B. Including baseline controls } \\
\hline Organizational structure chart available in the facility & 6 & 68 & 0.03 & $\begin{array}{c}0.590^{* * *} \\
{[0.116]}\end{array}$ & $\begin{array}{c}-0.0819 \\
{[0.0651]}\end{array}$ \\
\hline At least one staff meeting held last month & $1-6$ & 396 & 0.67 & $\begin{array}{c}0.179 * * \\
{[0.0549]}\end{array}$ & $\begin{array}{c}0.0215 \\
{[0.0625]}\end{array}$ \\
\hline N. meetings held last month & $1-6$ & 290 & 1.13 & $\begin{array}{c}0.165 * \\
{[0.0808]}\end{array}$ & $\begin{array}{c}-0.0380 \\
{[0.0744]}\end{array}$ \\
\hline Written summary for the most recent meeting last month & $1-6$ & 287 & 0.79 & $\begin{array}{c}0.0733 \\
{[0.0519]}\end{array}$ & $\begin{array}{c}0.0140 \\
{[0.0554]}\end{array}$ \\
\hline The officer-in-charge was approached by staff with suggestions for improvement & 1 and 6 & 400 & 0.25 & $\begin{array}{c}0.0474 \\
{[0.0464]}\end{array}$ & $\begin{array}{c}-0.0343 \\
{[0.0537]}\end{array}$ \\
\hline Currently working towards improvement targets & 6 & 64 & 0.61 & $\begin{array}{c}0.0649 \\
{[0.0915]} \\
\end{array}$ & $\begin{array}{c}-0.274^{* *} \\
{[0.102]} \\
\end{array}$ \\
\hline
\end{tabular}

Notes: The table reports results from Linear Probability Models estimated with Ordinary Least Squares. The standard specification (panel A) includes state fixed effects, survey round fixed effects, and SURE-P intervention status (see sections 3.4 and 4.4 for details). The additional baseline controls (panel B) were baseline values for the number of observation beds, the number of staff qualified as midwives or nurses, the number of antenatal care cases in the previous month, the number of days without any electricity in the previous week, the number of staff meetings in the past twelve months, and the absenteeism rate. Standard errors are clustered at the facility level in regressions including observations from multiple rounds. 


\subsection{Human resources management}

\begin{tabular}{|c|c|c|c|c|c|}
\hline & Rounds & Obs. & Ctrl Mean & $\begin{array}{c}\text { Full } \\
\text { Intervention }\end{array}$ & $\begin{array}{c}\text { Light } \\
\text { Intervention }\end{array}$ \\
\hline \multicolumn{6}{|l|}{ A. Standard specification } \\
\hline Facility has written list of all clinical staff & 1 and 6 & 159 & 0.83 & $\begin{array}{c}0.077 \\
{[0.0618]}\end{array}$ & $\begin{array}{c}-0.035 \\
{[0.0701]}\end{array}$ \\
\hline Facility has submitted a request for additional staff & 1 and 6 & 144 & 0.68 & $\begin{array}{c}-0.089 \\
{[0.0914]}\end{array}$ & $\begin{array}{c}-0.114 \\
{[0.0892]}\end{array}$ \\
\hline Facility has system for measuring personnel performance & 1 and 6 & 153 & 0.37 & $\begin{array}{c}-0.029 \\
{[0.0740]}\end{array}$ & $\begin{array}{c}0.029 \\
{[0.0794]}\end{array}$ \\
\hline Facility has system for rewarding personnel performance & 1 and 6 & 158 & 0.54 & $\begin{array}{c}0.0325 \\
{[0.0763]}\end{array}$ & $\begin{array}{c}-0.0160 \\
{[0.0738]}\end{array}$ \\
\hline Facility has enough staff (as assessed by the officer in charge) & 1 and 6 & 159 & 0.14 & $\begin{array}{c}0.038 \\
{[0.0845]} \\
\end{array}$ & $\begin{array}{c}0.029 \\
{[0.0795]}\end{array}$ \\
\hline \multicolumn{6}{|l|}{ B. Including baseline controls } \\
\hline Facility has written list of all clinical staff & 1 and 6 & 136 & 0.83 & $\begin{array}{c}0.0664 \\
{[0.0705]}\end{array}$ & $\begin{array}{c}-0.0936 \\
{[0.0711]}\end{array}$ \\
\hline Facility has submitted a request for additional staff & 1 and 6 & 126 & 0.68 & $\begin{array}{l}-0.0764 \\
{[0.114]}\end{array}$ & $\begin{array}{c}-0.137 \\
{[0.108]}\end{array}$ \\
\hline Facility has system for measuring personnel performance & 1 and 6 & 129 & 0.37 & $\begin{array}{c}0.0312 \\
{[0.0727]}\end{array}$ & $\begin{array}{c}0.0823 \\
{[0.0845]}\end{array}$ \\
\hline Facility has system for rewarding personnel performance & 1 and 6 & 134 & 0.54 & $\begin{array}{c}0.129 \\
{[0.0770]}\end{array}$ & $\begin{array}{c}0.0193 \\
{[0.0682]}\end{array}$ \\
\hline Facility has enough staff (as assessed by the officer in charge) & 1 and 6 & 136 & 0.14 & $\begin{array}{c}0.0959 \\
{[0.102]}\end{array}$ & $\begin{array}{c}0.0308 \\
{[0.0972]}\end{array}$ \\
\hline
\end{tabular}

Notes: The table reports results from Linear Probability Models estimated with Ordinary Least Squares. The standard specification (panel A) includes state fixed effects, survey round fixed effects, and SURE-P intervention status (see sections 3.4 and 4.4 for details). The additional baseline controls (panel B) were baseline values for the number of observation beds, the number of staff qualified as midwives or nurses, the number of antenatal care cases in the previous month, the number of days without any electricity in the previous week, the number of staff meetings in the past twelve months, and the absenteeism rate. Standard errors are clustered at the facility level in regressions including observations from multiple rounds. 


\subsection{Patient rights and access to care}

\begin{tabular}{|c|c|c|c|c|c|}
\hline & Rounds & Obs. & Ctrl Mean & $\begin{array}{c}\text { Full } \\
\text { Intervention }\end{array}$ & $\begin{array}{c}\text { Light } \\
\text { Intervention }\end{array}$ \\
\hline \multicolumn{6}{|l|}{ A. Standard specification } \\
\hline There is a patient rights charter posted in a public space & $1-6$ & 471 & 0.02 & $\begin{array}{c}0.632 * * * \\
{[0.0694]}\end{array}$ & $\begin{array}{c}-0.014 \\
{[0.0208]}\end{array}$ \\
\hline Any posters with clinical information put up last month & $1-6$ & 471 & 0.57 & $\begin{array}{c}0.072 \\
{[0.0444]}\end{array}$ & $\begin{array}{c}0.036 \\
{[0.0364]}\end{array}$ \\
\hline Number of ward screens available throughout the facility & $1-6$ & 471 & 1.74 & $\begin{array}{c}0.934 * * \\
{[0.346]}\end{array}$ & $\begin{array}{c}0.414 \\
{[0.261]} \\
\end{array}$ \\
\hline \multicolumn{6}{|l|}{ B. Including baseline controls } \\
\hline There is a patient rights charter posted in a public space & $1-6$ & 400 & 0.02 & $\begin{array}{c}0.633 * * * \\
{[0.0780]}\end{array}$ & $\begin{array}{c}-0.0285 \\
{[0.0354]}\end{array}$ \\
\hline Any posters with clinical information put up last month & $1-6$ & 400 & 0.57 & $\begin{array}{c}0.0530 \\
{[0.0448]}\end{array}$ & $\begin{array}{c}0.0469 \\
{[0.0428]}\end{array}$ \\
\hline Number of ward screens available throughout the facility & $1-6$ & 400 & 1.74 & $\begin{array}{c}0.719 * \\
{[0.284]}\end{array}$ & $\begin{array}{c}0.315 \\
{[0.265]}\end{array}$ \\
\hline
\end{tabular}

Notes: The table reports results from Linear Probability Models estimated with Ordinary Least Squares. The standard specification (panel A) includes state fixed effects, survey round fixed effects, and SURE-P intervention status (see sections 3.4 and 4.4 for details). The additional baseline controls (panel B) were baseline values for the number of observation beds, the number of staff qualified as midwives or nurses, the number of antenatal care cases in the previous month, the number of days without any electricity in the previous week, the number of staff meetings in the past twelve months, and the absenteeism rate. Standard errors are clustered at the facility level in regressions including observations from multiple rounds. 


\subsection{Management of information}

\begin{tabular}{|c|c|c|c|c|c|}
\hline & Rounds & Obs. & Ctrl Mean & $\begin{array}{c}\text { Full } \\
\text { Intervention }\end{array}$ & $\begin{array}{l}\text { Light } \\
\text { Intervention }\end{array}$ \\
\hline \multicolumn{6}{|l|}{ A. Standard specification } \\
\hline The facility keeps individual case records. & round 6 & 80 & 0.81 & $\begin{array}{c}0.0343 \\
{[0.0936]}\end{array}$ & $\begin{array}{c}0.00694 \\
{[0.0970]}\end{array}$ \\
\hline The enumerator observed 5 recent records. & round 6 & 67 & 0.96 & $\begin{array}{c}0.0192 \\
{[0.0430]}\end{array}$ & $\begin{array}{c}-0.0237 \\
{[0.0716]}\end{array}$ \\
\hline Case file completeness. & round 6 & 65 & 0.82 & $\begin{array}{c}0.0406 \\
{[0.0393]}\end{array}$ & $\begin{array}{c}-0.0111 \\
{[0.0411]}\end{array}$ \\
\hline Files are kept for all patients. & round 6 & 67 & 0.69 & $\begin{array}{c}0.0423 \\
{[0.161]}\end{array}$ & $\begin{array}{c}0.388 \\
{[0.223]}\end{array}$ \\
\hline \multicolumn{6}{|l|}{ B. Including baseline controls } \\
\hline The facility keeps individual case records. & round 6 & 68 & 0.81 & $\begin{array}{c}0.0339 \\
{[0.104]}\end{array}$ & $\begin{array}{c}0.0404 \\
{[0.109]}\end{array}$ \\
\hline The enumerator observed 5 recent records. & round 6 & 56 & 0.96 & $\begin{array}{c}0.0335 \\
{[0.0510]}\end{array}$ & $\begin{array}{l}-0.00553 \\
{[0.0968]}\end{array}$ \\
\hline Case file completeness. & round 6 & 54 & 0.82 & $\begin{array}{c}0.0384 \\
{[0.0449]}\end{array}$ & $\begin{array}{c}-0.0336 \\
{[0.0490]}\end{array}$ \\
\hline Files are kept for all patients. & round 6 & 56 & 0.69 & $\begin{array}{l}-0.0448 \\
{[0.150]} \\
\end{array}$ & $\begin{array}{c}0.435^{*} \\
{[0.212]} \\
\end{array}$ \\
\hline
\end{tabular}

Notes: The table reports results from Linear Probability Models estimated with Ordinary Least Squares. The standard specification (panel A) includes state fixed effects, survey round fixed effects, and SURE-P intervention status (see sections 3.4 and 4.4 for details). The additional baseline controls (panel B) were baseline values for the number of observation beds, the number of staff qualified as midwives or nurses, the number of antenatal care cases in the previous month, the number of days without any electricity in the previous week, the number of staff meetings in the past twelve months, and the absenteeism rate. Standard errors are clustered at the facility level in regressions including observations from multiple rounds. 


\subsection{Risk management- waste management}

\begin{tabular}{|c|c|c|c|c|c|}
\hline & Rounds & Obs. & Ctrl Mean & $\begin{array}{c}\text { Full } \\
\text { Intervention }\end{array}$ & $\begin{array}{c}\text { Light } \\
\text { Intervention }\end{array}$ \\
\hline \multicolumn{6}{|l|}{ A. Standard specification } \\
\hline Posters showing waste separation visible in the facility & 6 & 80 & 0.00 & $\begin{array}{c}0.174 * \\
{[0.0797]}\end{array}$ & $\begin{array}{c}0.052 \\
{[0.0492]}\end{array}$ \\
\hline Waste bin present in the facility & $1-6$ & 471 & 0.98 & $\begin{array}{c}0.004 \\
{[0.0131]}\end{array}$ & $\begin{array}{c}0.005 \\
{[0.0162]}\end{array}$ \\
\hline Waste bins for different types of waste clearly marked & 6 & 79 & 0.32 & $\begin{array}{l}0.322 * * \\
{[0.106]}\end{array}$ & $\begin{array}{c}-0.052 \\
{[0.0979]}\end{array}$ \\
\hline Medical waste and regular waste are disposed of separately & $1-6$ & 391 & 0.28 & $\begin{array}{c}-0.016 \\
{[0.0628]}\end{array}$ & $\begin{array}{c}0.006 \\
{[0.0643]}\end{array}$ \\
\hline Guidelines on health care waste management present in the facility & 6 & 80 & 0.00 & $\begin{array}{c}0.208 * \\
{[0.0826]}\end{array}$ & $\begin{array}{c}0.043 \\
{[0.0444]}\end{array}$ \\
\hline Officer in charge or other provider received training in waste management & 6 & 80 & 0.09 & $\begin{array}{c}0.117 \\
{[0.106]}\end{array}$ & $\begin{array}{c}0.000 \\
{[0.0827]}\end{array}$ \\
\hline \multicolumn{6}{|l|}{ B. Including baseline controls } \\
\hline Posters showing waste separation visible in the facility & 6 & 68 & 0.00 & $\begin{array}{c}0.129 \\
{[0.0739]}\end{array}$ & $\begin{array}{c}0.0409 \\
{[0.0551]}\end{array}$ \\
\hline Waste bin present in the facility & $1-6$ & 400 & 0.98 & $\begin{array}{c}0.00874 \\
{[0.0169]}\end{array}$ & $\begin{array}{c}0.0123 \\
{[0.0200]}\end{array}$ \\
\hline Waste bins for different types of waste clearly marked & 6 & 67 & 0.32 & $\begin{array}{c}0.280^{*} \\
{[0.118]}\end{array}$ & $\begin{array}{c}-0.181 \\
{[0.112]}\end{array}$ \\
\hline Medical waste and regular waste are disposed of separately & $1-6$ & 332 & 0.28 & $\begin{array}{l}-0.00674 \\
{[0.0593]}\end{array}$ & $\begin{array}{c}-0.0299 \\
{[0.0644]}\end{array}$ \\
\hline Guidelines on health care waste management present in the facility & 6 & 68 & 0.00 & $\begin{array}{c}0.243^{*} \\
{[0.100]}\end{array}$ & $\begin{array}{c}0.00703 \\
{[0.0518]}\end{array}$ \\
\hline Officer in charge or other provider received training in waste management & 6 & 68 & 0.09 & $\begin{array}{c}0.168 \\
{[0.129]}\end{array}$ & $\begin{array}{c}-0.0261 \\
{[0.0911]}\end{array}$ \\
\hline
\end{tabular}

Notes: The table reports results from Linear Probability Models estimated with Ordinary Least Squares. The standard specification (panel A) includes state fixed effects, survey round fixed effects, and SUREP intervention status (see sections 3.4 and 4.4 for details). The additional baseline controls (panel B) were baseline values for the number of observation beds, the number of staff qualified as midwives or nurses, the number of antenatal care cases in the previous month, the number of days without any electricity in the previous week, the number of staff meetings in the past twelve months, and the absenteeism rate. Standard errors are clustered at the facility level in regressions including observations from multiple rounds. 


\subsection{Risk management - general risk}

\begin{tabular}{|c|c|c|c|c|c|}
\hline & Rounds & Obs. & Ctrl Mean & $\begin{array}{c}\text { Full } \\
\text { Intervention }\end{array}$ & $\begin{array}{c}\text { Light } \\
\text { Intervention }\end{array}$ \\
\hline \multicolumn{6}{|l|}{ A. Standard specification } \\
\hline Contact phone numbers of external security sources are available & 6 & 80 & 0.28 & $\begin{array}{c}0.190 \\
{[0.118]}\end{array}$ & $\begin{array}{c}-0.081 \\
{[0.101]}\end{array}$ \\
\hline Flammable materials clearly labeled & 6 & 80 & 0.25 & $\begin{array}{c}0.107 \\
{[0.0921]}\end{array}$ & $\begin{array}{c}-0.144 \\
{[0.0880]}\end{array}$ \\
\hline There is a designated individual responsible for infection control at the facility & 6 & 80 & 0.16 & $\begin{array}{c}0.337 * * \\
{[0.114]}\end{array}$ & $\begin{array}{c}-0.019 \\
{[0.0926]}\end{array}$ \\
\hline Facility staff were trained on disinfection techniques in the last 6 months & 6 & 74 & 0.03 & $\begin{array}{c}0.176 \\
{[0.0953]}\end{array}$ & $\begin{array}{c}0.041 \\
{[0.0544]}\end{array}$ \\
\hline Different mops available for high and low risk areas in the facility & 6 & 80 & 0.63 & $\begin{array}{c}0.074 \\
{[0.129]}\end{array}$ & $\begin{array}{l}-0.311^{*} \\
{[0.127]}\end{array}$ \\
\hline There is a color system for these mops & 6 & 47 & 0.25 & $\begin{array}{c}0.371 * * \\
{[0.119]}\end{array}$ & $\begin{array}{c}0.428 * * \\
{[0.147]}\end{array}$ \\
\hline Medical gloves are available & 6 & 80 & 0.97 & $\begin{array}{c}0.020 \\
{[0.0306]}\end{array}$ & $\begin{array}{c}-0.021 \\
{[0.0581]}\end{array}$ \\
\hline Functional fire extinguishers present & $1-6$ & 468 & 0.52 & $\begin{array}{c}0.187^{*} \\
{[0.0869]}\end{array}$ & $\begin{array}{c}0.035 \\
{[0.0981]}\end{array}$ \\
\hline \multicolumn{6}{|l|}{ B. Including baseline controls } \\
\hline Contact phone numbers of external security sources are available & 6 & 68 & 0.28 & $\begin{array}{c}0.235 \\
{[0.151]}\end{array}$ & $\begin{array}{c}-0.138 \\
{[0.136]}\end{array}$ \\
\hline Flammable materials clearly labeled & 6 & 68 & 0.25 & $\begin{array}{c}0.0857 \\
{[0.118]}\end{array}$ & $\begin{array}{c}-0.186 \\
{[0.109]}\end{array}$ \\
\hline There is a designated individual responsible for infection control at the facility & 6 & 68 & 0.16 & $\begin{array}{l}0.324^{*} \\
{[0.145]}\end{array}$ & $\begin{array}{l}-0.0540 \\
{[0.121]}\end{array}$ \\
\hline Facility staff were trained on disinfection techniques in the last 6 months & 6 & 64 & 0.03 & $\begin{array}{c}0.197 \\
{[0.101]}\end{array}$ & $\begin{array}{c}0.0293 \\
{[0.0612]}\end{array}$ \\
\hline Different mops available for high and low risk areas in the facility & 6 & 68 & 0.63 & $\begin{array}{c}0.0462 \\
{[0.149]}\end{array}$ & $\begin{array}{c}-0.403 * * \\
{[0.144]}\end{array}$ \\
\hline There is a color system for these mops & 6 & 39 & 0.25 & $\begin{array}{l}0.379 * * \\
{[0.130]}\end{array}$ & $\begin{array}{c}0.507 * * \\
{[0.182]}\end{array}$ \\
\hline Medical gloves are available & 6 & 68 & 0.97 & $\begin{array}{c}0.00830 \\
{[0.0325]}\end{array}$ & $\begin{array}{l}-0.00356 \\
{[0.0694]}\end{array}$ \\
\hline Functional fire extinguishers present & $1-6$ & 397 & 0.52 & $\begin{array}{c}0.181 \\
{[0.107]}\end{array}$ & $\begin{array}{l}-0.0827 \\
{[0.101]}\end{array}$ \\
\hline
\end{tabular}

Notes: The table reports results from Linear Probability Models estimated with Ordinary Least Squares. The standard specification (panel A) includes state fixed effects, survey round fixed effects, and SUREP intervention status (see sections 3.4 and 4.4 for details). The additional baseline controls (panel B) were baseline values for the number of observation beds, the number of staff qualified as midwives or nurses, the number of antenatal care cases in the previous month, the number of days without any electricity in the previous week, the number of staff meetings in the past twelve months, and the absenteeism rate. Standard errors are clustered at the facility level in regressions including observations from multiple rounds. 


\subsection{Risk management - handwashing}

\begin{tabular}{|c|c|c|c|c|c|}
\hline & Rounds & Obs. & Ctrl Mean & $\begin{array}{c}\text { Full } \\
\text { Intervention }\end{array}$ & $\begin{array}{c}\text { Light } \\
\text { Intervention }\end{array}$ \\
\hline \multicolumn{6}{|l|}{ A. Standard specification } \\
\hline Poster on display describing hand-washing behavior & 6 & 80 & 0.16 & $\begin{array}{c}0.371^{* * *} \\
{[0.100]}\end{array}$ & $\begin{array}{c}0.006 \\
{[0.0812]}\end{array}$ \\
\hline There is a hand-washing facility for patients & $1-6$ & 471 & 0.42 & $\begin{array}{l}0.178^{* *} \\
{[0.0619]}\end{array}$ & $\begin{array}{c}0.114 \\
{[0.0847]}\end{array}$ \\
\hline There is a hand-washing facility for medical personnel & $1-6$ & 471 & 0.84 & $\begin{array}{c}0.132 * \\
{[0.0510]}\end{array}$ & $\begin{array}{l}0.155^{* *} \\
{[0.0546]}\end{array}$ \\
\hline Visible presence of hand washing supplies (soap and water) & $1-6$ & 438 & 0.83 & $\begin{array}{c}0.08 \\
{[0.0418]}\end{array}$ & $\begin{array}{c}0.014 \\
{[0.0613]}\end{array}$ \\
\hline Water available in the consulting room & $1-6$ & 453 & 0.29 & $\begin{array}{l}0.281^{* * *} \\
{[0.0808]}\end{array}$ & $\begin{array}{c}0.122 \\
{[0.0885]}\end{array}$ \\
\hline Water available in the bathrooms & $1-6$ & 393 & 0.35 & $\begin{array}{c}0.029 \\
{[0.0918]}\end{array}$ & $\begin{array}{c}0.066 \\
{[0.0805]}\end{array}$ \\
\hline Water available in the waiting room & $1-6$ & 448 & 0.32 & $\begin{array}{c}0.132 * \\
{[0.0647]}\end{array}$ & $\begin{array}{c}0.007 \\
{[0.0695]}\end{array}$ \\
\hline Water available in the delivery room & $1-6$ & 460 & 0.84 & $\begin{array}{c}0.036 \\
{[0.0501]} \\
\end{array}$ & $\begin{array}{c}-0.005 \\
{[0.0421]} \\
\end{array}$ \\
\hline \multicolumn{6}{|l|}{ B. Including baseline controls } \\
\hline Poster on display describing hand-washing behavior & 6 & 68 & 0.16 & $\begin{array}{l}0.341^{* *} \\
{[0.111]}\end{array}$ & $\begin{array}{l}-0.0266 \\
{[0.100]}\end{array}$ \\
\hline There is a hand-washing facility for patients & $1-6$ & 400 & 0.42 & $\begin{array}{l}0.210^{* *} \\
{[0.0720]}\end{array}$ & $\begin{array}{c}0.126 \\
{[0.0909]}\end{array}$ \\
\hline There is a hand-washing facility for medical personnel & $1-6$ & 400 & 0.84 & $\begin{array}{c}0.138^{*} \\
{[0.0550]}\end{array}$ & $\begin{array}{c}0.150^{*} \\
{[0.0579]}\end{array}$ \\
\hline Visible presence of hand washing supplies (soap and water) & $1-6$ & 372 & 0.83 & $\begin{array}{c}0.0718 \\
{[0.0438]}\end{array}$ & $\begin{array}{l}0.00182 \\
{[0.0574]}\end{array}$ \\
\hline Water available in the consulting room & $1-6$ & 385 & 0.29 & $\begin{array}{c}0.272 * * \\
{[0.0885]}\end{array}$ & $\begin{array}{c}0.145 \\
{[0.0815]}\end{array}$ \\
\hline Water available in the bathrooms & $1-6$ & 345 & 0.35 & $\begin{array}{c}0.111 \\
{[0.0974]}\end{array}$ & $\begin{array}{c}0.128 \\
{[0.0821]}\end{array}$ \\
\hline Water available in the waiting room & $1-6$ & 379 & 0.32 & $\begin{array}{c}0.203^{* *} \\
{[0.0737]}\end{array}$ & $\begin{array}{l}0.00956 \\
{[0.0750]}\end{array}$ \\
\hline Water available in the delivery room & $1-6$ & 392 & 0.84 & $\begin{array}{c}0.0661 \\
{[0.0539]}\end{array}$ & $\begin{array}{c}-0.0251 \\
{[0.0469]}\end{array}$ \\
\hline
\end{tabular}

Notes: The table reports results from Linear Probability Models estimated with Ordinary Least Squares. The standard specification (panel A) includes state fixed effects, survey round fixed effects, and SUREP intervention status (see sections 3.4 and 4.4 for details). The additional baseline controls (panel B) were baseline values for the number of observation beds, the number of staff qualified as midwives or nurses, the number of antenatal care cases in the previous month, the number of days without any electricity in the previous week, the number of staff meetings in the past twelve months, and the absenteeism rate. Standard errors are clustered at the facility level in regressions including observations from multiple rounds. 


\subsection{Care of patients}

\begin{tabular}{|c|c|c|c|c|c|}
\hline & Rounds & Obs. & Ctrl Mean & $\begin{array}{l}\text { Full } \\
\text { Intervention }\end{array}$ & $\begin{array}{c}\text { Light } \\
\text { Intervention }\end{array}$ \\
\hline \multicolumn{6}{|l|}{ A. Standard specification } \\
\hline Printed guidelines for the treatment of Malaria present & 1 and 6 & 160 & 0.95 & $\begin{array}{c}-0.032 \\
{[0.0448]}\end{array}$ & $\begin{array}{c}0.043 \\
{[0.0366]}\end{array}$ \\
\hline Individual malaria records kept & 6 & 67 & 0.23 & $\begin{array}{c}-0.0108 \\
{[0.0923]}\end{array}$ & $\begin{array}{c}-0.105 \\
{[0.0837]}\end{array}$ \\
\hline N. cases diagnosed via RDT/N. cases malaria & $1-6$ & 453 & 0.789 & $\begin{array}{c}-0.0854 \\
{[0.0484]}\end{array}$ & $\begin{array}{c}-0.0265 \\
{[0.0400]}\end{array}$ \\
\hline N. cases diagnosed via lab/N. cases malaria & $1-6$ & 453 & 0.0461 & $\begin{array}{c}0.0408 \\
{[0.0434]}\end{array}$ & $\begin{array}{l}-0.0434^{*} \\
{[0.0197]}\end{array}$ \\
\hline Of the 10 most recent births records, $\mathrm{N}$. with an "apgar" report & $1-6$ & 468 & 3.551 & $\begin{array}{l}1.407 * * \\
{[0.415]}\end{array}$ & $\begin{array}{l}-0.0962 \\
{[0.451]}\end{array}$ \\
\hline Individual ANC records kept & 6 & 67 & 0.769 & $\begin{array}{c}0.0247 \\
{[0.0976]}\end{array}$ & $\begin{array}{c}0.0777 \\
{[0.0779]}\end{array}$ \\
\hline The respondent used written records to answer the above questions & $1-6$ & 50 & 0.957 & $\begin{array}{c}0.0544 \\
{[0.0833]}\end{array}$ & $\begin{array}{c}0.00526 \\
{[0.0429]}\end{array}$ \\
\hline Partograph available in the facility & 1 and 6 & 159 & 0.270 & $\begin{array}{c}0.161^{*} \\
{[0.0757]}\end{array}$ & $\begin{array}{c}-0.0761 \\
{[0.0732]}\end{array}$ \\
\hline Partograph available and posted visibly & 1 and 6 & 49 & 0.294 & $\begin{array}{l}-0.0738 \\
{[0.169]}\end{array}$ & $\begin{array}{c}0.233 \\
{[0.222]}\end{array}$ \\
\hline Number of printed medical issue guidelines available (out of 7 required) & $1-6$ & 471 & 1.56 & $\begin{array}{c}0.114 \\
{[0.0739]} \\
\end{array}$ & $\begin{array}{c}0.110 \\
{[0.0913]}\end{array}$ \\
\hline \multicolumn{6}{|l|}{ B. Including baseline controls } \\
\hline Printed guidelines for the treatment of Malaria present & 1 and 6 & 136 & 0.95 & $\begin{array}{c}-0.0275 \\
{[0.0495]}\end{array}$ & $\begin{array}{c}0.0373 \\
{[0.0446]}\end{array}$ \\
\hline Individual malaria records kept & 6 & 56 & 0.23 & $\begin{array}{c}-0.00117 \\
{[0.111]}\end{array}$ & $\begin{array}{l}-0.0755 \\
{[0.110]}\end{array}$ \\
\hline N. cases diagnosed via RDT/N. cases malaria & rounds 1-6 & 388 & 0.789 & $\begin{array}{c}-0.0816 \\
{[0.0561]}\end{array}$ & $\begin{array}{c}0.00972 \\
{[0.0504]}\end{array}$ \\
\hline N. cases diagnosed via lab/N. cases malaria & rounds $1-6$ & 388 & 0.0461 & $\begin{array}{c}0.0558 \\
{[0.0486]}\end{array}$ & $\begin{array}{l}-0.0525^{*} \\
{[0.0261]}\end{array}$ \\
\hline Of the 10 most recent births records, $\mathrm{N}$. with an "apgar" report & $1-6$ & 398 & 3.551 & $\begin{array}{l}1.475 * * \\
{[0.522]}\end{array}$ & $\begin{array}{c}-0.127 \\
{[0.465]}\end{array}$ \\
\hline Individual ANC records kept & 6 & 56 & 0.769 & $\begin{array}{c}0.0378 \\
{[0.122]}\end{array}$ & $\begin{array}{c}0.0903 \\
{[0.102]}\end{array}$ \\
\hline The respondent used written records to answer the above questions & $1-6$ & 43 & 0.957 & $\begin{array}{c}0.193 \\
{[0.0984]}\end{array}$ & $\begin{array}{c}-0.155 \\
{[0.130]}\end{array}$ \\
\hline Partograph available in the facility & 1 and 6 & 135 & 0.270 & $\begin{array}{c}0.212 * * \\
{[0.0753]}\end{array}$ & $\begin{array}{c}0.0214 \\
{[0.0702]}\end{array}$ \\
\hline Partograph available and posted visibly & 1 and 6 & 44 & 0.294 & $\begin{array}{c}-0.268 \\
{[0.218]}\end{array}$ & $\begin{array}{l}-0.0556 \\
{[0.231]}\end{array}$ \\
\hline Number of printed medical issue guidelines available (out of 7 required) & $1-6$ & 400 & 1.56 & $\begin{array}{c}0.158 * \\
{[0.0726]} \\
\end{array}$ & $\begin{array}{c}0.128 \\
{[0.102]} \\
\end{array}$ \\
\hline
\end{tabular}

Notes: The table reports results from Linear Probability Models estimated with Ordinary Least Squares. The standard specification (panel A) includes state fixed effects, survey round fixed effects, and SUREP intervention status (see sections 3.4 and 4.4 for details). The additional baseline controls (panel B) were baseline values for the number of observation beds, the number of staff qualified as midwives or nurses, the number of antenatal care cases in the previous month, the number of days without any electricity in the previous week, the number of staff meetings in the past twelve months, and the absenteeism rate. Standard errors are clustered at the facility level in regressions including observations from multiple rounds. 


\subsection{Clinical support - Operating theatre and anesthetic services}

\begin{tabular}{|c|c|c|c|c|c|}
\hline & Rounds & Obs. & Ctrl Mean & $\begin{array}{c}\text { Full } \\
\text { Intervention }\end{array}$ & $\begin{array}{c}\text { Light } \\
\text { Intervention }\end{array}$ \\
\hline \multicolumn{6}{|l|}{ A. Standard specification } \\
\hline Materials for sterilization of equipment present & $1-5$ & 390 & 0.90 & $\begin{array}{c}-0.0704 \\
{[0.0495]}\end{array}$ & $\begin{array}{c}-0.0153 \\
{[0.0595]}\end{array}$ \\
\hline There is a functional autoclave & $1-5$ & 346 & 0.65 & $\begin{array}{c}0.031 \\
{[0.0872]}\end{array}$ & $\begin{array}{c}-0.014 \\
{[0.0720]} \\
\end{array}$ \\
\hline \multicolumn{6}{|l|}{ B. Including baseline controls } \\
\hline Materials for sterilization of equipment present & $1-5$ & 331 & 0.90 & $\begin{array}{c}-0.0398 \\
{[0.0454]}\end{array}$ & $\begin{array}{c}-0.0183 \\
{[0.0618]}\end{array}$ \\
\hline There is a functional autoclave & $1-5$ & 298 & 0.65 & $\begin{array}{c}0.0894 \\
{[0.0980]}\end{array}$ & $\begin{array}{c}-0.0165 \\
{[0.0818]}\end{array}$ \\
\hline
\end{tabular}

Notes: The table reports results from Linear Probability Models estimated with Ordinary Least Squares. The standard specification (panel A) includes state fixed effects, survey round fixed effects, and SURE-P intervention status (see sections 3.4 and 4.4 for details). The additional baseline controls (panel B) were baseline values for the number of observation beds, the number of staff qualified as midwives or nurses, the number of antenatal care cases in the previous month, the number of days without any electricity in the previous week, the number of staff meetings in the past twelve months, and the absenteeism rate. Standard errors are clustered at the facility level in regressions including observations from multiple rounds. 


\subsection{Clinical support - Medication management}

\begin{tabular}{|c|c|c|c|c|c|}
\hline & Rounds & Obs. & Ctrl Mean & $\begin{array}{c}\text { Full } \\
\text { Intervention }\end{array}$ & $\begin{array}{c}\text { Light } \\
\text { Intervention }\end{array}$ \\
\hline \multicolumn{6}{|l|}{ A. Standard specification } \\
\hline Drugs and vaccines are labeled and organized by expiration date & $1-6$ & 439 & 0.03 & $\begin{array}{l}0.197 * * \\
{[0.0673]}\end{array}$ & $\begin{array}{c}-0.017 \\
{[0.0259]}\end{array}$ \\
\hline There is a re-order level for drugs. & $1-6$ & 430 & 0.70 & $\begin{array}{c}-0.0411 \\
{[0.0495]}\end{array}$ & $\begin{array}{c}0.0384 \\
{[0.0493]}\end{array}$ \\
\hline There a re-order level for vaccines. & $1-6$ & 336 & 0.43 & $\begin{array}{c}-0.0193 \\
{[0.0452]}\end{array}$ & $\begin{array}{c}0.0117 \\
{[0.0466]}\end{array}$ \\
\hline N. out of 9 essential drugs are unexpired/valid ${ }^{(*)}$ & $1-6$ & 431 & 5.82 & $\begin{array}{c}0.635^{*} \\
{[0.260]}\end{array}$ & $\begin{array}{c}0.31 \\
{[0.211]}\end{array}$ \\
\hline N. out of 6 essential vaccines are unexpired/valid ${ }^{(* *)}$ & $1-6$ & 117 & 4.89 & $\begin{array}{c}-0.14 \\
{[0.327]}\end{array}$ & $\begin{array}{c}0.0753 \\
{[0.352]}\end{array}$ \\
\hline N. out of 9 essential drugs are available/in stock ${ }^{(*)}$ & $1-6$ & 431 & 5.91 & $\begin{array}{c}0.587^{*} \\
{[0.266]}\end{array}$ & $\begin{array}{c}0.283 \\
{[0.216]}\end{array}$ \\
\hline N. out of 6 essential vaccines are available/in stock ${ }^{(* *)}$ & $1-6$ & 117 & 4.91 & $\begin{array}{c}-0.143 \\
{[0.332]}\end{array}$ & $\begin{array}{c}0.0418 \\
{[0.348]}\end{array}$ \\
\hline \multicolumn{6}{|l|}{ B. Including baseline controls } \\
\hline Drugs and vaccines are labeled and organized by expiration date & $1-6$ & 375 & 0.03 & $\begin{array}{c}0.185 * \\
{[0.0756]}\end{array}$ & $\begin{array}{c}-0.0426 \\
{[0.0385]}\end{array}$ \\
\hline There is a re-order level for drugs. & $1-6$ & 375 & 0.70 & $\begin{array}{c}-0.0572 \\
{[0.0539]}\end{array}$ & $\begin{array}{c}0.0370 \\
{[0.0547]}\end{array}$ \\
\hline There a re-order level for vaccines. & $1-6$ & 294 & 0.43 & $\begin{array}{l}-0.0135 \\
{[0.0516]}\end{array}$ & $\begin{array}{c}0.00804 \\
{[0.0519]}\end{array}$ \\
\hline N. out of 9 essential drugs are unexpired/valid ${ }^{(*)}$ & $1-6$ & 373 & 5.82 & $\begin{array}{c}0.723^{*} \\
{[0.275]}\end{array}$ & $\begin{array}{c}0.298 \\
{[0.235]}\end{array}$ \\
\hline N. out of 6 essential vaccines are unexpired/valid ${ }^{(* *)}$ & $1-6$ & 103 & 4.89 & $\begin{array}{c}0.219 \\
{[0.258]}\end{array}$ & $\begin{array}{c}0.306 \\
{[0.441]}\end{array}$ \\
\hline N. out of 9 essential drugs are available/in stock ${ }^{(*)}$ & $1-6$ & 373 & 5.91 & $\begin{array}{c}0.695^{*} \\
{[0.278]}\end{array}$ & $\begin{array}{c}0.277 \\
{[0.235]}\end{array}$ \\
\hline N. out of 6 essential vaccines are available/in stock ${ }^{(* *)}$ & $1-6$ & 103 & 4.91 & $\begin{array}{c}0.220 \\
{[0.264]}\end{array}$ & $\begin{array}{c}0.262 \\
{[0.440]}\end{array}$ \\
\hline
\end{tabular}

Notes: The table reports results from Linear Probability Models estimated with Ordinary Least Squares. The standard specification (panel A) includes state fixed effects, survey round fixed effects, and SURE-P intervention status (see sections 3.4 and 4.4 for details). The additional baseline controls (panel B) were baseline values for the number of observation beds, the number of staff qualified as midwives or nurses, the number of antenatal care cases in the previous month, the number of days without any electricity in the previous week, the number of staff meetings in the past twelve months, and the absenteeism rate. Standard errors are clustered at the facility level in regressions including observations from multiple rounds. $\left({ }^{*}\right)$ Drugs defined as essential are Misoprostol, Oxytocin, Magnesium Sulfate (MG), Zinc, Chlorhexidine, Amoxycillin, ORS, ACT, Fansidar/IPT. (**) The essential vaccines are BCG, Penta, Polio, Measles, Yellow Fever, Hepatitis B. 


\subsection{Facility management services}

\begin{tabular}{|c|c|c|c|c|c|}
\hline & Rounds & Obs. & Ctrl Mean & $\begin{array}{c}\text { Full } \\
\text { Intervention }\end{array}$ & $\begin{array}{c}\text { Light } \\
\text { Intervention }\end{array}$ \\
\hline \multicolumn{6}{|l|}{ A. Standard specification } \\
\hline The facility is connected to national power grid & $1-6$ & 471 & 0.74 & $\begin{array}{c}-0.026 \\
{[0.078]}\end{array}$ & $\begin{array}{c}-0.111 \\
{[0.104]}\end{array}$ \\
\hline There is a functional generator in the facility & $1-6$ & 459 & 0.58 & $\begin{array}{c}0.066 \\
{[0.091]}\end{array}$ & $\begin{array}{c}0.022 \\
{[0.091]}\end{array}$ \\
\hline There is currently fuel for the generator & $1-6$ & 277 & 0.58 & $\begin{array}{l}0.257 * * \\
{[0.093]}\end{array}$ & $\begin{array}{c}-0.012 \\
{[0.117]}\end{array}$ \\
\hline At least 1 hour connected to the grid in last working day & $1-6$ & 471 & 0.45 & $\begin{array}{c}-0.041 \\
{[0.096]}\end{array}$ & $\begin{array}{c}-0.072 \\
{[0.096]}\end{array}$ \\
\hline No electricity interruptions in past two weeks & 6 & 64 & 0.56 & $\begin{array}{c}0.106 \\
{[0.113]}\end{array}$ & $\begin{array}{c}0.0338 \\
{[0.122]}\end{array}$ \\
\hline 7 days access to power last week & $1-6$ & 410 & 0.22 & $\begin{array}{c}0.048 \\
{[0.068]}\end{array}$ & $\begin{array}{c}0.041 \\
{[0.059]}\end{array}$ \\
\hline Clean water is available all year & 1 and 6 & 160 & 0.86 & $\begin{array}{c}0.056 \\
{[0.065]}\end{array}$ & $\begin{array}{c}-0.051 \\
{[0.076]}\end{array}$ \\
\hline 7 days access to clean water last week & $1-6$ & 469 & 0.90 & $\begin{array}{c}0.038 \\
{[0.041]}\end{array}$ & $\begin{array}{c}-0.024 \\
{[0.043]}\end{array}$ \\
\hline No water supply interruptions in past two weeks & 6 & 75 & 0.93 & $\begin{array}{c}-0.051 \\
{[0.080]}\end{array}$ & $\begin{array}{c}-0.039 \\
{[0.085]}\end{array}$ \\
\hline \multicolumn{6}{|l|}{ B. Including baseline controls } \\
\hline The facility is connected to national power grid & $1-6$ & 400 & 0.74 & $\begin{array}{c}-0.142 \\
{[0.084]}\end{array}$ & $\begin{array}{c}-0.260 * * \\
{[0.093]}\end{array}$ \\
\hline There is a functional generator in the facility & $1-6$ & 389 & 0.58 & $\begin{array}{c}0.061 \\
{[0.096]}\end{array}$ & $\begin{array}{c}-0.014 \\
{[0.106]}\end{array}$ \\
\hline There is currently fuel for the generator & $1-6$ & 242 & 0.58 & $\begin{array}{c}0.332 * * * \\
{[0.092]}\end{array}$ & $\begin{array}{c}0.078 \\
{[0.109]}\end{array}$ \\
\hline At least 1 hour connected to the grid in last working day & $1-6$ & 400 & 0.45 & $\begin{array}{c}-0.158 \\
{[0.105]}\end{array}$ & $\begin{array}{l}-0.190 * \\
{[0.087]}\end{array}$ \\
\hline No electricity interruptions in past two weeks & 6 & 54 & 0.56 & $\begin{array}{c}0.122 \\
{[0.149]}\end{array}$ & $\begin{array}{c}0.015 \\
{[0.181]}\end{array}$ \\
\hline 7 days access to power last week & $1-6$ & 346 & 0.22 & $\begin{array}{c}0.083 \\
{[0.079]}\end{array}$ & $\begin{array}{c}0.079 \\
{[0.066]}\end{array}$ \\
\hline Clean water is available all year & 1 and 6 & 136 & 0.86 & $\begin{array}{c}0.117 \\
{[0.072]}\end{array}$ & $\begin{array}{c}-0.021 \\
{[0.082]}\end{array}$ \\
\hline 7 days access to clean water last week & $1-6$ & 398 & 0.90 & $\begin{array}{c}0.070 \\
{[0.036]}\end{array}$ & $\begin{array}{c}-0.028 \\
{[0.046]}\end{array}$ \\
\hline No water supply interruptions in past two weeks & 6 & 63 & 0.93 & $\begin{array}{c}-0.064 \\
{[0.109]}\end{array}$ & $\begin{array}{c}-0.023 \\
{[0.107]}\end{array}$ \\
\hline
\end{tabular}

Notes: The table reports results from Linear Probability Models estimated with Ordinary Least Squares. The standard specification (panel A) includes state fixed effects, survey round fixed effects, and SURE-P intervention status (see sections 3.4 and 4.4 for details). The additional baseline controls (panel B) were baseline values for the number of observation beds, the number of staff qualified as midwives or nurses, the number of antenatal care cases in the previous month, the number of days without any electricity in the previous week, the number of staff meetings in the past twelve months, and the absenteeism rate. Standard errors are clustered at the facility level in regressions including observations from multiple rounds. 


\subsection{Support services}

\begin{tabular}{|c|c|c|c|c|c|}
\hline & Rounds & Obs. & Ctrl Mean & $\begin{array}{c}\text { Full } \\
\text { Intervention }\end{array}$ & $\begin{array}{c}\text { Light } \\
\text { Intervention }\end{array}$ \\
\hline \multicolumn{6}{|l|}{ A. Standard specification } \\
\hline There are clean bed linens in storage. & 6 & 80 & 0.53 & $\begin{array}{c}0.0815 \\
{[0.112]}\end{array}$ & $\begin{array}{c}0.0960 \\
{[0.133]}\end{array}$ \\
\hline The facility has a toilet for patients. & $1-6$ & 471 & 0.98 & $\begin{array}{c}-0.0872 \\
{[0.0518]}\end{array}$ & $\begin{array}{c}-0.0183 \\
{[0.0234]}\end{array}$ \\
\hline The patient toilets are "clean" or "very clean". & $1-6$ & 467 & 0.41 & $\begin{array}{l}0.227^{* *} \\
{[0.0705]}\end{array}$ & $\begin{array}{c}0.0636 \\
{[0.0691]}\end{array}$ \\
\hline The waiting room is "clean" or "very clean". & $1-6$ & 471 & 0.80 & $\begin{array}{c}0.101^{*} \\
{[0.0446]}\end{array}$ & $\begin{array}{c}0.0808 \\
{[0.0540]}\end{array}$ \\
\hline \multicolumn{6}{|l|}{ B. Including baseline controls } \\
\hline There are clean bed linens in storage. & 6 & 68 & 0.53 & $\begin{array}{c}0.0315 \\
{[0.141]}\end{array}$ & $\begin{array}{c}0.106 \\
{[0.147]}\end{array}$ \\
\hline The facility has a toilet for patients. & $1-6$ & 400 & 0.41 & $\begin{array}{c}-0.0828 \\
{[0.0591]}\end{array}$ & $\begin{array}{c}-0.0179 \\
{[0.0235]}\end{array}$ \\
\hline The patient toilets are "clean" or "very clean". & $1-6$ & 396 & 0.68 & $\begin{array}{l}0.276 * * * \\
{[0.0677]}\end{array}$ & $\begin{array}{c}0.0568 \\
{[0.0701]}\end{array}$ \\
\hline The waiting room is "clean" or "very clean". & $1-6$ & 400 & 0.80 & $\begin{array}{c}0.108^{*} \\
{[0.0512]} \\
\end{array}$ & $\begin{array}{c}0.0841 \\
{[0.0523]} \\
\end{array}$ \\
\hline
\end{tabular}

Notes: The table reports results from Linear Probability Models estimated with Ordinary Least Squares. The standard specification (panel A) includes state fixed effects, survey round fixed effects, and SURE-P intervention status (see sections 3.4 and 4.4 for details). The additional baseline controls (panel B) were baseline values for the number of observation beds, the number of staff qualified as midwives or nurses, the number of antenatal care cases in the previous month, the number of days without any electricity in the previous week, the number of staff meetings in the past twelve months, and the absenteeism rate. Standard errors are clustered at the facility level in regressions including observations from multiple rounds. 


\subsection{Intermediate outcomes}

\begin{tabular}{|c|c|c|c|c|c|}
\hline & Rounds & Obs. & Ctrl Mean & $\begin{array}{c}\text { Full } \\
\text { Intervention }\end{array}$ & $\begin{array}{c}\text { Light } \\
\text { Intervention }\end{array}$ \\
\hline \multicolumn{6}{|l|}{ A. Standard specification } \\
\hline There are clean bed linens in storage. & 6 & 80 & 0.53 & $\begin{array}{c}0.0815 \\
{[0.112]}\end{array}$ & $\begin{array}{r}0.0960 \\
{[0.133]}\end{array}$ \\
\hline The patient toilets are "clean" or "very clean". & $1-6$ & 467 & 0.41 & $\begin{array}{c}0.227^{* *} \\
{[0.0705]}\end{array}$ & $\begin{array}{c}0.0636 \\
{[0.0691]}\end{array}$ \\
\hline The waiting room is "clean" or "very clean". & $1-6$ & 471 & 0.80 & $\begin{array}{c}0.101^{*} \\
{[0.0446]}\end{array}$ & $\begin{array}{c}0.0808 \\
{[0.0540]}\end{array}$ \\
\hline Drugs and vaccines are labeled and organized by expirati & $1-6$ & 439 & 0.03 & $\begin{array}{c}0.197 * * \\
{[0.0673]}\end{array}$ & $\begin{array}{c}-0.017 \\
{[0.0259]}\end{array}$ \\
\hline There is a re-order level for drugs. & $1-6$ & 430 & 0.70 & $\begin{array}{c}-0.0411 \\
{[0.0495]}\end{array}$ & $\begin{array}{c}0.0384 \\
{[0.0493]}\end{array}$ \\
\hline There a re-order level for vaccines. & $1-6$ & 336 & 0.43 & $\begin{array}{c}-0.0193 \\
{[0.0452]}\end{array}$ & $\begin{array}{c}0.0117 \\
{[0.0466]}\end{array}$ \\
\hline N. out of 9 essential drugs are unexpired/valid ${ }^{(*)}$ & $1-6$ & 431 & 5.82 & $\begin{array}{c}0.635^{*} \\
{[0.260]}\end{array}$ & $\begin{array}{c}0.31 \\
{[0.211]}\end{array}$ \\
\hline N. out of 6 essential vaccines are unexpired/valid ${ }^{(* *)}$ & $1-6$ & 117 & 4.89 & $\begin{array}{c}-0.14 \\
{[0.327]}\end{array}$ & $\begin{array}{c}0.0753 \\
{[0.352]}\end{array}$ \\
\hline N. out of 9 essential drugs are available/in stock ${ }^{(*)}$ & $1-6$ & 431 & 5.91 & $\begin{array}{c}0.587 * \\
{[0.266]}\end{array}$ & $\begin{array}{c}0.283 \\
{[0.216]}\end{array}$ \\
\hline N. out of 6 essential vaccines are available/in stock ${ }^{(* *)}$ & $1-6$ & 117 & 4.91 & $\begin{array}{c}-0.143 \\
{[0.332]} \\
\end{array}$ & $\begin{array}{c}0.0418 \\
{[0.348]}\end{array}$ \\
\hline \multicolumn{6}{|l|}{ B. Including baseline controls } \\
\hline There are clean bed linens in storage. & 6 & 68 & 0.53 & $\begin{array}{c}0.0315 \\
{[0.141]}\end{array}$ & $\begin{array}{c}0.106 \\
{[0.147]}\end{array}$ \\
\hline The patient toilets are "clean" or "very clean". & $1-6$ & 396 & 0.68 & $\begin{array}{l}0.276^{* * *} \\
{[0.0677]}\end{array}$ & $\begin{array}{c}0.0568 \\
{[0.0701]}\end{array}$ \\
\hline The waiting room is "clean" or "very clean". & $1-6$ & 400 & 0.80 & $\begin{array}{c}0.108 * \\
{[0.0512]}\end{array}$ & $\begin{array}{c}0.0841 \\
{[0.0523]}\end{array}$ \\
\hline Drugs and vaccines are labeled and organized by expirati & $1-6$ & 375 & 0.03 & $\begin{array}{c}0.185^{*} \\
{[0.0756]}\end{array}$ & $\begin{array}{c}-0.0426 \\
{[0.0385]}\end{array}$ \\
\hline There is a re-order level for drugs. & $1-6$ & 375 & 0.70 & $\begin{array}{c}-0.0572 \\
{[0.0539]}\end{array}$ & $\begin{array}{c}0.0370 \\
{[0.0547]}\end{array}$ \\
\hline There a re-order level for vaccines. & $1-6$ & 294 & 0.43 & $\begin{array}{c}-0.0135 \\
{[0.0516]}\end{array}$ & $\begin{array}{c}0.00804 \\
{[0.0519]}\end{array}$ \\
\hline N. out of 9 essential drugs are unexpired/valid ${ }^{(*)}$ & $1-6$ & 373 & 5.82 & $\begin{array}{c}0.723^{*} \\
{[0.275]}\end{array}$ & $\begin{array}{c}0.298 \\
{[0.235]}\end{array}$ \\
\hline N. out of 6 essential vaccines are unexpired/valid ${ }^{(* *)}$ & $1-6$ & 103 & 4.89 & $\begin{array}{c}0.219 \\
{[0.258]}\end{array}$ & $\begin{array}{c}0.306 \\
{[0.441]}\end{array}$ \\
\hline N. out of 9 essential drugs are available/in stock ${ }^{(*)}$ & $1-6$ & 373 & 5.91 & $\begin{array}{c}0.695^{*} \\
{[0.278]}\end{array}$ & $\begin{array}{c}0.277 \\
{[0.235]}\end{array}$ \\
\hline N. out of 6 essential vaccines are available/in stock ${ }^{(* *)}$ & $1-6$ & 103 & 4.91 & $\begin{array}{c}0.220 \\
{[0.264]} \\
\end{array}$ & $\begin{array}{c}0.262 \\
{[0.440]} \\
\end{array}$ \\
\hline
\end{tabular}

Notes: The table reports results from Linear Probability Models estimated with Ordinary Least Squares. The standard specification (panel A) includes state fixed effects, survey round fixed effects, and SURE-P intervention status (see sections 3.4 and 4.4 for details). The additional baseline controls (panel B) were baseline values for the number of observation beds, the number of staff qualified as midwives or nurses, the number of antenatal care cases in the previous month, the number of days without any electricity in the previous week, the number of staff meetings in the past twelve months, and the absenteeism rate. Standard errors are clustered at the facility level in regressions including observations from multiple rounds. 


\section{Appendix Table 4: Classification of study survey indicators by government-designated responsibility and by researcher-designated control and effort requirements}

\section{Panel A: Responsible - Government designation}

\begin{tabular}{|l|l|}
\hline \multicolumn{2}{|l|}{ Facility (30 indicators) } \\
\hline The facility has an organizational structure chart. & Files are kept for all patients. \\
\hline At least one staff meeting was held at the facility in the past month. & Case file completeness. \\
\hline Number of meeting held in the past month. & $\begin{array}{l}\text { There a designated individual responsible for infection control at } \\
\text { the facility. }\end{array}$ \\
\hline Written summary of the most recent meeting is available. & Staff were trained on disinfection technqiues (last 6 months). \\
\hline Currently working towards any improvement targets. & $\begin{array}{l}\text { Flammable materials are clearly labelled (fuel, kerosene, meth } \\
\text { spirit, etc.). }\end{array}$ \\
\hline $\begin{array}{l}\text { The officer-in-charge was approached by staff with suggestions for } \\
\text { improvement. }\end{array}$ & $\begin{array}{l}\text { There at least one poster on display describing hand-washing } \\
\text { behavior. }\end{array}$ \\
\hline There is a re-order level for drugs. & $\begin{array}{l}\text { Contact phone numbers of external security sources (e.g. police, } \\
\text { civil defence and vigilantee) are available. }\end{array}$ \\
\hline There is a re-order level for vaccines. & Patients are diagnosed via rapid diagnostic test (RDT). \\
\hline $\begin{array}{l}\text { The drug storage space is well organized (different drugs and } \\
\text { vaccines labeled and arranged by expiration date). }\end{array}$ & $\begin{array}{l}\text { Patients are diagnosed with other lab testing methods (for } \\
\text { example microscope). }\end{array}$ \\
\hline The facility has a written list of all clinical staff & $\begin{array}{l}\text { There are printed guidelines for the treatment of [listed] medical } \\
\text { issues. }\end{array}$ \\
\hline
\end{tabular}




\begin{tabular}{|l|l|} 
The facility has submitted a request for additional staff. & Number of "apgar" reported for the 10 most recent birth records. \\
\hline There is a system for measuring personnel performance. & Individual ANC records are kept. \\
\hline There is a system for rewarding personnel performance. & There are printed guidelines for the treatment of malaria. \\
\hline The facility keeps individual case records. & Individual malaria records are kept. \\
\hline The enumerator observed 5 records. & $\begin{array}{l}\text { "Silent question": The respondent used written records to answer } \\
\text { any of the questions above. }\end{array}$ \\
\hline
\end{tabular}

\section{Facility/Ministry of Health and/or Local Government (25 indicators)}

\begin{tabular}{|l|l|}
\hline Essential drugs are valid/not expired & $\begin{array}{l}\text { Facility personnel has received training in health care waste } \\
\text { management practices in the past two years. }\end{array}$ \\
\hline Essential vaccines are valid/not expired & The facility has a schedule for burning waste. \\
\hline There are waste bins in the facility. & There is a patient rights charter posted in a public space. \\
\hline All waste bins are covered & Any posters with clinical information were put up last month. \\
\hline $\begin{array}{l}\text { Waste bins for different types of waste are clearly marked (for } \\
\text { example color coded). }\end{array}$ & There is a partograph available in the facility. \\
\hline $\begin{array}{l}\text { There are different mops available for high and low risk areas in the } \\
\text { facility. }\end{array}$ & If available, the partograph is posted visibly. \\
\hline There a color coded system for these mops & There is a handwashing facility for medical personnel. \\
\hline
\end{tabular}




\begin{tabular}{|l|l|} 
There are materials for sterilization of equipment in the facility. & There is a handwashing facility for patients. \\
\hline There is a functioning autoclave in the facility. & Hand washing supplies (soap and water) are visibly present. \\
\hline The facility has guidelines on health care waste management. & Water is available in the consulting room. \\
\hline There are posters showing waste separation in the facility. & Water is available in the toilets. \\
\hline Medical waste is disposed of separately from regular waste. & Water is available in the waiting room. \\
\hline & Water is available in the delivery room. \\
\hline
\end{tabular}

\begin{tabular}{|l|l|}
\hline \multicolumn{2}{|l|}{ Ministry of Health and/or Local Government (19 indicators) } \\
\hline Essential drugs are available/in stock & At least 1 hour connected to grid (last day working). \\
\hline Essential vaccines are available/in stock & No power interruptions in the past two weeks. \\
\hline Number of ward screens available throughout the facility. & 7 days access to power last week. \\
\hline $\begin{array}{l}\text { Given your normal patient load, the officer-in-charge feels the } \\
\text { facility has enough staff. }\end{array}$ & 7 days access to clean water last week. \\
\hline Medical gloves are available in the facility. & No water interruptions in past two weeks. \\
\hline There is a functional fire extinguisher. & Clean water is available all year. \\
\hline
\end{tabular}




\begin{tabular}{|l|l|} 
The facility is connected to the national power grid. & The stored bed linens are clean. \\
\hline The facility has a functional generator. & The waiting room is clean. \\
\hline The facility has fuel for the generator. & The facility has a toilet for patients. \\
\hline & The patient toilets are clean. \\
\hline
\end{tabular}




\section{Appendix Table 4 Panel B: Feasibility - Researcher designation}

\begin{tabular}{|l|l|}
\hline \multicolumn{2}{|l|}{ High feasibility (17 indicators) } \\
\hline The facility has an organizational structure chart. & $\begin{array}{l}\text { Contact phone numbers of external security sources (e.g. police, } \\
\text { civil defence and vigilantee) are available. }\end{array}$ \\
\hline Currently working towards any improvement targets. & $\begin{array}{l}\text { Waste bins for different types of waste are clearly marked (for } \\
\text { example color coded). }\end{array}$ \\
\hline There is a re-order level for drugs. & The facility has guidelines on health care waste management. \\
\hline There is a re-order level for vaccines. & There are posters showing waste separation in the facility. \\
\hline The facility has a written list of all clinical staff & There is a patient rights charter posted in a public space. \\
\hline The facility has submitted a request for additional staff. & Any posters with clinical information were put up last month. \\
\hline $\begin{array}{l}\text { There a designated individual responsible for infection control at } \\
\text { the facility. }\end{array}$ & There is a partograph available in the facility. \\
\hline $\begin{array}{l}\text { Flammable materials are clearly labelled (fuel, kerosene, meth } \\
\text { spirit, etc.). }\end{array}$ & If available, the partograph is posted visibly. \\
\hline $\begin{array}{l}\text { There at least one poster on display describing hand-washing } \\
\text { behavior. }\end{array}$ & \\
\hline
\end{tabular}




\begin{tabular}{|c|c|}
\hline \multicolumn{2}{|l|}{ Medium feasibilty (39 indicators) } \\
\hline At least one staff meeting was held at the facility in the past month. & Essential vaccines are valid/not expired \\
\hline Number of meeting held in the past month. & There are waste bins in the facility. \\
\hline Written summary of the most recent meeting is available. & All waste bins are covered \\
\hline $\begin{array}{l}\text { The officer-in-charge was approached by staff with suggestions for } \\
\text { improvement. }\end{array}$ & $\begin{array}{l}\text { There are different mops available for high and low risk areas in } \\
\text { the facility. }\end{array}$ \\
\hline $\begin{array}{l}\text { The drug storage space is well organized (different drugs and } \\
\text { vaccines labeled and arranged by expiration date). }\end{array}$ & There a color coded system for these mops \\
\hline There is a system for measuring personnel performance. & Medical waste is disposed of separately from regular waste. \\
\hline The facility keeps individual case records. & $\begin{array}{l}\text { Facility personnel has received training in health care waste } \\
\text { management practices in the past two years. }\end{array}$ \\
\hline The enumerator observed 5 records. & The facility has a schedule for burning waste. \\
\hline Files are kept for all patients. & There is a handwashing facility for medical personnel. \\
\hline Case file completeness. & There is a handwashing facility for patients. \\
\hline Staff were trained on disinfection techniques (last 6 months). & Hand washing supplies (soap and water) are visibly present. \\
\hline Patients are diagnosed via rapid diagnostic test (RDT). & Water is available in the consulting room. \\
\hline $\begin{array}{l}\text { Patients are diagnosed with other lab testing methods (for example } \\
\text { microscope). }\end{array}$ & Water is available in the toilets. \\
\hline
\end{tabular}




\begin{tabular}{|l|l|} 
Number of "apgar" reported for the 10 most recent birth records. & Water is available in the waiting room. \\
\hline Individual ANC records are kept. & Water is available in the delivery room. \\
\hline There are printed guidelines for the treatment of malaria. & Medical gloves are available in the facility. \\
\hline $\begin{array}{l}\text { Individual malaria records are kept. } \\
\text { "Silent question": The respondent used written records to answer } \\
\text { any of the questions abpve. }\end{array}$ & The facility has fuel for the generator. \\
\hline Essential drugs are valid/not expired & The waiting room is clean. \\
\hline & The patient toilets are clean. \\
\hline
\end{tabular}

\section{Low (18 indicators)}

There is a system for rewarding personnel performance.

The facility is connected to the national power grid.

There are printed guidelines for the treatment of [listed] medical issues.

The facility has a functional generator.

There are materials for sterilization of equipment in the facility.

At least 1 hour connected to grid (last day working).

There is a functioning autoclave in the facility. 


\begin{tabular}{|l|l|} 
Essential drugs are available/in stock & 7 days access to power last week. \\
\hline Essential vaccines are available/in stock & 7 days access to clean water last week. \\
\hline Number of ward screens available throughout the facility. & No water interruptions in past two weeks. \\
\hline $\begin{array}{l}\text { Given your normal patient load, the officer-in-charge feels the } \\
\text { facility has enough staff. }\end{array}$ & Clean water is available all year. \\
\hline There is a functional fire extinguisher. & The facility has a toilet for patients. \\
\hline
\end{tabular}


Appendix Table 5: Mapping between Quality Improvement Plan (QIP) action items and study survey questions and

indicators. This table lists those Quality Improvement Plan (QIP) action items that line up with questions in the main survey for this impact evaluation ("IE survey question") and the SURE-P survey ("SURE-P survey question”), as well as the entity considered to be responsible for implementing the action ("Responsible - government designation") and the degree fo feasibility of the action ("Feasibility - researcher designation).

\begin{tabular}{|c|c|c|c|c|}
\hline Category & QIP action & $\begin{array}{l}\text { Responsible } \\
\text { (government designation) }\end{array}$ & Study survey indicator & $\begin{array}{l}\text { Feasibility } \\
\text { (researcher designation) }\end{array}$ \\
\hline \multirow{6}{*}{ Governance and management } & $\begin{array}{l}\text { Design an organizational chart or document which describes the lines of authority and } \\
\text { accountability from governance and within the service. }\end{array}$ & Facility & The facility has an organizational structure chart. & High \\
\hline & \multirow{2}{*}{$\begin{array}{l}\text { Introduce a quality management system in the facility (appoint quality manager, train staff, } \\
\text { organize bi-weekly quality team meetings, keep minutes of these meetings). }\end{array}$} & \multirow{2}{*}{ Facility } & At least one staff meeting was held at the facility in the past month. & Medium \\
\hline & & & Number of meeting held in the past month. & Medium \\
\hline & \multirow{3}{*}{$\begin{array}{l}\text { Institute effective mechanisms of communication and collaboration which include handover } \\
\text { meetings, ward rounds, clinical meetings, quality team meetings, etc. Keep records. } \\
\text { Document and implement action plans. }\end{array}$} & \multirow{3}{*}{ Facility } & Written summary of the most recent meeting is available. & Medium \\
\hline & & & Currently working towards any improvement targets. & High \\
\hline & & & $\begin{array}{l}\begin{array}{l}\text { The officer-in-charge was approached by staff with suggestions for } \\
\text { improvement. }\end{array} \\
\end{array}$ & Medium \\
\hline \multirow{5}{*}{ Human resources management } & $\begin{array}{l}\text { Ensure the provision of the needed staff cadres according to the Minimum Standards for } \\
\text { PHCs in Nigeria. }\end{array}$ & Ministry of Health / Local Government & $\begin{array}{l}\text { Given your normal patient load, the officer-in-charge feels the facility has } \\
\text { enough staff. }\end{array}$ & Low \\
\hline & \multirow{2}{*}{$\begin{array}{l}\text { Using the Essential Staff Requirement gap analysis result, ensure the provision of the } \\
\text { needed staff cadres (especially housekeeping and security). Provide the necessary } \\
\text { personnel management with proper induction/orientation. }\end{array}$} & \multirow{2}{*}{ Facility } & The facility has a written list of all clinical staff & High \\
\hline & & & The facility has submitted a request for additional staff. & High \\
\hline & \multirow{2}{*}{$\begin{array}{l}\text { Create a mechanism that ensures that at the facility levels, job descriptions are known and } \\
\text { facility-level performance measurement is done to inform designation and delegation of } \\
\text { duties. }\end{array}$} & \multirow{2}{*}{ Facility } & There is a system for measuring personnel performance. & Medium \\
\hline & & & There is a system for rewarding personnel performance. & Low \\
\hline \multirow{3}{*}{ Patient rights and access to care } & $\begin{array}{l}\text { Obtain patients rights charter. Display strategically in the facility. Train all staff on the } \\
\text { patient's right to privacy during examinations, counselling \& provision of information (OPD, } \\
\text { wards, pharmacy, laboratory, etc). }\end{array}$ & Facility/Ministry of Heatth & There is a patient rights charter posted in a public space. & High \\
\hline & $\begin{array}{l}\text { Patients are given adequate information about the services provided by the healthcare } \\
\text { facility and how to access those services. }\end{array}$ & Facility/Ministry of Health & Any posters with clinical information were put up last month. & High \\
\hline & $\begin{array}{l}\text { Make provision for more ward screens in all relevant areas (ward, examination room etc.). } \\
\text { Ensure the availability of ward screens in relevant areas of the facility (at least } 1 \text { ward } \\
\text { screen to } 2 \text { beds). Ensure windows in patient interaction areas have drapes \& doors are } \\
\text { kept closed during examinations \& counselling. }\end{array}$ & Ministry of Health & Number of ward screens available throughout the facility. & Low \\
\hline
\end{tabular}




\begin{tabular}{|c|c|c|c|c|c|}
\hline \multicolumn{2}{|l|}{ Category } & QIP action & $\begin{array}{l}\text { Responsible } \\
\text { (government designation) }\end{array}$ & Study survey indicator & \begin{tabular}{|l} 
Feasibility \\
(researcher designation)
\end{tabular} \\
\hline \multirow{4}{*}{\multicolumn{2}{|c|}{ Management of information }} & \multirow{4}{*}{$\begin{array}{l}\text { Ensure all patient records are standardised, dated, up to date, signed and contain the } \\
\text { designation/name of personnel carrying out the assessment. }\end{array}$} & \multirow{4}{*}{ Facility } & The facility keeps individual case records. & Medium \\
\hline & & & & The enumerator observed 5 records. & Medium \\
\hline & & & & Files are kept for all patients. & Medium \\
\hline & & & & $\begin{array}{l}\text { Case file completeness: The following is indicated: } \\
\text {-Name of patient } \\
\text {-DDete of vist } \\
\text {-Initials or name of health worker } \\
\text {-Condition (last visit) }\end{array}$ & Medium \\
\hline \multirow{15}{*}{ Risk management } & \multirow{8}{*}{ Waste management } & \multirow{5}{*}{$\begin{array}{l}\text { Obtain policy on waste management. Train personnel on waste segregation \& containers } \\
\text { for collection. Keep adequate records. Monitor implementation. Display posters on waste } \\
\text { segregation at different areas of the facility. } \\
\text { Establish a policy-guided waste management system at the facility. Provide relevant } \\
\text { tools/resources (sharps boxes, PPEs, pedaled bins, etc). Train personnel, provide } \\
\text { reminders and monitor the adherence to protocols. }\end{array}$} & \multirow{5}{*}{$\begin{array}{l}\text { Facility / Ministry of Health / Local } \\
\text { Government }\end{array}$} & The facility has guidelines on health care waste management. & High \\
\hline & & & & There are posters showing waste separation in the facility. & High \\
\hline & & & & Medical waste is disposed of separately from regular waste. & Medium \\
\hline & & & & $\begin{array}{l}\text { Facility personnel has received training in health care waste management } \\
\text { practices in the past two years. }\end{array}$ & Medium \\
\hline & & & & The facility has a schedule for burning waste. & Medium \\
\hline & & \multirow{3}{*}{$\begin{array}{l}\text { Ensure the availability of safety boxes and covered dustbins in all areas of the facility for } \\
\text { waste collection. Dustbins should have colour coded bin liners or should be painted with } \\
\text { the respective colour codes. }\end{array}$} & \multirow{3}{*}{ Facility / Ministry of Health } & There are waste bins in the facility. & Medium \\
\hline & & & & All waste bins are covered & Medium \\
\hline & & & & $\begin{array}{l}\begin{array}{l}\text { Waste bins for different types of waste are clearly marked (for example } \\
\text { color coded). }\end{array} \\
\end{array}$ & High \\
\hline & \multirow{7}{*}{ General risk managemen } & \multirow{2}{*}{$\begin{array}{l}\text { A colour coded system should be employed for mops \& brooms in cleaning different areas } \\
\text { of the facility (a designated mop/broom for the labour room, toilets, consulting area etc). }\end{array}$} & \multirow{2}{*}{ Facility / Ministry of Health } & $\begin{array}{l}\text { There are different mops available for high and low risk areas in the } \\
\text { facility. }\end{array}$ & Medium \\
\hline & & & & There a color coded system for these mops & Medium \\
\hline & & $\begin{array}{l}\text { Ensure availability of personal protective equipment (gloves, masks, aprons e.t.c) for staff } \\
\text { in all relevant areas. }\end{array}$ & Ministry of Health / Local Government & Medical gloves are available in the facility. & Medium \\
\hline & & $\begin{array}{l}\text { Designate an individual to be responsible for infection control and ensure the provision of } \\
\text { continuous in-service training on infection control to all personnel. Keep records of all } \\
\text { training(content of training and attendance list). }\end{array}$ & Facility & $\begin{array}{l}\text { There a designated individual responsible for infection control at the } \\
\text { facility. }\end{array}$ & High \\
\hline & & Retrain staff on disinfection techniques. & Facility & Staff were trained on disinfection technqiues (last 6 months). & Medium \\
\hline & & $\begin{array}{l}\text { Provision for fire fighting equipment should be made. Staff should be trained on how to use } \\
\text { these equipment and regular servicing of fire-fighting equipment should be done. }\end{array}$ & Ministry of Health / Local Government & There is a functional fire extinguisher. & Low \\
\hline & & $\begin{array}{l}\text { Ensure all flammable materials (fuel, kerosene, methylated spirit, etc.) are clearly labelled } \\
\text { and have appropriate signage in its environs. }\end{array}$ & Facility & $\begin{array}{l}\text { Flammable materials are clearly labelled (fuel, kerosene, meth spirit, } \\
\text { etc.). }\end{array}$ & High \\
\hline
\end{tabular}




\begin{tabular}{|c|c|c|c|c|c|}
\hline \multicolumn{2}{|l|}{ Category } & \multirow{2}{*}{\begin{tabular}{|l} 
QIP action \\
Display posters addressing hand washing at different areas of the facility.
\end{tabular}} & \multirow{2}{*}{\begin{tabular}{|l} 
Responsible \\
(government designation)
\end{tabular}} & \multirow{2}{*}{\begin{tabular}{|l|} 
Study survey indicator \\
There at least one poster on display describing hand-washing behavior. \\
\end{tabular}} & \multirow{2}{*}{\begin{tabular}{|l} 
Feasibility \\
(researcher designation)
\end{tabular}} \\
\hline & \multirow{8}{*}{ Handwashing } & & & & \\
\hline & & \multirow{7}{*}{$\begin{array}{l}\text { Ensurue the provision of soap, water and paper towels/single use towels at hand washing } \\
\text { failities. Water can be distributed to relevant areas of the facility with the use of buckets } \\
\text { with tap heads (veronica buckets). }\end{array}$} & \multirow{7}{*}{$\begin{array}{l}\text { Ministry of Heath / Local Government / } \\
\text { Facility }\end{array}$} & There is a handwashing facility for medical personnel. & Medium \\
\hline & & & & There is a handwashing facility for patients. & Medium \\
\hline & & & & Hand washing supplies (soap and water) are visibly present. & Medium \\
\hline & & & & Water is available in the consulting room. & Medium \\
\hline & & & & Water is available in the toilets. & Medium \\
\hline & & & & Water is available in the waiting room. & Medium \\
\hline & & & & Water is available in the delivery room. & Medium \\
\hline & Safety and security & $\begin{array}{l}\text { Develop a mechanism for summoning the assistance of external sources of security in case } \\
\text { of an emergency (eg. Police, community guards, etc.). Document this mechanism and } \\
\text { make it known to all personnel. }\end{array}$ & Facility & $\begin{array}{l}\text { Contact phone numbers of external security sources (e.g. police, civil } \\
\text { defence and vigilantee) are available. }\end{array}$ & High \\
\hline \multirow{9}{*}{ Care of patients } & \multirow[b]{2}{*}{$\begin{array}{l}\text { Primary healthcare } \\
\text { services }\end{array}$} & \multirow{2}{*}{$\begin{array}{l}\text { Implement a system that ensures all equipment and supplies are available, properly stored } \\
\text { and distributed to all relevant areas of the facility. A list of all equipment and supplies } \\
\text { should be avavilable. }\end{array}$} & \multirow{2}{*}{ Facility } & Patients are diagnosed via rapid diagnostic test (RDT). & Medium \\
\hline & & & & $\begin{array}{l}\begin{array}{l}\text { Patients are diagnosed with other lab testing methods (for example } \\
\text { microscope). }\end{array} \\
\end{array}$ & Medium \\
\hline & \multirow{4}{*}{$\begin{array}{l}\text { Antenatal care and } \\
\text { deliveries }\end{array}$} & Ensure the availability and use of partographs to monitor all deliveries at the facility. & Facility / Ministry of Health & There is a partograph available in the facility. & High \\
\hline & & $\begin{array}{l}\text { Ensure the use of partograph to monitor all deliveries and keep records of apgar score for } \\
\text { newborns. Ensure all tests, observations and examinations are recorded for all antenatal } \\
\text { and postnatal cases. }\end{array}$ & Facility / Ministry of Health & If available, the partograph is posted visibly. & High \\
\hline & & $\begin{array}{l}\text { Record the Apgar score for each newborn baby in the respective patient's card and } \\
\text { delivery register. Ensure the use of partograph to monitor all deliveries and keep records of } \\
\text { apgar score for newborns. Ensure all tests, observations and examinations are recorded } \\
\text { for all antenatata and postnatat cases. }\end{array}$ & Facility & Number of "apgar" reported for the 10 most recent bith records. & Medium \\
\hline & & $\begin{array}{l}\text { Ensure all records of ANC, labour and post-natal care are kept for each patient in their } \\
\text { respective patient cards. Provide individual patient records template for Labour, Postnatal } \\
\text { \& Inpatient care. }\end{array}$ & Facility & Individual ANC records are kept. & Medium \\
\hline & \multirow{3}{*}{$\begin{array}{l}\text { Diagnosis and treatment } \\
\text { of malaria }\end{array}$} & $\begin{array}{l}\text { Obtain national guidelines for the treatment of malaria and ensure compliance these } \\
\text { gutidelenins. Keep completet records for the malaria acses managed. Keep appropriate } \\
\text { records of cases receiving ACT following a Laboratory conflrmation. }\end{array}$ & Facility & There are printed guidelines for the treatment of malaria. & Medium \\
\hline & & \multirow{2}{*}{ Keep appropriate records of malaria cases treated on the basis of clinical diagnosis only. } & Facility & Individual malaria records are kept. & Medium \\
\hline & & & Facility & $\begin{array}{l}\text { "Silent question": The respondent used written records to answer any of } \\
\text { the questions abpve. }\end{array}$ & Medium \\
\hline
\end{tabular}




\begin{tabular}{|c|c|c|c|c|c|}
\hline Category & & QIP action & $\begin{array}{l}\text { Responsible } \\
\text { (government designation) }\end{array}$ & Study survey indicator & $\begin{array}{l}\text { Feasibility } \\
\text { (researcher designation) }\end{array}$ \\
\hline \multirow{9}{*}{ Clinical support } & \multirow[b]{2}{*}{$\begin{array}{l}\text { Operating theater and } \\
\text { anaesthetics }\end{array}$} & $\begin{array}{l}\text { Establish an effective sterilization process (with regular testing) and provide the appropriate } \\
\text { training for the personnel. }\end{array}$ & Facility / Ministry of Health & There are materials for sterilization of equipment in the facility. & Low \\
\hline & & $\begin{array}{l}\text { An autoclave should be provided \& installed and used for sterilizing instruments. Staff } \\
\text { should be trained on how to use the autoclave. Where autoclaves/pressure pots are } \\
\text { present, these should be installed and used for sterilizing instruments. Provide training on } \\
\text { the use. }\end{array}$ & Facility / Ministry of Health & There is a functioning autoclave in the facility. & Low \\
\hline & \multirow{7}{*}{ Medication management } & \multirow{2}{*}{$\begin{array}{l}\text { Ensure regular supply of all essential drugs and family planning consumables to prevent } \\
\text { stock outs. }\end{array}$} & \multirow{2}{*}{ Ministry of Health } & Essential drugs are available/in stock & Low \\
\hline & & & & Essential vaccines are available/in stock & Low \\
\hline & & \multirow{2}{*}{$\begin{array}{l}\text { Carry out checks on expiry date of all pharmaceutical and laboratory supplies in all areas } \\
\text { of the facility. Ensure proper documentation of these checks. Ensure the 'first expired first } \\
\text { out' principle is adhered to. }\end{array}$} & \multirow{2}{*}{ Facility / Ministry of Health } & Essential drugs are valid/not expired & Medium \\
\hline & & & & Essential vaccines are valid/not expired & Medium \\
\hline & & \multirow{2}{*}{$\begin{array}{l}\text { Implement a stock management system with definitions of maximum and reorder levels. } \\
\text { Records of stock received should be kept as well as records of distribution to different } \\
\text { units of the facility. }\end{array}$} & \multirow{2}{*}{ Facility } & There is a re-order level for drugs. & High \\
\hline & & & & There is a re-order level for vaccines. & High \\
\hline & & $\begin{array}{l}\text { General storage facilities should be secure, adequate, ventilated and well organised putting } \\
\text { different groups of items in sections. }\end{array}$ & Facility & $\begin{array}{l}\text { The drug storage space is well organized (different drugs and vaccines } \\
\text { labeled and arranged by expiration date). }\end{array}$ & Medium \\
\hline \multirow{13}{*}{ Ancillary services } & \multirow{9}{*}{$\begin{array}{l}\text { Facility management } \\
\text { services }\end{array}$} & \multirow{6}{*}{$\begin{array}{l}\text { Ensure the provision of a regular source of power supply. Ensure that a back-up system } \\
\text { for power supply is avaiable and functional. }\end{array}$} & \multirow{6}{*}{ Ministry of Health / Local Government } & The facility is connected to the national power grid. & Low \\
\hline & & & & The facility has a functional generator. & Low \\
\hline & & & & The facility has fuel for the generator. & Medium \\
\hline & & & & At least 1 hour connected to grid (last day working). & Low \\
\hline & & & & No power interruptions in the past two weeks. & Low \\
\hline & & & & 7 days access to power last week. & Low \\
\hline & & \multirow{3}{*}{$\begin{array}{l}\text { Make provision for a reliable and safe source of water supply to this facility. Ensure that } \\
\text { there is a back-up source of water in case of contamination or failure. }\end{array}$} & \multirow{3}{*}{ Ministry of Health / Local Government } & 7 days access to clean water last week. & Low \\
\hline & & & & No water interruptions in past two weeks. & Low \\
\hline & & & & Clean water is available all year. & Low \\
\hline & \multirow{4}{*}{ Support services } & Ensure the availability of bed linen at this facility and secure storage facilities for these. & \multirow{4}{*}{ Ministry of Health / Local Government } & There are clean bed linens in storage. & Medium \\
\hline & & $\begin{array}{l}\text { Provision should be made for at least } 2 \text { cleaners who will be responsible for the daily } \\
\text { cleaning of the facility, and should be guided by written service-related policies and } \\
\text { procedures. }\end{array}$ & & The facility has a toilet for patients. & Low \\
\hline & & \multirow{2}{*}{$\begin{array}{l}\text { Ensure the provision of a minimum of } 2 \text { functional sanitary facilities (patient and staff) in the } \\
\text { facility. }\end{array}$} & & The patient toilets are clean. & Medium \\
\hline & & & & The waiting room is clean. & Medium \\
\hline
\end{tabular}


Appendix Figure 1: Main results - By category

1.1 - Governance and management

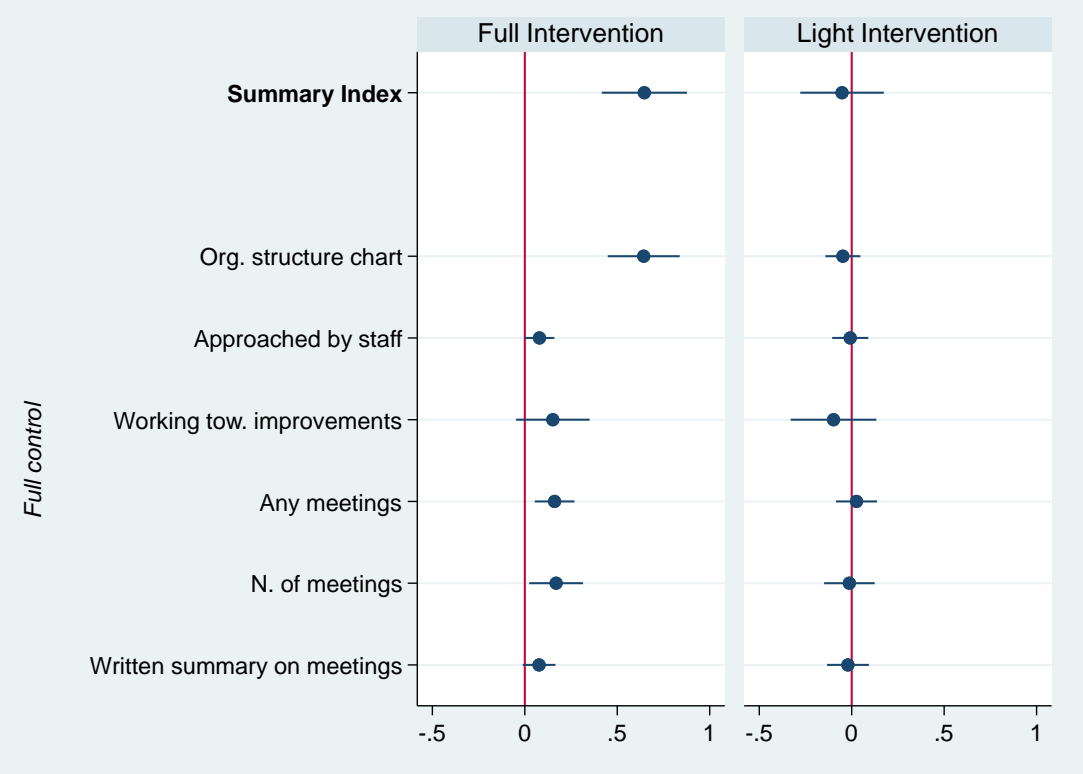

\section{2 - Human Resources Management}

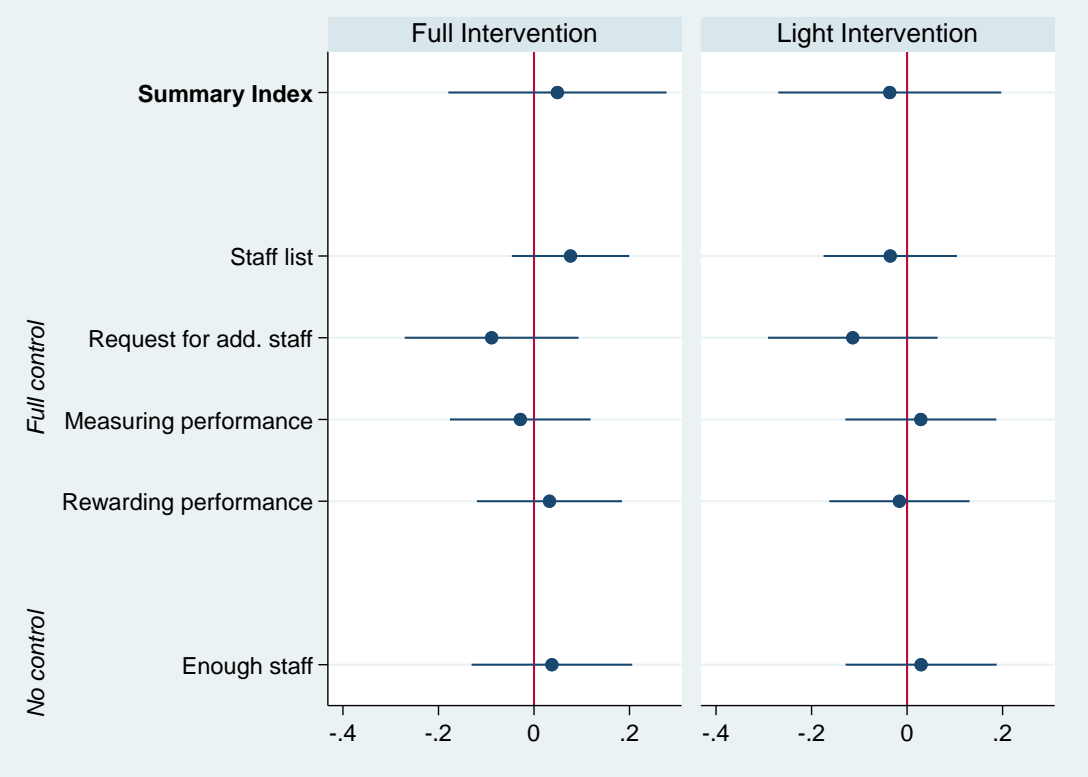


1.3 - Patient rights and access to care

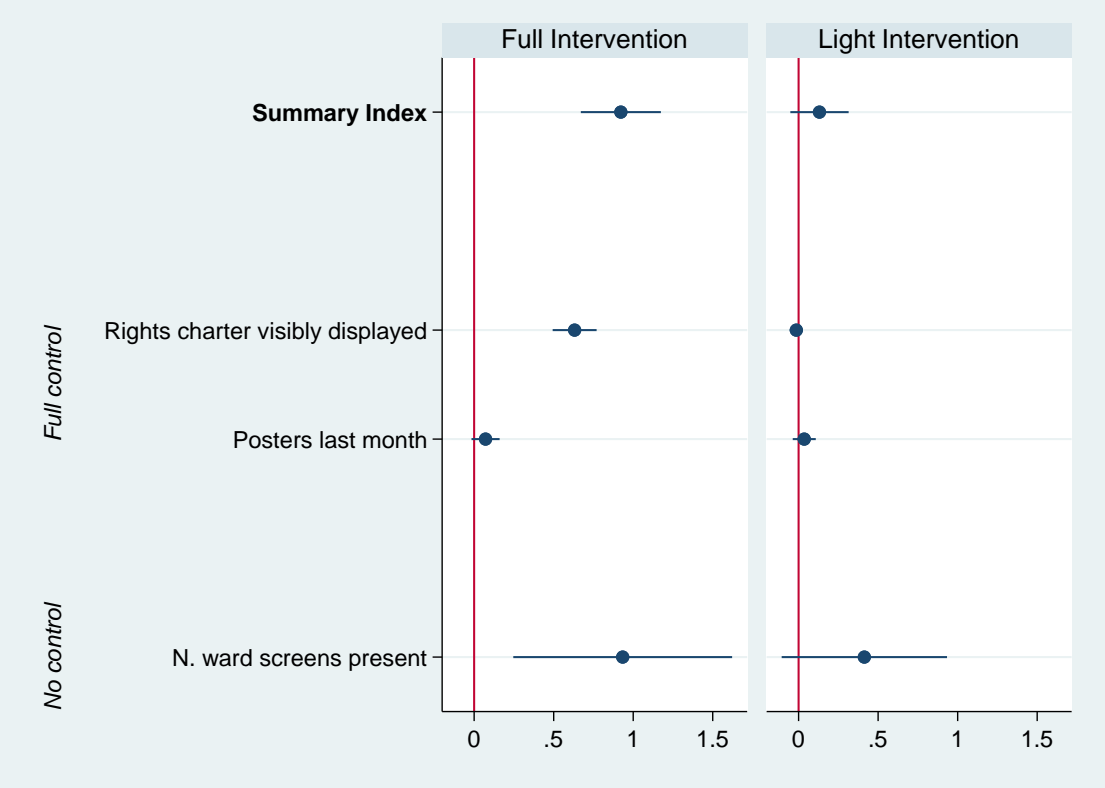

\section{4 - Management of information}

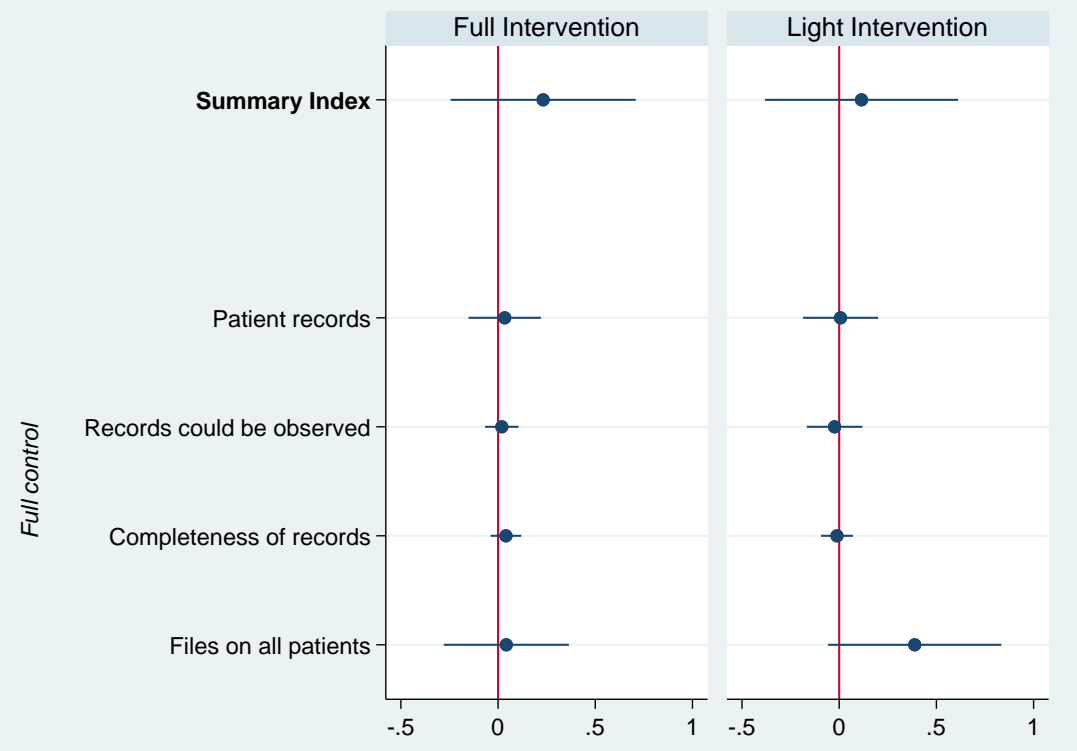




\section{5 - Risk management - waste management}

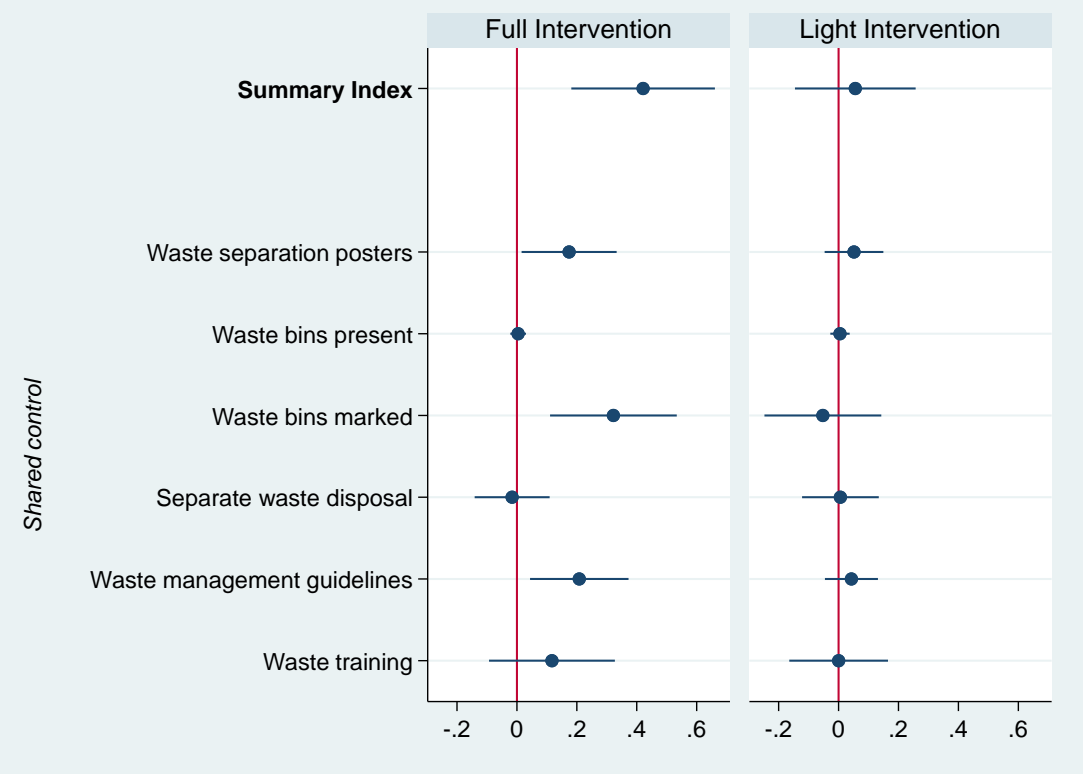

1.6 - Risk Management - general risk

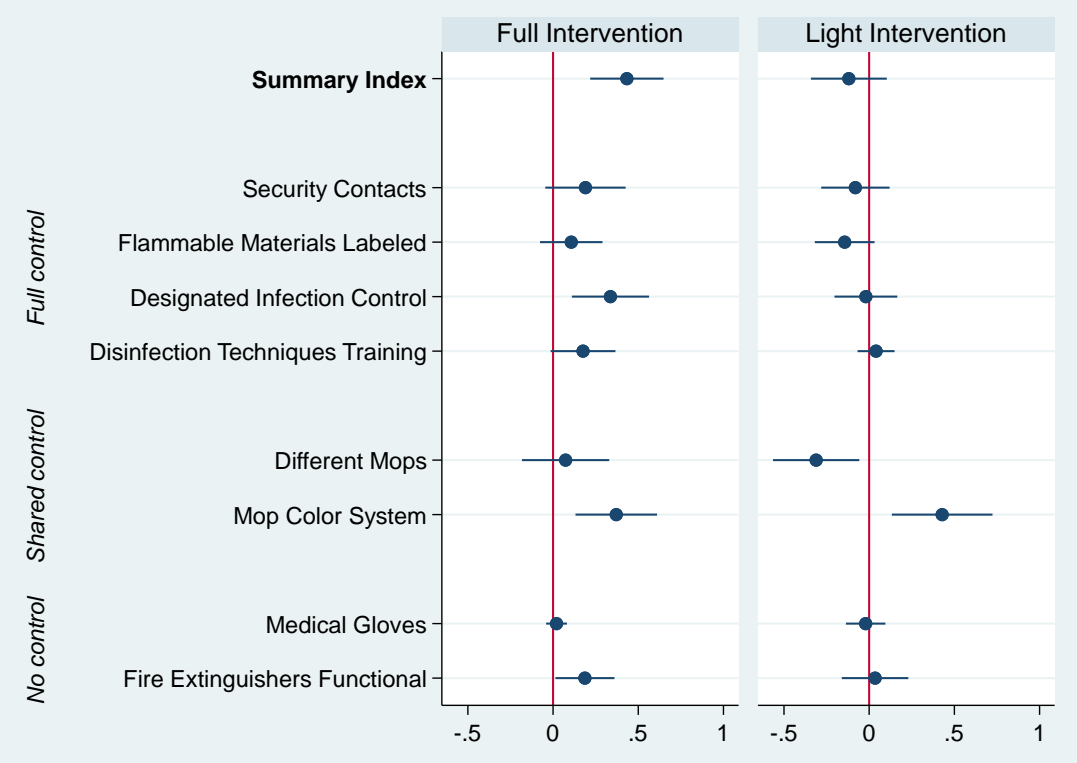




\section{7 - Risk management - handwashing}

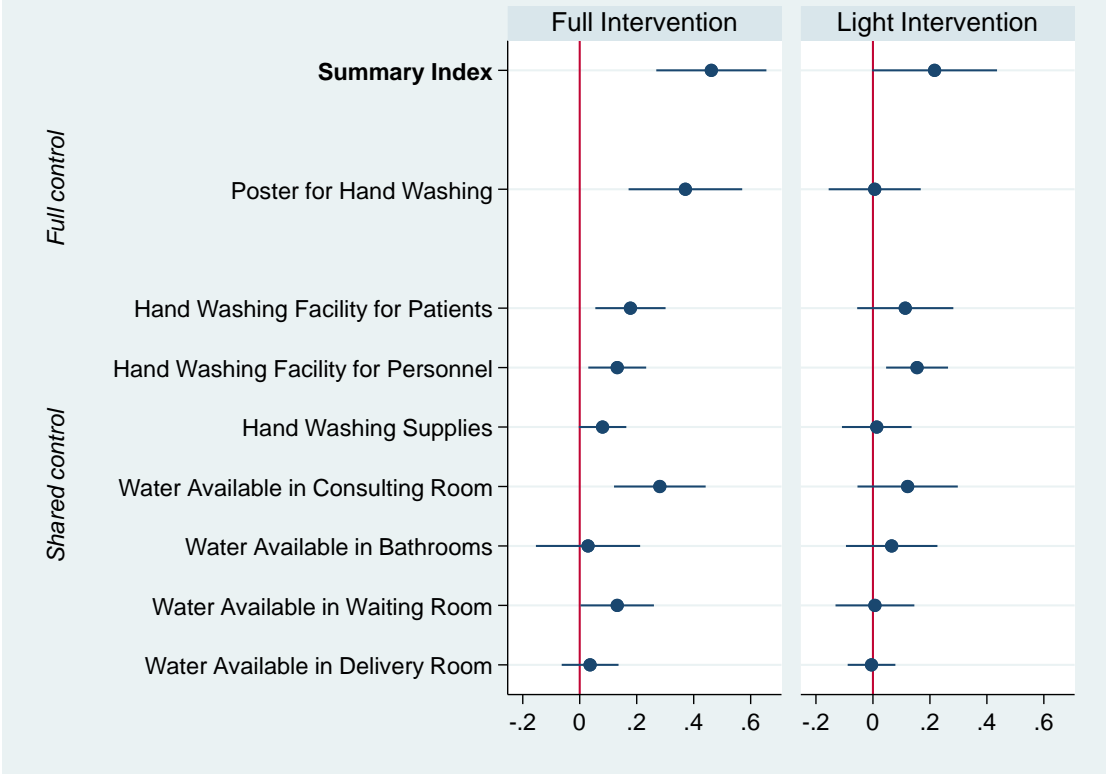

\section{8 -Care of patients}

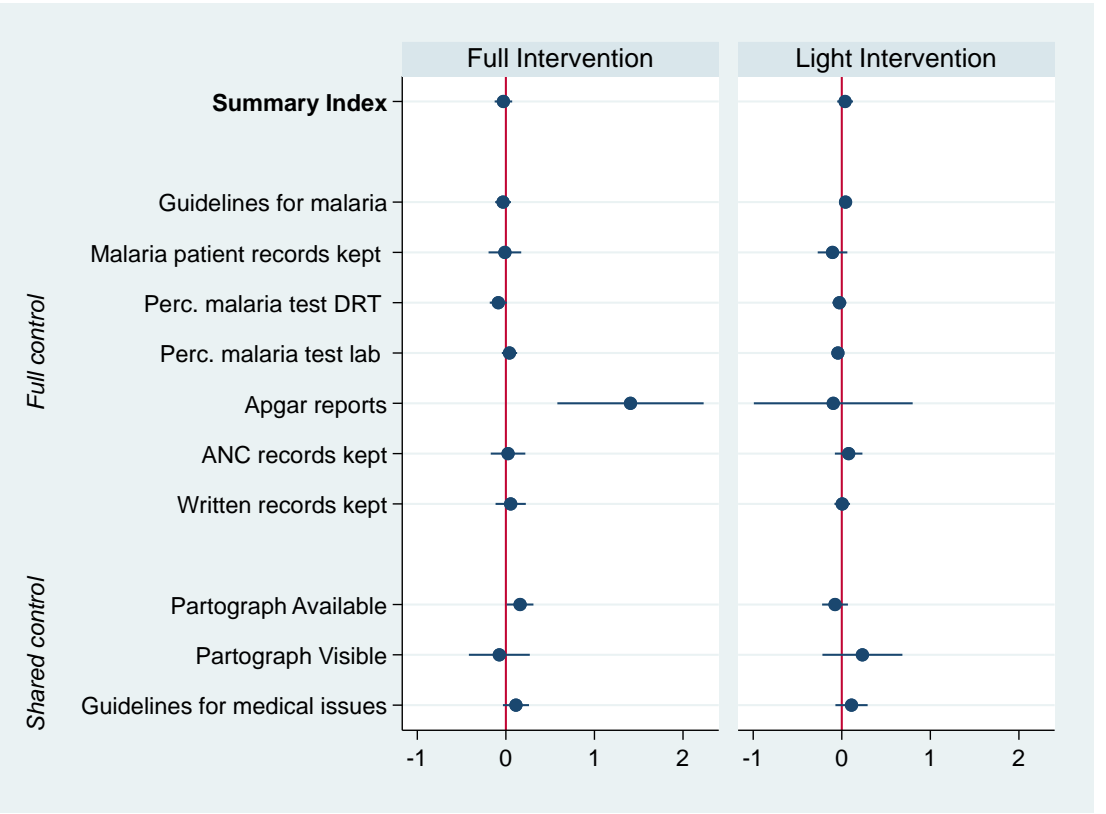

Note: Written records refers to whether the respondent referred to written records when answering the question about antenatal care (ANC) records. 
1.9 - Clinical support - operating theater services

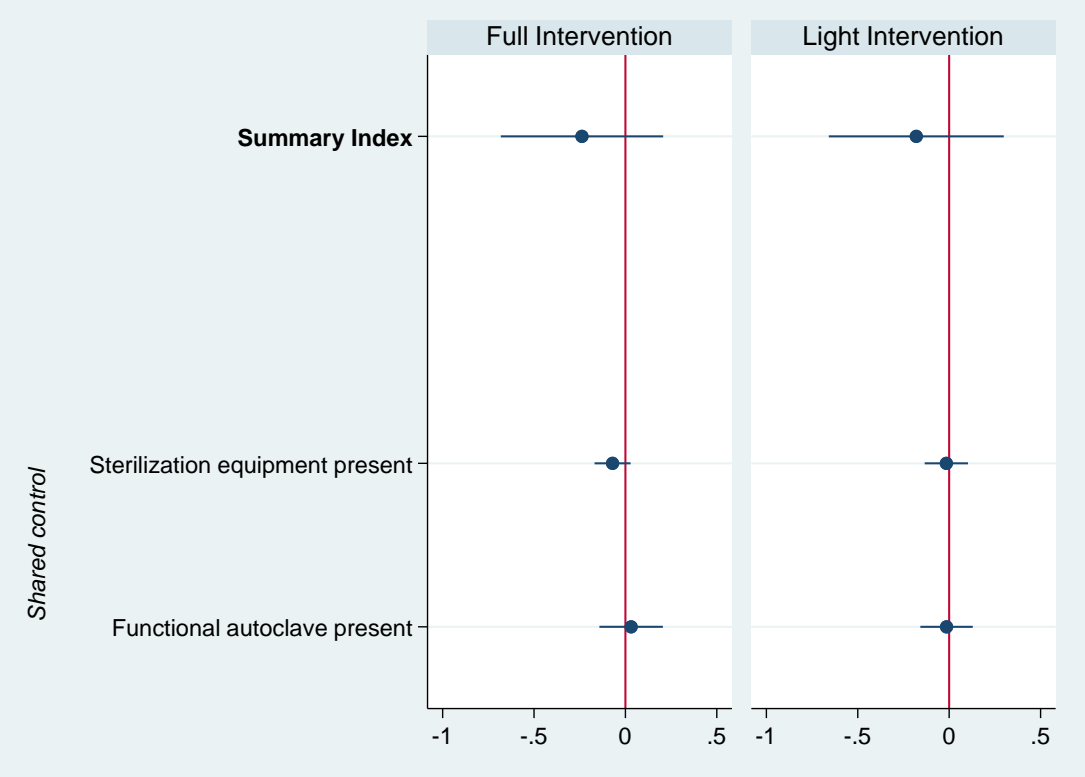

\subsection{0 - Clinical support: Medication management}

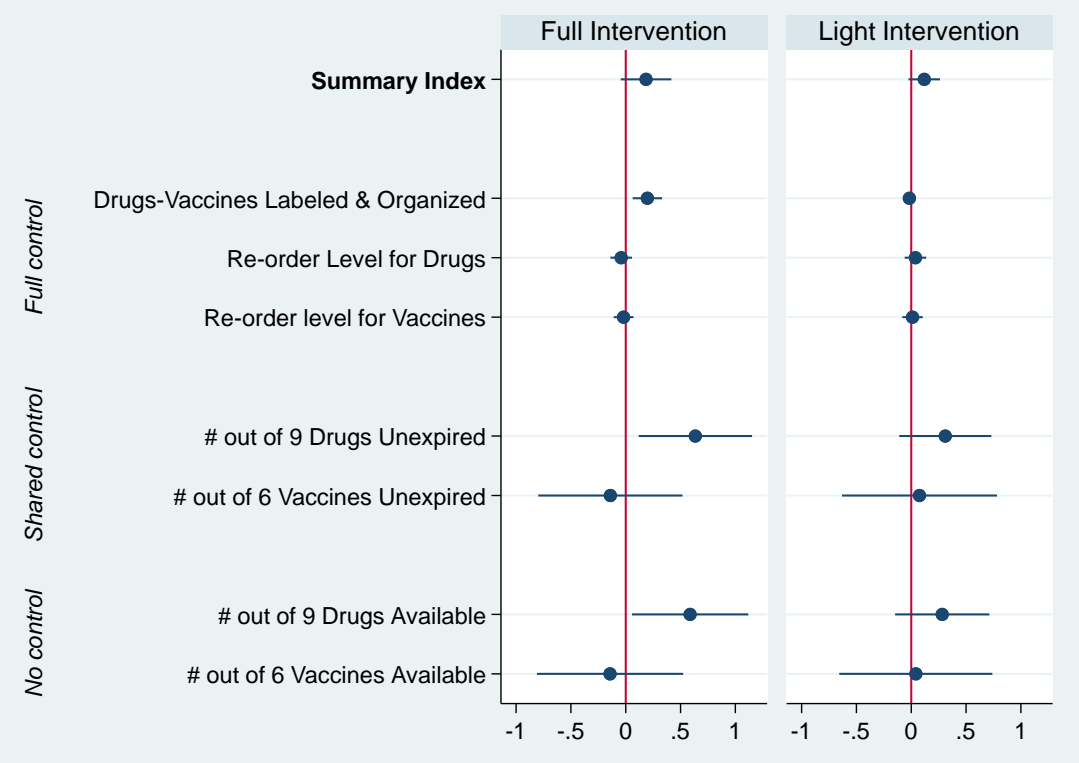




\subsection{1 - Facility Management Services}

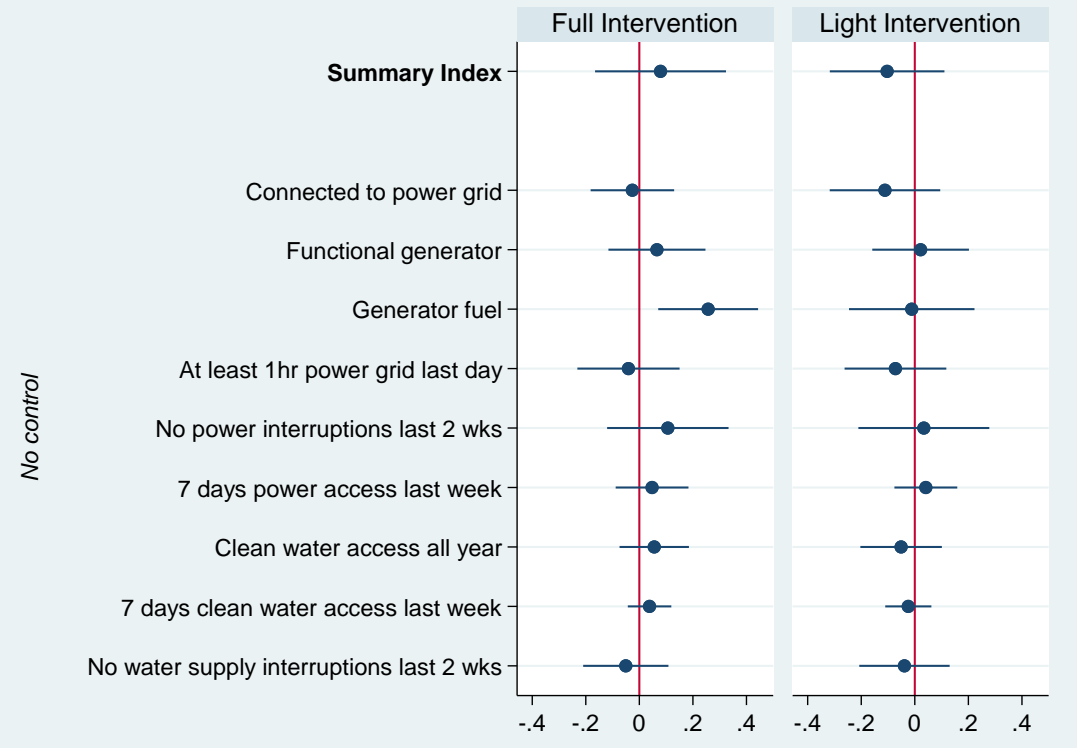

\subsection{2 - Support Services}

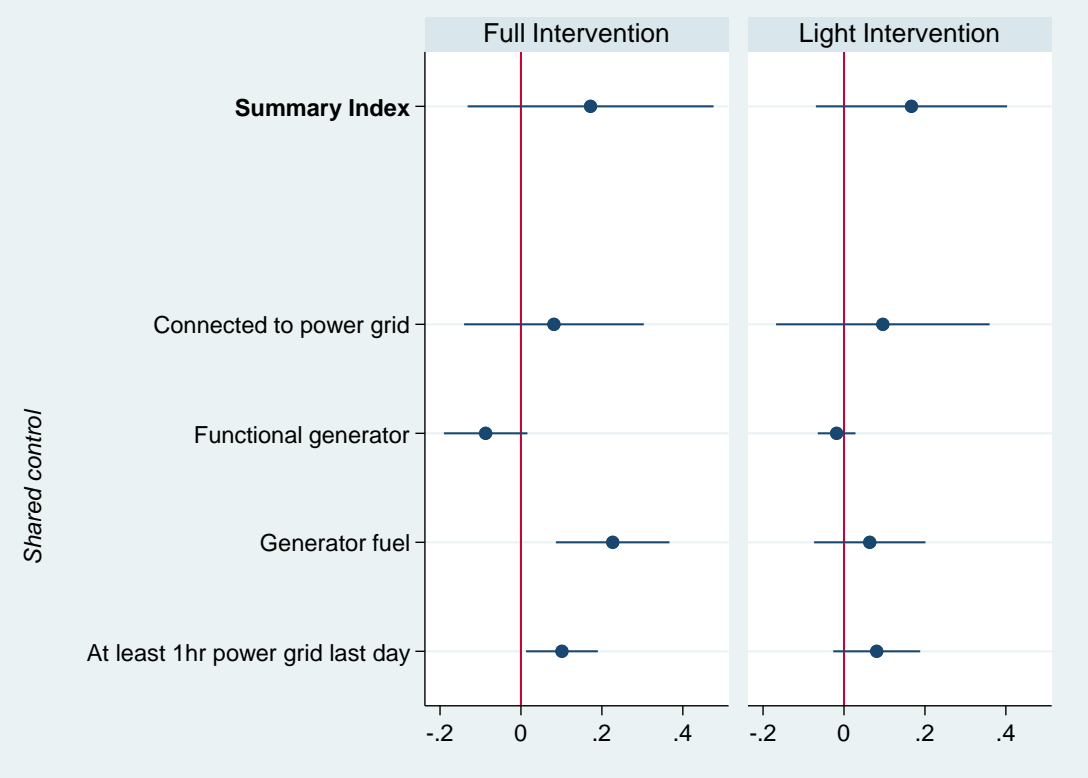

